\title{
5 Research Square

\section{The Role of S100A9 in the Interaction Between Pancreatic Ductal Adenocarcinoma Cells and Stromal Cells}

\author{
Pin-Jui Kung \\ National Taiwan University Hospital Department of Surgery \\ Ting-Yu Lai \\ National Taiwan University \\ Jerry Cao \\ Wollongong Hospital \\ Li-Chung Hsu \\ National Taiwan University \\ Tsai-Chen Chiang \\ National Taiwan University Hospital Department of Surgery \\ Pu Ou-Yang \\ National Taiwan University Hospital \\ Ching-Yi Tsai \\ National Taiwan University Hospital \\ Yi-Fen Tsai \\ National Taiwan University Hospital Department of Surgery \\ Chih-Wen Lin \\ E-Da Hospital
}

Chien-Chia Chen

National Taiwan University Hospital Department of Surgery

Meng-Kun Tsai

National Taiwan University Hospital Hsin-Chu Branch

Yu-Wen Tien

National Taiwan University Hospital Department of Surgery

CHIH-YUAN LEE ( $\sim$ gs2119@gmail.com )

National Taiwan University Hospital

\section{Research}

Keywords: S100A9, PD-L1, Pancreatic ductal adenocarcinoma, PSC 
Posted Date: November 18th, 2020

DOI: https://doi.org/10.21203/rs.3.rs-105978/v1

License: (c) (1) This work is licensed under a Creative Commons Attribution 4.0 International License. Read Full License

Version of Record: A version of this preprint was published at Cancer Immunology, Immunotherapy on August 10th, 2021. See the published version at https://doi.org/10.1007/s00262-021-03026-y. 


\section{RESEARCH}

\section{The Role of S100A9 in the Interaction between Pancreatic Ductal Adenocarcinoma Cells and Stromal Cells}

Pin-Jui Kung ${ }^{1,2}$, Ting-Yu Lai ${ }^{3}$, Jerry $\mathrm{Cao}^{4}$, Li-Chung Hsu ${ }^{3}$, Tsai-Chen Chiang ${ }^{1}$, Pu Ou-Yang ${ }^{5}$, Ching-Yi Tsai $^{5}$, Yi-Fen Tsai ${ }^{1}$, Chih-Wen Lin ${ }^{6}$, Chien-Chia Chen ${ }^{1}$, Meng-Kun Tsai ${ }^{1,7}$, Yu-Wen Tien ${ }^{1}$ and Chih-Yuan $\operatorname{Lee}^{1 *}$

\author{
${ }^{*}$ Correspondence: \\ gs2119@gmail.com \\ ${ }^{1}$ Department of Surgery, National \\ Taiwan University Hospital and \\ College of Medicine, National \\ Taiwan University, Taipei, Taiwan \\ Full list of author information is \\ available at the end of the article
}

\begin{abstract}
Background: A major feature of the microenvironment in pancreatic ductal adenocarcinoma (PDAC) is the significant amount of extracellular matrix produced by pancreatic stellate cells (PSCs), which have been reported to enhance the invasiveness of pancreatic cancer cells and negatively impact the prognosis.
\end{abstract}

Methods: We analyzed the data from two publicly available microarray datasets deposited in the Gene Expression Omnibus and found that the expression of S100 calcium binding protein A9 (S100A9) was increased in PDAC cells with metastatic potential and PDAC cells cocultured with PSCs. We studied the interaction between PDAC cells and PSCs in vitro and verified our finding with the survival data of patients with PDAC from the website of The Human Protein Atlas.

Results: We found that PSCs stimulated PDAC cells to secrete S100A9, which attracted circulatory monocytes into cancer tissue and enhanced the expression of programmed death-ligand 1 (PD-L1) on macrophages. When analyzing the correlation of S100A9 and PD-L1 expression with the clinical outcomes of patients with PDAC, we ascertained that high expression of S100A9 and PD-L1 was associated with poor survival in patients with PDAC.

Conclusions: We found that PSCs stimulated PDAC cells to secrete S100A9, which attracted circulatory monocytes into cancer tissue and enhanced the expression of programmed death-ligand 1 (PD-L1) on macrophages. When analyzing the correlation of S100A9 and PD-L1 expression with the clinical outcomes of patients with PDAC, we ascertained that high expression of S100A9 and PD-L1 was associated with poor survival in patients with PDAC.

Keywords: S100A9; PD-L1; Pancreatic ductal adenocarcinoma; PSC

\section{Background}

Pancreatic cancer is one of the most lethal cancers worldwide. Approximately 80 $\%$ of pancreatic cancers originate from exocrine cells, and the majority of pancreatic cancers are pancreatic ductal adenocarcinomas (PDACs). A major focus in the field of cancer research has been the cancer cells themselves; however, cancers do not simply consist of malignant cells alone. One of the features of PDAC is the presence of an extensive desmoplastic reaction consisting of pancreatic stellate cells (PSCs), immune cells, fibroblasts, endothelial cells and extracellular matrix. 
Studying the nature of the tumor microenvironment may be as important for future cancer therapies as studying the cancer cell itself. Different types of stromal cells in the tumor microenvironment can be recruited by cancer cells to support their growth and facilitate metastasis[1]. Cancer cells do not act in isolation, and their growth is determined not only by themselves but also by their interactions with the microenvironment[2]. As malignancy progresses, the surrounding microenvironment continues to interact with cancer cells and delivers signals that promote growth, foster chemoresistance, and ultimately facilitate distant metastasis[3, 4]. Macrophages, inflammatory cells and other stromal cells can also be attracted and activated by signals generated in the cancer microenvironment.

A major feature of the microenvironment in PDAC is the significant amount of extracellular matrix produced by stromal cells $[5,6]$. PSCs are likely to produce the extracellular matrix and interstitial connective tissue components, including collagen type I and fibronectin[7]. Several studies have reported that PSCs enhance the invasiveness and proliferation of pancreatic cancer cells and negatively impact prognosis $[8,9]$. Therefore, we tried to study the interaction between PDAC cells and PSCs. There are publicly available microarray data deposited in the Gene Expression Omnibus (GEO) database at http://www.ncbi.nlm.nih.gov/geo/, and we analyzed the dataset GSE36775, in which the gene expression of pancreatic adenocarcinoma cells cocultured with or without PSCs was studied. We also analyzed the GSE9350 dataset, in which the gene expression of pancreatic cancer cell lines with metastatic and growth potential was explored. After combining the results of the analyses of the two datasets (GSE36775 and GSE9350), we found that the gene expression of S100 calcium binding protein A9 (S100A9) was increased in both datasets.

S100A9, a member of the S100 family of calcium binding proteins, has been detected in infiltrating macrophages in rheumatoid arthritis and other inflammatory conditions $[10,11]$. S100A9 can be found in cells of myeloid origin, such as monocytes, neutrophils and dendritic cells[12]. After secretion, S100A9 acts as a chemoattractant to recruit inflammatory cells into the surrounding microenvironment[13, 14, 15]. Secreted S100A9 protein has also been reported to play a role in the establishment of a favorable environment for cancer growth[16, 17]. It was indicated that S100A9 protein secreted by myeloid cells within primary cancers and metastatic sites promotes the accumulation of more myeloid cells, which plays an important role in modulating tumor progression and the formation of premetastatic niches at metastatic sites[17, 18, 19, 20] Tumor-associated macrophages interact with cancer cells and contribute to cancer aggressiveness as an integral part of the tumorigenic pathway[21]. However, the expression of S100A8 and S100A9 in macrophages is lost rapidly after their differentiation from monocytes[16, 22].

Immune surveillance is the first-line defense to identify and eliminate cancer cells, which have developed numerous strategies to evade immune surveillance mechanisms and continue neoplastic progression. Immune checkpoints include several costimulatory and inhibitory signals of immune cells for the prevention of autoimmunity. However, these machineries can be hijacked by cancer cells to evade immune surveillance[23]. Programmed death-ligand 1 (PD-L1) overexpression has been reported in infiltrating immune cells in PDAC, and increased PD-L1 expression is associated with poor survival[24]. 
In this study, we found that PSCs stimulate pancreatic cancer cells to secrete S100A9, which initiates the attraction of circulatory monocytes into cancer tissue. When analyzing the correlation of S100A9 and PD-L1 expression with clinical outcomes of patients with PDAC, we ascertained that high expression of S100A9 and PD-L1 was associated with worse overall survival than low expression of these proteins in a cohort of patients with PDAC.

\section{Materials and Methods}

Microarray Data Analysis

The microarray datasets used in this study, GSE36775 and GSE9350, were downloaded from Gene Expression Omnibus (GEO), which can be accessed at http://www.ncbi.nlm.nih.gov/geo/. We analyzed the dataset GSE36775, which contained gene expression data of pancreatic adenocarcinoma cells cocultured with or without PSCs. We also analyzed the dataset GSE9350, which contained gene expression data of pancreatic cancer cell lines with high metastatic and growth potential under normoxic growth conditions. We analyzed these datasets with the web-based tool GEO2R at https://www.ncbi.nlm.nih.gov/geo/geo2r/ to obtain adjusted p-values for multiple comparisons with the Benjamini \& Hochberg method and $\log 2$-transformed fold change values. The microarray datasets were deposited by the original investigators, and individual quality control measures were reported in the original references $[9,25]$.

\section{Patients}

In this study, we retrospectively collected specimens for immunofluorescence staining from 16 patients with PDAC varying from stage IIa to stage IV who received operative intervention at National Taiwan University Hospital between 2001 and 2008. The study was approved by the institutional review boards (201705130RINC).

\section{Cell Culture}

Human PSCs were purchased from ScienCell Research Laboratories, Inc. (Carlsbad, CA). The other cell lines were obtained from the Bioresource Collection and Research Center (Hsinchu, Taiwan). The human pancreatic cancer cell lines AsPC1, HPAF-II and PANC-1 were cultivated in RPMI 1640 medium (Thermo Fisher), MEM (Thermo Fisher) and DMEM (Thermo Fisher) supplemented with $10 \%$ fetal bovine serum (FBS) (Thermo Fisher). PSCs were cultured in SteCM medium (ScienCellTM, CA, USA) containing 2\% FBS, essential and nonessential amino acids, vitamins, organic and inorganic compounds, hormones, growth factors and trace minerals. The human monocyte and lymphocyte-like cell lines THP-1 and U937 (CRL-1593.2) were maintained in RPMI 1640 medium with 10\% FBS. All cell lines were incubated at $37{ }^{\circ} \mathrm{C}$ with $5 \% \mathrm{CO} 2$. Pancreatic cancer cells $\left(5 \times 10^{5}\right)$ were seeded in 6-well plates and cocultured with or without $5 \times 10^{5}$ PSCs on $0.4 \mu \mathrm{m}$ PET hanging inserts (Millipore, Germany). All cell lines were tested for mycoplasma contamination by the MycoAlertTM PLUS Mycoplasma Detection Kit (LT07-701, Lonza).

\section{Plasmids and Transfection}

We seeded $1 \times 10^{6}$ HEK293 cells in a 6 -well plate one day before transfection. On the next day, we transfected plasmids into HEK293 cells with Lipofectamine ${ }^{T M} 3000$ 
Reagent (Thermo Fisher) according to the manufacturer's protocol and collected the cell pellets for further analysis 72 hours after transfection.

shRNA-Mediated Gene Silencing

Short hairpin RNA ( $s h R N A$ ) constructs encoding shRNAs against human S100A9 in pLKO-puro vectors were obtained from the National RNAi Core Facility, Academia Sinica, Taiwan. The clone identity numbers were TRCN0000415789 for S100A9 shRNA\#1, TRCN0000425882 for S100A9 shRNA\#2, TRCN0000419023 for S100A9 shRNA\#3, TRCN0000433650 for S100A9 shRNA\#4 and TRCN0000072243 for shControl. We transfected the shRNAs into cells with Lipofectamine ${ }^{T M} 3000$ Reagent (Thermo Fisher) according to the manufacturer's protocol.

\section{Conditioned Media Preparation}

Pancreatic cancer cells were counted and seeded in 6-well plates with RPMI medium. After 24 hours, cells were washed twice with phosphate-buffered saline (PBS) and incubated in RPMI medium for an additional 24 hours at $37^{\circ} \mathrm{C}$. Pancreatic cancer cells $\left(5 \times 10^{5}\right)$ were seeded in 6 -well plates and co-cultured with or without $5 \times 10^{5}$ PSCs on $0.4 \mu \mathrm{m}$ PET Millicell@ hanging inserts (Millipore, Germany) for 24-72 hours. The conditioned medium was generated by centrifugation at $1000 \mathrm{~g}$ for 5 minutes to separate cell debris.

\section{Transwell Migration Assays}

THP-1 $\left(2 \times 10^{5}\right)$ or U937 $\left(2 \times 10^{5}\right)$ cells were seeded inside hanging inserts (Millicell $(\mathrm{R}$ ) hanging inserts, $8 \mu \mathrm{m}$ Merck) suspended over wells with conditioned media in a 12 -well plate. The conditioned media were obtained from $5 \times 10^{5}$ pancreatic cancer cells (AsPC-1, HPAF-II or PANC-1 cells) cocultured with $5 \times 10^{5}$ PSCs in a Millicell $(\mathrm{B})$ hanging insert ( $0.4 \mu \mathrm{m}$ polyethylene terephthalate membrane, Merck) in 6 -well plates for 24 hours. The conditioned media were centrifuged at $1000 \mathrm{~g}$ for 5 minutes before being employed in further experiments. The migrated cells were counted in four different fields, and the experiments were repeated in triplicate.

\section{Precipitation of Proteins in the Culture Medium}

The culture medium was precipitated by adding $20 \%$ trichloroacetic acid (TCA), mixed well and stored in a refrigerator at $-20{ }^{\circ} \mathrm{C}$ overnight, and then centrifuged at $12,000 \mathrm{~g}$ for 30 minutes. After centrifugation, the pellet was washed twice with acetone, and lysis buffer was added to the dry pellet for further analysis.

\section{Antibodies}

Antibodies against S100A9 (PA5-19075, 1:1000) and Flag (PA1-984B, 1:1000) were obtained from Thermo Fisher, and anti-GAPDH antibodies (\#5174, 1:1000) were obtained from Cell Signaling Technology (Danvers, MA). The anti-PD-L1 monoclonal antibody (29E.2A3) was obtained from BioLegend (San Diego, CA). Allophycocyanin (APC)-conjugated anti-mouse IgG antibodies (115-605-166) were obtained from Jackson ImmunoResearch Inc. (West Grove, PA). 


\section{Immunoblotting Analysis}

We collected and washed cells twice with PBS, added RIPA buffer containing protease inhibitor into each tube and centrifuged the samples at 12,000 g for 30 minutes. The protein concentration was measured using a Pierce BCA protein assay kit (Thermo) according to the manufacturer's protocol. Protein extracts $(20-40 \mu \mathrm{g})$ and the concentrated product of each supernatant $(10 \mu \mathrm{L})$ were run on $12 \%$ SDS polyacrylamide gels, and separated proteins were transferred to a PVDF membrane for further detection.

mRNA Purification and Quantitative RT-PCR

We extracted mRNA with a NucleoSpin RNA Kit (Macherey-Nagel, GmbH \& Co., KG, Düren) and synthesized cDNA with a PrimeScriptTM RT Reagent Kit (Takara, Japan) according to the manufacturers' instructions. Real-time quantitative PCR (qPCR) was performed with Maxima SYBR Green/ROX qPCR Master Mix (Thermo Scientific, Rockford, IL) on a QuantStudio 3 instrument (Thermo Scientific) according to the manufacturer's recommendations. All qPCR values were normalized to cyclophilin mRNA levels as an internal control to obtain the relative values. All experiments were performed in triplicate. The primer sequences are shown in Supplementary Table S3.

\section{Differentiation of U937 Monocytes into Macrophages}

The human monocytic cell line U937 was maintained in RPMI-1640 medium with 10\% FBS (Gibcoß) and penicillin/streptomycin (Gibcoß). Cells were maintained at $37{ }^{\circ} \mathrm{C}$ in a humidified $5 \% \mathrm{CO} 2$ atmosphere. For differentiation, U937 cells were grown overnight on a 12 -well plate at a density of $2 \times 10^{5}$ cells per well. Cells were then incubated with $25 \mathrm{ng} / \mathrm{mL}$ phorbol-12-myristate-13-acetate (PMA) (Sigma-Aldrich, St. Louis, MO) for 48 hours and washed with Dulbecco's phosphate-buffered saline (DPBS) to remove nonadherent cells. Cells were incubated in RPMI-1640 medium for 24 hours before they were ready for further assays.

\section{Immunofluorescence}

Wax-embedded human pancreas blocks were cut into $5 \mu \mathrm{m}$-thick sections and dewaxed, and antigens were retrieved by TrilogyTM (Cell Marque) treatment at 121 ${ }^{\circ} \mathrm{C}$ for 3 minutes. Sections were blocked with $3 \%$ BSA for 30 minutes and then incubated overnight with appropriate primary antibodies (anti-S100A9, 1:200, 269921-AP, Proteintech; anti- $\alpha$-SMA, 1:200, MMS-466S, BioLegend). After washing in DPBS, the pancreas sections were further incubated with fluorophore-conjugated secondary antibodies (Alexa Fluor 488, 1:300, Jackson ImmunoResearch. Alexa Fluor 594, 1:300, A-21207, Thermo Fisher Scientific) for 1 hour. Hoechst 33342 Solution (1:10,000, Thermo Fisher Scientific) was used for staining nuclei. Images were captured by TissueFAXS PLUS (TissueGnostics, Vienna, Austria) and quantified by the StrataQuest Analysis System (TissueGnostics).

Flow Cytometry

PD-L1 expression levels on differentiated U937 macrophages were measured by flow cytometry. Briefly, cells were incubated with anti-human PD-L1 monoclonal antibodies (29E.2A3, BioLegend, San Diego, CA), followed by staining with APCconjugated anti-mouse IgG antibodies (115-605-166, Jackson ImmunoResearch Inc. 
West Grove, PA). Stained cells were processed on a BD FACSVerse cell analyzer, and flow cytometry data were analyzed by FlowJo ${ }^{T M}$ Software for Windows Version 10 (Becton, Dickinson and Company, Ashland).

\section{Results}

\section{Microarray Data Analysis}

The publicly available microarray datasets GSE36775 and GSE9350 were downloaded from Gene Expression Omnibus (https://www.ncbi.nlm.nih.gov/geo/). We retrieved the microarray dataset GSE36775, which included gene expression data of pancreatic adenocarcinoma cells exposed to stromal PSCs in a 3D gel matrix, and analyzed the dataset with GEO2R at https://www.ncbi.nlm.nih.gov/geo/geo2r/ (Supplementary Table S1). We also analyzed the dataset GSE9350, which included gene expression data of pancreatic cancer cell lines with high metastatic and growth potential under normoxic conditions (Supplementary Table S2). After combining the results of the analyses of the two datasets (GSE36775 and GSE9350), we found that the gene expression of S100A9 was increased in both datasets. According to the analyses of the two microarray datasets, we hypothesized that PSCs might stimulate pancreatic cancer cells to secrete S100A9 and influence the progression of pancreatic cancer.

The Expression of S100A9 in Pancreatic Cancer Cells is Induced by PSCs

To validate the results of the microarray analysis, we used a coculture system with Millicell@ hanging cell culture inserts (polyethylene terephthalate insert with a pore size of $0.4 \mu \mathrm{m}$, Merck) to examine the interaction between pancreatic adenocarcinoma cell lines and PSCs. For coculture with hanging inserts, we cultured pancreatic cancer cell lines, including AsPC-1, HPAF-II and PANC-1 cells, in 6-well plates and seeded PSCs on the hanging inserts. The gene expression of S100A9 in AsPC-1, HPAF-II and PANC-1 cells cocultured with PSCs in the coculture system was increased compared to that in cells cultured alone (Figure 1). The protein level of S100A9 in pancreatic cancer cell lines was also increased when the cells were cocultured with PSCs in the coculture system (Figure 1d-f).

\section{PDAC Cells Cocultured with PSCs Enhance the Migration of Monocytes}

According to published reports, S100A9 can induce chemotaxis of immune cells[26, 27]. Therefore, we aimed to determine whether the secretion of S100A9 from pancreatic cancer cells induced by PSCs could induce the migration of monocytes. In a transwell cell migration assay (Millicell $(\mathbb{R}$ ) hanging inserts, $8.0 \mu \mathrm{m}$, Merck), we placed THP-1 $\left(2 \times 10^{5}\right)$ or U937 $\left(2 \times 10^{5}\right)$ cells inside the hanging inserts $(8.0 \mu \mathrm{m}$, Millipore) and suspended the hanging inserts in the wells of culture plates containing conditioned media from pancreatic cancer cell lines cocultured with or without PSCs. We found that the conditioned media from pancreatic cancer cell lines cocultured with PSCs enhanced the migration of monocytes (Figure 2a and b) in the transwell migration assay.

S100A9-Enriched Conditioned Medium Induces the Migration of Monocytes

To examine whether S100A9 was the factor responsible for the chemotaxis of monocytes, we constructed a S100A9 vector with a Flag tag at the $\mathrm{C}$ terminus in a 
pcDNA3.0 vector and transduced the S100A9-Flag vector into HEK293 cells. We verified the expression of S100A9 in HEK293 cells by Western blot with an antiS100A9 antibody (Figure 2c) and an anti-Flag antibody (Figure 2d). In the culture medium from HEK293 cells transduced with the S100A9-Flag vector, we also detected the secretion of S100A9-Flag by Western blot (Figure 2e). In transwell migration assays, we placed conditioned media from HEK293 cells transduced with S100A9-Flag vector or control vector (empty vector only) in the culture plates and seeded monocyte cell lines, including THP-1 or U937 cells, in the hanging inserts (Millicell@) hanging inserts, $8.0 \mu \mathrm{m}$, Merck). After 24 hours, we calculated the number of migrated THP-1 (Figure 2f) and U937 (Figure 2g) cells. We found that conditioned media with S100A9 enhanced the migration of THP-1 and U937 cells.

To further verify the function of S100A9 in monocyte chemotaxis, we knocked down S100A9 expression with shRNA in PDAC cell lines, including AsPC-1 (Figure $3 \mathrm{a}$ ) and HPAF-II cells (Figure 3b). The shControl construct was used as a knockdown control in this assay. We found that conditioned medium from PDAC cells cocultured with PSCs enhanced the migration of U-937 cells. The conditioned medium from PSCs cocultured with S100A9-knockdown AsPC-1 (Figure 3c) and HPAF-II (Figure 3d) cells induced less attraction of U-937 cells than the conditioned medium from PSCs cocultured with knockdown-control cells. In summary, PDAC cells cocultured with PSCs enhanced the expression of S100A9, which modulated the migration of monocytes. In contrast, S100A9-knockdown PDAC cells cocultured with PSCs attenuated monocyte chemotaxis.

\section{S100A9 Induces Surface Expression of PD-L1 in Monocytes}

In addition to its chemotactic effect, S100A9 has been reported to be the endogenous ligand of Toll-like receptor 4 (TLR4) and to induce surface expression of PD-L1 in primary hematopoietic cells[28, 29]. High expression of PD-L1 in PDAC was associated with poor prognosis[30]; however, the mechanism that regulates the expression of PD-L1 in PDAC is not clear. To verify the effect of S100A9 on the expression of PD-L1 on monocytes, we treated U937 cells with interferon gamma (IFN- $\gamma$ )along with recombinant S100A9 and detected the surface expression of PD-L1 with flow cytometry. We found that treatment with recombinant S100A9 in IFN- $\gamma$ primed U937 cells for 6 (Figure 4a) and 24 hours (Figure 4b) enhanced the surface expression of PD-L1.

\section{S100A9-Expressing Cells are Located Near PSCs in Pancreatic Cancer Samples}

Specimens from 22 patients with PDAC were obtained and stained for S100A9 and $\alpha$-smooth muscle actin ( $\alpha$-SMA), a differentiation marker for activated PSCs, with double immunofluorescence staining. As can be seen in the representative figures, we found that S100A9-expressing cells were located near PSCs in the specimens from patients with PDAC with metastasis (Figure 5a and b). High levels of PSC infiltration were accompanied by increased numbers of nearby S100A9-expressing cells (Figure 5a and b), whereas less PSC infiltration correlated with fewer S100A9expressing cells in specimens from patients with PDAC without metastasis (Figure $5 \mathrm{c}$ and $\mathrm{d}$ ). This results suggest that PSCs can induce surrounding cells to produce S100A9 or attract S100A9-expressing myeloid cells. To study the correlation 
between the expression of S100A9 and $\alpha$-SMA (as determined by the immunofluorescence staining) in the specimens from the 16 patients with PDAC, we scanned the whole area of slides subjected to double immunofluorescence staining (Figure 5a-d) with the TissueFAXS system (TissueGnostics, Vienna, Austria) to avoid sampling error on the slides. Then, we quantified the scanning results of the slides with the StrataQuest Analysis System (TissueGnostics). The correlation between the numbers of cells expressing S100A9 and the numbers of cells expressing $\alpha$-SMA in samples from patients with PDAC was significant in regression models $\left(R^{2}=0.849\right.$, $\mathrm{p}<0.001)$. Each spot represents staining of a specimen from one patient $(\mathrm{N}=22)$. (Figure 5e).

\section{Expression of S100A9 and PD-L1 Affects the Survival of Patients with PDAC}

We next explored the Human Protein Atlas (https://www.proteinatlas.org/) database to identify correlations of S100A9 and PD-L1 expression with clinical outcomes of PDAC[31, 32]. The Human Protein Atlas database has data on the clinical outcomes and immunohistochemical staining of S100A9 and PD-L1 from 176 patients with PDAC. The clinical and pathological characteristics are described in Supplementary Table S4. Most of the patients included in the database had stage I or II disease (94.3\%), and high expression of S100A9 predicted worse survival than low expression of S100A9 in this cohort ( $\mathrm{p}=0.017$, log-rank test). In the cohort of 176 patients, we also found that higher levels of S100A9 expression correlated with higher levels of $\alpha$-SMA, which is regarded as a marker of activated stellate cells $[33,34](\mathrm{p}<0.001$, chi-square test, Supplementary Table S4). The relationship between the expression of $\alpha$-SMA and the survival of patients with PDAC was not significant ( $\mathrm{p}=0.144, \log$-rank test, Supplementary Figure $\mathrm{S} 1$ ). Using univariate and multivariate Cox regression analyses of potential factors affecting patient survival in the cohort, we found that both patient age $(\mathrm{p}=0.019)$ and S100A9 expression $(\mathrm{p}=0.037)$ affected patient survival (Supplementary Table S5). With a cutoff for S100A9 and PD-L1 immunohistochemical expression determined by the default setting on The Human Protein Atlas website, high expression of S100A9 (Figure 6a) and high expression of PD-L1 (Figure 6b) correlated with worse overall survival than low expression of either marker in the cohort $(p=0.013$ for S100A9; $p=0.007$ for PD-L1, log-rank test).

\section{Discussion}

Cancers are not composed of only neoplastic cells and also include fibroblasts, immune cells, endothelial cells, and specialized stromal cells. These different cell types in the cancer microenvironment can be recruited by neoplastic cells to support their growth and dissemination. The interactions between cancer cells and stromal cells exert a major impact on neoplastic growth and progression[35, 36]. Understanding the interactions between cancer cells and their biological environment may be as important for future cancer therapies as understanding the cancer cell itself.

S100A9 is a calcium binding protein and may exist as a homodimer or heterodimer with S100A8[37]. However, we were not able to detect significant changes in S100A8 expression in PDAC cells cocultured with PSCs by either quantitative PCR or Western blot (data not shown). One possible reason is that according to published reports, mature macrophages differentiated from monocytes initially express S100A8 
and S100A9 but later lose S100A8 expression at inflammatory sites[38, 39]. S100A9 is expressed in many cell types, especially those of myeloid origin, and can bind to cell surface receptors that trigger signaling pathways related to numerous cellular processes, including cell cycle progression, cell survival, proliferation, differentiation, and migration[40]. S100A9 is also upregulated in many cancer types, including breast cancer, colon cancer, hepatocellular carcinoma, gastric cancer, colorectal cancer, non-small-cell lung cancer, and cervical cancer[38, 41]. The expression of S100A9 is associated with a poor prognosis among non-small-cell lung cancer patients, which is consistent with our findings[41]. Three types of receptors have been reported for S100A9, including TLR4[29, 42], receptor for advanced glycation end products (RAGE)[43] and extracellular matrix metalloproteinase inducer (EMMPRIN)[19]. It has been indicated that the level of S100A9 is increased at sites of inflammation and that S100A9 can induce the migration of myeloid cells[42]. Several studies on different types of cancer cells have shown that S100A9 induces activation of NF- $\kappa \mathrm{B}$ and that knockdown of S100A9 expression decreases tumor invasion[17, 38, 44, 45]. S100A9 is abundant in myeloid cells and can be released upon activation[20,40]. Our current study demonstrates that secretion of S100A9 is not limited to myeloid cells. We found that the secretion of S100A9 could be enhanced in pancreatic cancer cells when they were incubated with PSCs and that S100A9 acts as a chemoattractant to recruit monocytes.

In many cancers, the interaction of costimulatory molecules on $\mathrm{T}$ lymphocytes with the tumor-associated membrane-bound protein PD-L1 can lead to apoptosis of activated T cells. Tumor-associated PD-L1 expression was reported to increase the apoptosis of activated T lymphocytes and assist cancer cells in escaping immune surveillance[30, 46]. High expression of PD-L1 in pancreatic cancers is associated with a poor prognosis[24]. According to published reports, S100A8 and S100A9 can induce the expression of PD-L1 in macrophages[28, 47]. Therefore, we examined the effect of S100A9 on monocytes and found that S100A9 not only had chemotactic effects but could also induce surface expression of PD-L1 in monocytes. When exploring the Human Protein Atlas database to identify correlations of S100A9 and PD-L1 expression with clinical outcomes of PDAC, we found that high expression of S100A9 and PD-L1 was associated with worse overall survival than low expression of these proteins in patients with PDAC. In the specimens of 176 patients from the database, low expression levels of S100A9 correlated with reduced expression of PD-L1.

\section{Conclusion}

In summary, in this study, we demonstrate that the secretion of S100A9 is not only limited to myeloid cells and may also be induced in pancreatic cancer cells incubated with PSCs. As indicated in Figure 7, we found that S100A9 acts as a chemoattractant to recruit monocytes and induces the surface expression of PD-L1 on macrophages. Our results highlight that high expression of S100A9 and PDL1 correlates with worse overall survival than low expression of these proteins in patients with PDAC.

\section{List of abbreviations}

$\alpha$-SMA: $\alpha$-smooth muscle actin 
EMMPRIN: extracellular matrix metalloproteinase inducer

GEO: Gene Expression Omnibus

IFN- $\gamma$ : interferon gamma

PBS: phosphate-buffered saline

PCR: polymerase chain reaction

PDAC: pancreatic ductal adenocarcinoma

PD-L1: programmed death-ligand 1

PSC: pancreatic stellate cell

RAGE: receptor?for advanced glycation end products

S100A8: S100 calcium binding protein A9

S100A9: S100 calcium binding protein A9

shRNA: Short hairpin RNA

TLR4: Toll-like receptor 4

\section{Declarations}

Availability of data and materials

The datasets and materials used during the current study are available from the corresponding author on reasonable request.

Ethics approval and consent to participate

We retrospectively collected specimens for immunofluorescence staining from 16 patients with PDAC varying from stage IIa to stage IV who received operative intervention at National Taiwan University Hospital between 2001 and 2008. The study was approved by the institutional review boards (201705130RINC). All patients provided written informed consent.

Consent for publication

Not applicable.

Competing interests

The authors declare no competing financial interests.

\section{Funding}

This work was supported by National Taiwan University Hospital (NTUH109M4628 to C.-Y. Tsai and 109C101-22 to C.-Y. Lee), the Ministry of Science and Technology (MOST) of Taiwan (109-2314-B-002-080 to C.-Y. Lee; and 109-2326-B002-003 to Y.-W. Tien), and the E-Da Dachang Hospital, I-Shou University (108EDN11 and 109-EDN03 to C.-Y. Lee and C.-W. Lin).

\section{Authors' contributions}

P.-J. Kung, T.-Y. Lai, C.-Y. Lee, and Y.-W. Tien designed and performed most of the experiments. T.-C. Chiang, P. Ou-Yang, C.-Y. Tsai and Y.-F. Tsai assisted with some experiments. T.-Y. Lai, C.-Y. Lee and J. Cao wrote the paper. L.-C. Hsu, C.-C. Chen, M.-K. Tsai and C.-W. Lin provided expert opinions. All authors discussed the results and approved the manuscript. 


\section{Acknowledgements}

We are grateful for the technical support provided by the 3rd Core Facility and the Microscopy Core Facility of Department of Medical Research at National Taiwan University Hospital and the National RNAi Core Facility at Academia Sinica in Taiwan for providing shRNA reagents and related technical services. We would like to acknowledge the plasmid construction service provided by the 1st Core Facility at National Taiwan University College of Medicine.

\section{Author details}

${ }^{1}$ Department of Surgery, National Taiwan University Hospital and College of Medicine, National Taiwan University, Taipei, Taiwan. ${ }^{2}$ Genome and Systems Biology Degree Program, National Taiwan University and Academia Sinica, Taipei, Taiwan. ${ }^{3}$ Institute of Molecular Medicine, College of Medicine, National Taiwan University, Taipei, Taiwan. ${ }^{4}$ Department of Surgery, Wollongong Hospital, NSW, Australia. ${ }^{5}$ Department of Medical Research, National Taiwan University Hospital, Taipei, Taiwan. ${ }^{6}$ Division of Gastroenterology and Hepatology, E-Da Dachang Hospital, and School of Medicine, College of Medicine, I-Shou University, Kaohsiung City, Taiwan. ${ }^{7}$ Department of Surgery, ational Taiwan University Hospital, Hsin-Chu Branch, Hsin-Chu City, Taiwan.

\section{References}

1. Ahn, D.H., Ramanathan, R.K., Bekaii-Saab, T.: Emerging therapies and future directions in targeting the tumor stroma and immune system in the treatment of pancreatic adenocarcinoma. Cancers 10, 193 (2018)

2. Kalluri, R.: Basement membranes: structure, assembly and role in tumour angiogenesis. Nature Reviews Cancer 3, 422-433 (2003)

3. Pietras, K., Östman, A.: Hallmarks of cancer: interactions with the tumor stroma. Experimental cell research 316, 1324-1331 (2010)

4. Weniger, M., Honselmann, K.C., Liss, A.S.: The extracellular matrix and pancreatic cancer: a complex relationship. Cancers 10, 316 (2018)

5. Kuniyasu, H., Abbruzzese, J.L., Cleary, K.R., Fidler, I.J.: Induction of ductal and stromal hyperplasia by basic fibroblast growth factor produced by human pancreatic carcinoma. International journal of oncology 19, 681-685 (2001)

6. Thomas, D., Radhakrishnan, P.: Tumor-stromal crosstalk in pancreatic cancer and tissue fibrosis. Molecular cancer 18, 1-15 (2019)

7. Bachem, M.G., Schünemann, M., Ramadani, M., Siech, M., Beger, H., Buck, A., Zhou, S., Schmid-Kotsas, A. Adler, G.: Pancreatic carcinoma cells induce fibrosis by stimulating proliferation and matrix synthesis of stellate cells. Gastroenterology 128, 907-921 (2005)

8. Fujita, H., Ohuchida, K., Mizumoto, K., Nakata, K., Yu, J., Kayashima, T., Cui, L., Manabe, T., Ohtsuka, T., Tanaka, M.: $\alpha$-smooth muscle actin expressing stroma promotes an aggressive tumor biology in pancreatic ductal adenocarcinoma. Pancreas 39, 1254-1262 (2010)

9. Kadaba, R., Birke, H., Wang, J., Hooper, S., Andl, C.D., Di Maggio, F., Soylu, E., Ghallab, M., Bor, D., Froeling, F.E., et al.: Imbalance of desmoplastic stromal cell numbers drives aggressive cancer processes. The Journal of pathology 230, 107-117 (2013)

10. Goebeler, M., Roth, J., Van den Bos, C., Ader, G., Sorg, C.: Increase of calcium levels in epithelial cells induces translocation of calcium-binding proteins migration inhibitory factor-related protein $8(\mathrm{mrp} 8)$ and mrp14 to keratin intermediate filaments. Biochemical Journal 309, 419-424 (1995)

11. Odink, K., Cerletti, N., Brüggen, J., Clerc, R.G., Tarcsay, L., Zwadlo, G., Gerhards, G., Schlegel, R., Sorg, C.: Two calcium-binding proteins in infiltrate macrophages of rheumatoid arthritis. Nature 330, 80-82 (1987)

12. Gross, S.R., Sin, C.G.T., Barraclough, R., Rudland, P.S.: Joining s100 proteins and migration: for better or for worse, in sickness and in health. Cellular and molecular life sciences 71, 1551-1579 (2014)

13. Leach, S.T., Day, A.S.: S100 proteins in the pathogenesis and diagnosis of inflammatory bowel disease. Expert review of clinical immunology 2, 471-480 (2006)

14. Lim, S.Y., Yuzhalin, A.E., Gordon-Weeks, A.N., Muschel, R.J.: Tumor-infiltrating monocytes/macrophages promote tumor invasion and migration by upregulating s100a8 and s100a9 expression in cancer cells. Oncogene 35, 5735-5745 (2016)

15. Passey, R.J., Xu, K., Hume, D.A., Geczy, C.L.: S100a8: emerging functions and regulation. Journal of leukocyte biology 66, 549-556 (1999)

16. Averill, M.M., Barnhart, S., Becker, L., Li, X., Heinecke, J.W., LeBoeuf, R.C., Hamerman, J.A., Sorg, C., Kerkhoff, C., Bornfeldt, K.E.: S100a9 differentially modifies phenotypic states of neutrophils, macrophages, and dendritic cells: implications for atherosclerosis and adipose tissue inflammation. Circulation 123, 1216-1226 (2011)

17. Ichikawa, M., Williams, R., Wang, L., Vogl, T., Srikrishna, G.: S100a8/a9 activate key genes and pathways in colon tumor progression. Molecular cancer research 9, 133-148 (2011)

18. Deguchi, A., Tomita, T., Ohto, U., Takemura, K., Kitao, A., Akashi-Takamura, S., Miyake, K., Maru, Y.: Eritoran inhibits s100a8-mediated t/r4/md-2 activation and tumor growth by changing the immune microenvironment. Oncogene 35, 1445-1456 (2016)

19. Hibino, T., Sakaguchi, M., Miyamoto, S., Yamamoto, M., Motoyama, A., Hosoi, J., Shimokata, T., Ito, T., Tsuboi, R., Huh, N.-h.: S100a9 is a novel ligand of emmprin that promotes melanoma metastasis. Cellular and molecular life sciences 73, 172-183 (2013) 
20. Nedjadi, T., Evans, A., Sheikh, A., Barerra, L., Al-Ghamdi, S., Oldfield, L., Greenhalf, W., Neoptolemos, J.P., Costello, E.: S100a8 and s100a9 proteins form part of a paracrine feedback loop between pancreatic cancer cells and monocytes. Bmc Cancer 18, 1255 (2018)

21. Alahari, S.V., Dong, S., Alahari, S.K.: Are macrophages in tumors good targets for novel therapeutic approaches? Molecules and cells 38, 95 (2015)

22. Lagasse, E., Weissman, I.: Mouse mrp8 and mrp14, two intracellular calcium-binding proteins associated with the development of the myeloid lineage. Blood 79, 1907-1915 (1992)

23. Martinez-Bosch, N., Vinaixa, J., Navarro, P.: Immune evasion in pancreatic cancer: from mechanisms to therapy. Cancers 10, 6 (2018)

24. Nomi, T., Sho, M., Akahori, T., Hamada, K., Kubo, A., Kanehiro, H., Nakamura, S., Enomoto, K., Yagita, H. Azuma, M., et al.: Clinical significance and therapeutic potential of the programmed death-1 ligand/programmed death-1 pathway in human pancreatic cancer. Clinical cancer research 13, 2151-2157 (2007)

25. Camaj, P., Jäckel, C., Krebs, S., DeToni, E.N., Blum, H., Jauch, K.-W., Nelson, P.J., Bruns, C.J.: Hypoxia-independent gene expression mediated by sox9 promotes aggressive pancreatic tumor biology. Molecular Cancer Researc 12, 421-432 (2014)

26. Chernov, A.V., Dolkas, J., Hoang, K., Angert, M., Srikrishna, G., Vogl, T., Baranovskaya, S., Strongin, A.Y., Shubayev, V.I.: The calcium-binding proteins s100a8 and s100a9 initiate the early inflammatory program in injured peripheral nerves. Journal of Biological Chemistry 290, 11771-11784 (2015)

27. Ryckman, C., Vandal, K., Rouleau, P., Talbot, M., Tessier, P.A.: Proinflammatory activities of s100: proteins s100a8, s100a9, and s100a8/a9 induce neutrophil chemotaxis and adhesion. The Journal of Immunology $\mathbf{1 7 0}$ 3233-3242 (2003)

28. Cheng, P., Eksioglu, E.A., Chen, X., Kandell, W., Le Trinh, T., Cen, L., Qi, J., Sallman, D.A., Zhang, Y., Tu, $\mathrm{N}$., et al.: S100a9-induced overexpression of pd-1/pd-I1 contributes to ineffective hematopoiesis in myelodysplastic syndromes. Leukemia 33, 2034-2046 (2019)

29. Vogl, T., Tenbrock, K., Ludwig, S., Leukert, N., Ehrhardt, C., Van Zoelen, M.A., Nacken, W., Foell, D., Van der Poll, T., Sorg, C., et al.: Mrp8 and mrp14 are endogenous activators of toll-like receptor 4, promoting lethal, endotoxin-induced shock. Nature medicine 13, 1042-1049 (2007)

30. Wang, X., Li, X., Wei, X., Jiang, H., Lan, C., Yang, S., Wang, H., Yang, Y., Tian, C., Xu, Z., et al.: Pd-I1 is a direct target of cancer-foxp3 in pancreatic ductal adenocarcinoma (pdac), and combined immunotherapy with antibodies against pd-I1 and $\mathrm{ccl} 5$ is effective in the treatment of pdac. Signal transduction and targeted therapy 5, 1-12 (2020)

31. Thul, P.J., Åkesson, L., Wiking, M., Mahdessian, D., Geladaki, A., Blal, H.A., Alm, T., Asplund, A., Björk, L. Breckels, L.M., et al.: A subcellular map of the human proteome. Science 356, 3321 (2017)

32. Uhlon, M., Fagerberg, L., Hallstrom, B., et al.: Proteomics. tissue-based map of the human proteome. Science 347, 1260419 (2015)

33. Krizhanovsky, V., Yon, M., Dickins, R.A., Hearn, S., Simon, J., Miething, C., Yee, H., Zender, L., Lowe, S.W.: Senescence of activated stellate cells limits liver fibrosis. Cell 134, 657-667 (2008)

34. Veenstra, V.L., Garcia-Garijo, A., Van Laarhoven, H.W., Bijlsma, M.F.: Extracellular influences: molecular subclasses and the microenvironment in pancreatic cancer. Cancers 10, 34 (2018)

35. Bremnes, R.M., Dønnem, T., Al-Saad, S., Al-Shibli, K., Andersen, S., Sirera, R., Camps, C., Marinez, I., Busund, L.-T.: The role of tumor stroma in cancer progression and prognosis: emphasis on carcinoma-associated fibroblasts and non-small cell lung cancer. Journal of thoracic oncology 6, 209-217 (2011)

36. Lin, H.-J., Lin, J.: Seed-in-soil: pancreatic cancer influenced by tumor microenvironment. Cancers 9, 93 (2017)

37. Itou, H., Yao, M., Fujita, I., Watanabe, N., Suzuki, M., Nishihira, J., Tanaka, I.: The crystal structure of human mrp14 (s100a9), a ca2+-dependent regulator protein in inflammatory process. Journal of molecular biology 316, 265-276 (2002)

38. Markowitz, J., Carson III, W.E.: Review of s100a9 biology and its role in cancer. Biochimica et Biophysica Acta (BBA)-Reviews on Cancer 1835, 100-109 (2013)

39. Zwadlo, G., Brüggen, J., Gerhards, G., Schlegel, R., Sorg: Two calcium-binding proteins associated with specific stages of myeloid cell differentiation are expressed by subsets of macrophages in inflammatory tissues. Clinical and experimental immunology 72, 510-515 (1988)

40. Shabani, F., Farasat, A., Mahdavi, M., Gheibi, N.: Calprotectin (s100a8/s100a9): a key protein between inflammation and cancer. Inflammation Research 67, 801-812 (2018)

41. Kawai, H., Minamiya, Y., Takahashi, N.: Prognostic impact of s100a9 overexpression in non-small cell lung cancer. Tumor Biology 32, 641-646 (2011)

42. Ehrchen, J.M., Sunderkötter, C., Foell, D., Vogl, T., Roth, J.: The endogenous toll-like receptor 4 agonist s100a8/s100a9 (calprotectin) as innate amplifier of infection, autoimmunity, and cancer. Journal of leukocyte biology 86, 557-566 (2009)

43. Tesarova, P., Kalousova, M., Zima, T., Tesarc, V.: Hmgb1, s100 proteins and other rage ligands in cancer-markers, mediators and putative therapeutic targets. Biomedical Papers of the Medical Faculty of Palacky University in Olomouc 160, 1-10 (2016)

44. Srikrishna, G.: S100a8 and s100a9: new insights into their roles in malignancy. Journal of innate immunity 4 , 31-40 (2012)

45. Zhong, J.-M., Li, J., Kang, A.-D., Huang, S.-Q., Liu, W.-B., Zhang, Y., Liu, Z.-H., Zeng, L.: Protein s100-a8: A potential metastasis-associated protein for breast cancer determined via itraq quantitative proteomic and clinicopathological analysis. Oncology Letters 15, 5285-5293 (2018)

46. Feng, M., Xiong, G., Cao, Z., Yang, G., Zheng, S., Song, X., You, L., Zheng, L., Zhang, T., Zhao, Y.: $\mathrm{Pd}-1 / \mathrm{pd}-\mathrm{I} 1$ and immunotherapy for pancreatic cancer. Cancer letters 407, 57-65 (2017)

47. Li, Z., Wang, J., Zhang, X., Liu, P., Zhang, X., Wang, J., Zheng, X., Wei, L., Peng, Q., Liu, C., et al.: Proinflammatory s100a8 induces pd-I1 expression in macrophages, mediating tumor immune escape. The Journal of Immunology 204, 2589-2599 (2020) 
Figure 1 Expression of S100A9 in PDAC cells was enhanced when they are cocultured with PSCs. The protein and gene expression of S100A9 was upregulated when PSCs were cocultured with PDAC cell lines, including AsPC-1 cells ( $a$ and d), HPAF-II cells (b and e) and PANC-1 cells (c and $f$ ). In the coculture system, PDAC cells were cultured in a 6 -well plate with or without PSCs in Millicell $\mathbb{R} 0.4 \mu \mathrm{m}$-pore hanging inserts (Millipore) for the indicated time points. All experiments were performed in triplicate.

Figure 2 S100A9 in conditioned media from PDAC cells cocultured with PSCs enhanced the migration of monocytes. In transwell migration assays, THP-1 (a) or U937 (b) cells were cultured inside hanging inserts $(8.0 \mu \mathrm{m}$, Millipore) for 24 hours in conditioned media from AsPC-1, HPAF-II and PANC-1 cells cocultured with or without PSCs. The migrated cells were counted in four fields for each sample, and the experiments were performed in triplicate. The migration of THP-1 (a) or U937 (b) cells was enhanced in the conditioned media from pancreatic cancer cell lines cocultured with PSCs for 24 hours. We constructed a S100A9 plasmid with a Flag tag at the C terminus in the pcDNA3.0 vector and transfected the S100A9-Flag vector into HEK293 cells. The expression of S100A9 in HEK293 cells was verified by immunoblot with an anti-S100A9 antibody (c) and an anti-Flag antibody (d). The empty vector served as a control. Flag-tagged S100A9 protein was detected in the culture medium by immunoblot after precipitation with trichloroacetic acid (e). In the transwell migration assays, we placed conditioned media from HEK293 cells transduced with the S100A9 expression vector or control in the culture plates and seeded monocyte cell lines, including THP-1 or U937 $\left(2 \times 10^{5}\right)$ cells, in the hanging inserts, followed by incubation for 24 hours. We calculated the numbers of migrated THP-1 ( $f$ ) and U937 (g) cells. We found that conditioned media with S100A9 enhanced the migration of THP-1 and U937 cells. The migrated cells were counted in four different fields, and the experiments were repeated in triplicate. $\mathrm{p}$ values were obtained by $\mathrm{t}$-test: ${ }^{* *} \mathrm{p}<0.005,{ }^{* * *} \mathrm{p}<0.001$.

Figure 3 Knockdown of S100A9 in PDAC cells affected the migration of monocytes in transwell migration assays. The S100A9 mRNA levels in AsPC-1 (a) and HPAF-II (b) cells after knockdown of S100A9 with shRNA are shown. The mRNA level was determined by quantitative real-time PCR. We examined transwell migration of U-937 cells $\left(1 \times 10^{5}\right)$ cultured in conditioned medium from AsPC-1 (c) or HPAF-II (d) cells with either knocked down or normal S100A9 expression cocultured with or without PSCs. We found that conditioned medium from PDAC cells cocultured with PSCs enhanced the migration of U-937 cells. The conditioned medium from PSCs cocultured with S100A9-knockdown AsPC-1 (c) and HPAF-II (d) cells induced less attraction of U-937 cells than the conditioned medium from PSCs cocultured with control cells. DMEM: Dulbecco's modified Eagle's medium, RPMI 1640: Roswell Park Memorial Institute.

Figure 4 The surface expression of PD-L1 in monocytes was increased after stimulation with S100A9. We treated U937 cells with IFN- $\gamma$ along with recombinant S100A9 and detected the surface expression of PD-L1 with flow cytometry. We found that treatment of IFN- $\gamma$-primed U937 cells with S100A9 protein for 6 (a) and 24 (b) hours enhanced the surface expression of PD-L1. We performed the experiments in triplicate. $\mathrm{p}$ values were determined by $\mathrm{t}$-test: ${ }^{*} \mathrm{p}<0.005$.

Figure 5 Immunofluorescence analysis of S100A9 and stellate cells in human PDAC tissue. Using immunofluorescence, S100A9-expressing cells (red) were found to be located near cells expressing $\alpha$-SMA (green), a marker for activated PSCs, in specimens from PDAC patients with metastasis (a and b). Less PSC infiltration correlated with fewer S100A9-expressing cells in the specimens from patients with PDAC without metastasis (c and d). We used Hoechst 33342 for nuclear counterstaining (blue). (e) The correlation between the number of cells expressing of S100A9 and the number of cells expressing $\alpha$-SMA in patients with PDAC was significant in the regression model $(R 2=0.849, p<0.001)$. Each spot represents staining of a specimen from one patient $(\mathrm{N}=22)$. 
Figure 6 Kaplan-Meier survival curves generated based on S100A9 (a) and PD-L1 (b) expression. We obtained survival and immunohistochemistry staining data from 176 patients with PDAC from The Human Protein Atlas (https://www.proteinatlas.org/). Patients were divided into high and low expression groups based on the default setting on the website. The survival of each group was examined by Kaplan-Meier survival estimators, and the survival outcomes of the two groups were compared by log-rank tests. The patients with lower expression of S100A9 (a, p=0.013, log-rank test) and PD-L1 (b, p=0.007, log-rank test) in their PDAC samples had better survival than those with high expression.

Figure $7 \mathrm{~A}$ proposed model summarizing the interaction between PDAC cells and their surrounding microenvironment. S100A9 expression can be induced in PDAC cells incubated with PSCs and acts as a chemoattractant for monocytes. S100A9 can also induce surface expression of PD-L1 on macrophages. 
Additional Files

Additional file 1 - Supplementary Table S1.

Top 50 upregulated genes in pancreatic adenocarcinoma cells exposed to pancreatic stellate cells in the microarray dataset GSE36775. The microarray dataset was downloaded from Gene Expression Omnibus (GEO) at

https://www.ncbi.nlm.nih.gov/geo/. We analyzed the dataset with GEO2R at

https://www.ncbi.nlm.nih.gov/geo/geo2r/ to obtain log2-transformed fold change values and adjusted p-values for multiple comparisons.

\begin{tabular}{|c|c|c|}
\hline Gene symbol & Log fold change & Adjusted p-value \\
\hline SAA1 & 2.17 & 0.0018 \\
\hline FCGBP & 1.94 & 0.00201 \\
\hline PIGR & 1.91 & 0.00167 \\
\hline SAA2 & 1.91 & 0.00167 \\
\hline TFF3 & 1.77 & 0.0018 \\
\hline ATP10B & 1.75 & 0.00243 \\
\hline HLA-DRA & 1.69 & 0.00243 \\
\hline RNASE1 & 1.68 & 0.00165 \\
\hline AGR2 & 1.67 & 0.00243 \\
\hline S100A8 & 1.67 & 0.00165 \\
\hline RARRES1 & 1.65 & 0.0101 \\
\hline DMBT1 & 1.63 & 0.00165 \\
\hline CDC42EP5 & 1.57 & 0.00109 \\
\hline ASS1 & 1.54 & 0.00964 \\
\hline CFB & 1.49 & 0.00667 \\
\hline CD74 & 1.45 & 0.00435 \\
\hline HLA-DPA1 & 1.42 & 0.00331 \\
\hline GBP2 & 1.36 & 0.00684 \\
\hline HSD17B2 & 1.33 & 0.00165 \\
\hline MUC1 & 1.33 & 0.00443 \\
\hline PSCA & 1.33 & 0.01877 \\
\hline RARRES3 & 1.29 & 0.02695 \\
\hline CEACAM 1 & 1.26 & 0.02399 \\
\hline PDZK1IP1 & 1.23 & 0.03226 \\
\hline PRR15L & 1.23 & 0.00312 \\
\hline HLA-DRB6 & 1.18 & 0.00243 \\
\hline CAPN5 & 1.17 & 0.00697 \\
\hline CYP3A5 & 1.17 & 0.01538 \\
\hline LGALS4 & 1.16 & 0.00547 \\
\hline CD24 & 1.14 & 0.00667 \\
\hline $\mathrm{PI3}$ & 1.14 & 0.04351 \\
\hline SERPINA3 & 1.14 & 0.04645 \\
\hline CCPG1 & 1.13 & 0.03932 \\
\hline HLA-DMA & 1.13 & 0.0018 \\
\hline $\mathrm{MB}$ & 1.13 & 0.0018 \\
\hline VSIG2 & 1.11 & 0.01812 \\
\hline WIPI1 & 1.11 & 0.0083 \\
\hline S100A9 & 1.1 & 0.02042 \\
\hline AZGP1 & 1.09 & 0.00167 \\
\hline KLHL24 & 1.08 & 0.02311 \\
\hline SAA4 & 1.08 & 0.00697 \\
\hline TRAPPC6A & 1.07 & 0.0018 \\
\hline ALDH3B2 & 1.07 & 0.00264 \\
\hline PRSS1 & 1.06 & 0.01563 \\
\hline PLA2G10 & 1.04 & 0.00167 \\
\hline TSPAN1 & 1.03 & 0.00243 \\
\hline
\end{tabular}


Additional file 2 - Supplementary Table S2.

Top 50 upregulated genes in pancreatic cancer cell lines with high metastatic and growth potential under normoxic growth conditions in the microarray dataset GSE9350. The microarray dataset was downloaded from GEO. We analyzed the dataset with GEO2R at https://www.ncbi.nlm.nih.gov/geo/geo2r/ to obtain log2-transformed fold change values and adjusted p-values for multiple comparisons.

\begin{tabular}{|c|c|c|}
\hline Gene symbol & Log fold change & Adjusted p-value \\
\hline SOSTDC1 & 6.657 & 9.11E-05 \\
\hline NTRK2 & 6.496 & 0.000174 \\
\hline IL1R1 & 5.191 & 0.001213 \\
\hline $\mathrm{BCHE}$ & 4.9 & 0.000248 \\
\hline PLAT & 4.524 & 0.000219 \\
\hline PTPRZ1 & 4.441 & 0.000581 \\
\hline HLA-DRA & 4.384 & $8.06 \mathrm{E}-05$ \\
\hline PHLDA1 & 4.241 & 0.000219 \\
\hline MUC2 & 4.131 & 0.00155 \\
\hline PTHLH & 3.949 & 0.00111 \\
\hline MPPED2 & 3.946 & 0.00069 \\
\hline SAGE1 & 3.933 & 0.000228 \\
\hline PHLDA1 & 3.875 & 0.001309 \\
\hline DUSP6 & 3.851 & 0.001231 \\
\hline ALDH1A3 & 3.838 & 0.00069 \\
\hline HS3ST1 & 3.675 & 0.000568 \\
\hline NTRK2 & 3.603 & 0.00023 \\
\hline DKK3 & 3.327 & 0.000791 \\
\hline SLC6A15 & 3.284 & 0.00049 \\
\hline PAK3 & 3.249 & 0.000486 \\
\hline GLUL & 3.22 & 8.06E-05 \\
\hline MME & 3.173 & 0.001438 \\
\hline PIK3AP1 & 3.172 & 0.000421 \\
\hline PADI3 & 3.07 & 0.000248 \\
\hline PAK3 & 3.065 & 0.000581 \\
\hline DUSP6 & 3.048 & 0.001214 \\
\hline GLUL & 3.017 & 0.000123 \\
\hline GCNT3 & 3.013 & 0.000219 \\
\hline ABCA1 & 2.973 & 0.000356 \\
\hline VEGFC & 2.934 & 0.00111 \\
\hline S100A9 & 2.933 & 0.00036 \\
\hline PHLDA1 & 2.813 & 0.000741 \\
\hline STC1 & 2.801 & 0.001546 \\
\hline GLUL & 2.79 & 0.000128 \\
\hline TNFSF10 & 2.763 & 0.001225 \\
\hline MPPED2 & 2.723 & 0.000737 \\
\hline ABCA1 & 2.627 & 0.000341 \\
\hline GBP6 & 2.603 & 0.00069 \\
\hline TNFSF10 & 2.403 & 0.001406 \\
\hline LINC00673 & 2.275 & 0.000822 \\
\hline SLC6A15 & 2.259 & 0.001664 \\
\hline CEP19 & 2.245 & 0.000822 \\
\hline CEP19 & 2.24 & 0.001111 \\
\hline TIPARP & 2.238 & 0.000292 \\
\hline B4GALT6 & 2.218 & 0.000356 \\
\hline NFKBIZ & 2.198 & 0.000453 \\
\hline IL18R1 & 2.192 & 0.000669 \\
\hline IKZF2 & 2.178 & 0.000219 \\
\hline EDNRA & 2.115 & 0.001755 \\
\hline NRP2 & 2.049 & 0.00111 \\
\hline
\end{tabular}


Additional file 3 - Supplementary Table S3.

Primer pairs for real-time PCR

$\begin{array}{ll}\text { S100A8 F: } & \text { 5' GGGGAATTTCCATGCCGTCTAC 3' } \\ \text { S100A8 R: } & \text { 5' CTGCCACGCCCATCTTTATCAC 3' } \\ \text { S100A9 F: } & \text { 5' TCAAAGAGCTGGTGCGAAAGAT 3' } \\ \text { S100A9 R: } & \text { 5' CCTCGCCATCAGCATGATGAACT 3' } \\ \text { Cyclophilin F: } & \text { 5' ATACGGGTCCTGGCATCTTGTC 3' } \\ \text { Cyclophilin R: } & \text { 5' GGTGATCTTCTTGCTGGTCTTG 3' }\end{array}$

Additional file 4 - Supplementary Table S4.

Clinical and pathological characteristics of the study cohort from The Human Protein Atlas website. We obtained data from 176 patients with pancreatic ductal carcinoma via The Human Protein Atlas website

(https://www.proteinatlas.org/). The patients were divided into high and low expression groups based on the default setting on the website. $\mathrm{p}$ values were calculated via $*$ t-test, $* *$ chi-square test, or ${ }^{* * *}$ Fisher's exact test. $\alpha$-SMA: $\alpha$-smooth muscle actin.

\begin{tabular}{cccc}
\hline \multirow{2}{*}{ Characteristics } & \multicolumn{2}{c}{ S100A9 level } & \multirow{2}{*}{ p value } \\
\cline { 2 - 3 } & Low & High & \\
\cline { 2 - 3 } & $\mathrm{N}=37$ & $\mathrm{~N}=139$ & \\
\hline Age (Years) & $63.1+10.5$ & $65.1+11$ & $0.303^{*}$ \\
Gender & & & $0.156^{* *}$ \\
Male & 24 & 72 & \\
Female & 12 & 67 & \\
Stage & & & \\
I-II & $32(18.2 \%)$ & $134(76.1 \%)$ & \\
III-IV & $4(2.3 \%)$ & $3(1.7 \%)$ & \\
Not available & $1(0.6 \%)$ & $2(1.1 \%)$ & \\
$\alpha$-SMA level & & & \\
Low & 24 & 29 & $<0.001^{* *}$ \\
High & 13 & 110 & \\
& & &
\end{tabular}

Additional file 5 - Supplementary Table S5.

Univariate and multivariate Cox regression analyses of potential factors affecting patient survival in 176 patients with pancreatic ductal carcinoma from the Human Protein Atlas database (https://www.proteinatlas.org/). $\alpha$-SMA: $\alpha$-smooth muscle actin.

\begin{tabular}{|c|c|c|c|c|}
\hline \multirow[b]{2}{*}{ Factor } & \multicolumn{2}{|c|}{ Univariate model } & \multicolumn{2}{|c|}{ Multivariate model } \\
\hline & $\mathrm{HR}(95 \% \mathrm{Cl})$ & $\mathrm{p}$ value & $\operatorname{HR}(95 \% \mathrm{Cl})$ & $\mathrm{p}$ value \\
\hline Age & $1.03(1.01-1.05)$ & 0.006 & $1.03(1-1.05)$ & 0.019 \\
\hline Male & $0.82(0.54-1.24)$ & 0.344 & & \\
\hline \multicolumn{5}{|l|}{ Stage } \\
\hline I & $0.46(0.21-0.99)$ & 0.028 & & \\
\hline II & $2.37(1.22-4.59)$ & 0.005 & & \\
\hline III & $0.6(0.08-4.32)$ & 0.581 & & \\
\hline IV & $1(0.25-4.12)$ & 0.99 & & \\
\hline S100A9 expression & $2(1.14-3.49)$ & 0.009 & $1.82(1.04-3.21)$ & 0.037 \\
\hline$\alpha$-SMA expression & $1.41(0.89-2.24)$ & 0.136 & & \\
\hline
\end{tabular}

Additional file 6 - Supplementary Figure S1

Kaplan-Meier survival curves according $\alpha$-SMA expression. We obtained survival and immunohistochemistry staining data from 176 patients with pancreatic ductal carcinoma from The Human Protein Atlas

(https://www.proteinatlas.org/). Patients were divided into high and low expression groups based on the default setting on the website. The survival of each group was examined by Kaplan-Meier survival estimators, and the survival outcomes of the two groups were compared by log-rank tests. The expression of $\alpha$-SMA did not have a significant effect on the survival of the patients with PDAC ( $p=0.144$, log-rank test). 

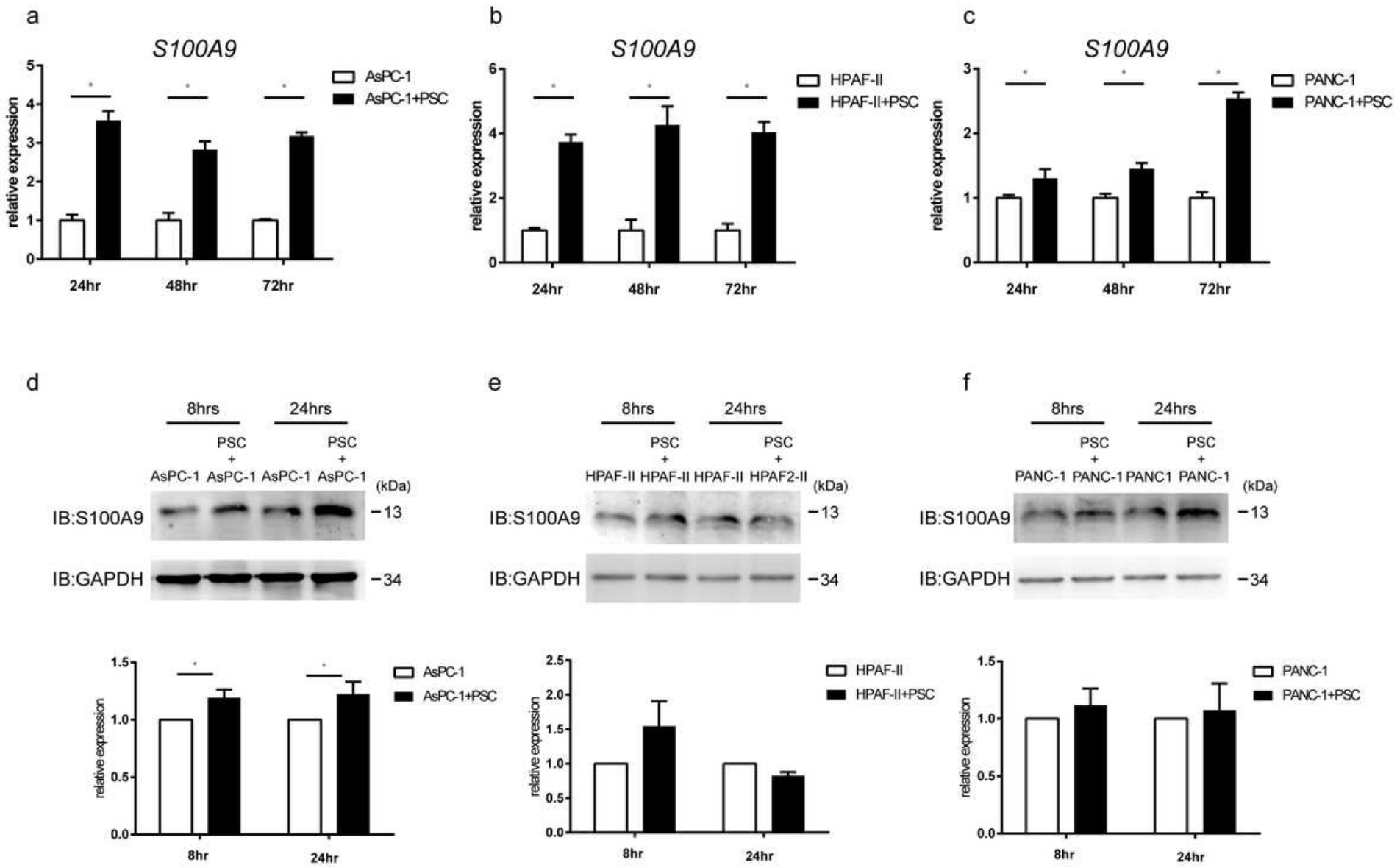

\section{Figure 1}

Expression of S100A9 in PDAC cells was enhanced when they are cocultured with PSCs. The protein and gene expression of S100A9 was upregulated when PSCs were cocultured with PDAC cell lines, including AsPC-1 cells ( $a$ and d), HPAF-II cells ( $b$ and e) and PANC-1 cells ( $c$ and $f$ ). In the coculture system, PDAC cells were cultured in a 6-well plate with or without PSCs in Millicell ${ }^{\circledR} 0.4 \mu \mathrm{m}$-pore hanging inserts (Millipore) for the indicated time points. All experiments were performed in triplicate. 


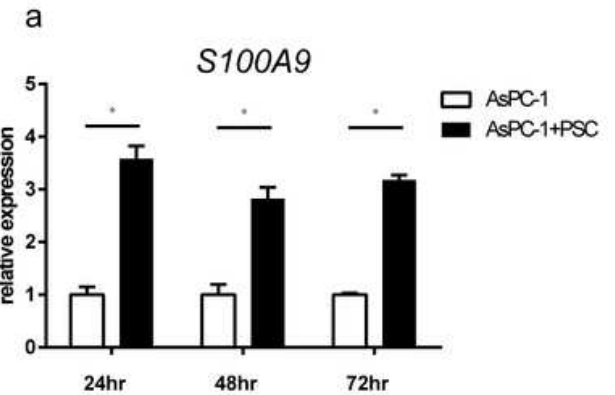

b
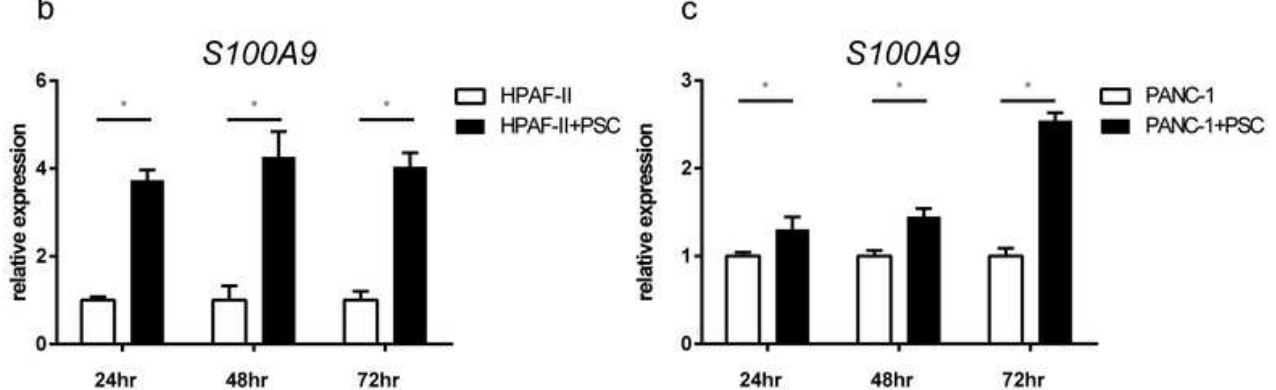

d

e
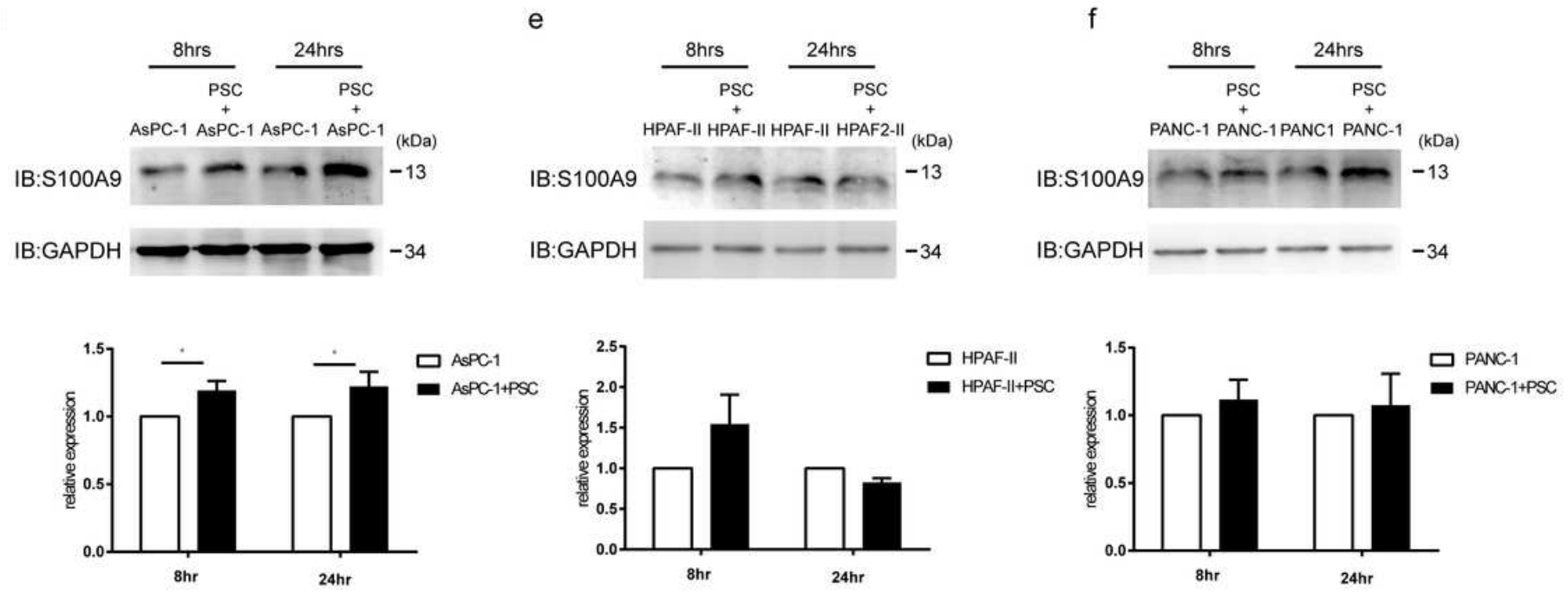

Figure 1

Expression of S100A9 in PDAC cells was enhanced when they are cocultured with PSCs. The protein and gene expression of S100A9 was upregulated when PSCs were cocultured with PDAC cell lines, including AsPC-1 cells ( $a$ and d), HPAF-II cells (b and e) and PANC- 1 cells ( $c$ and $f$ ). In the coculture system, PDAC cells were cultured in a 6-well plate with or without PSCs in Millicell ${ }^{\circledR} 0.4 \mu \mathrm{m}$-pore hanging inserts (Millipore) for the indicated time points. All experiments were performed in triplicate. 


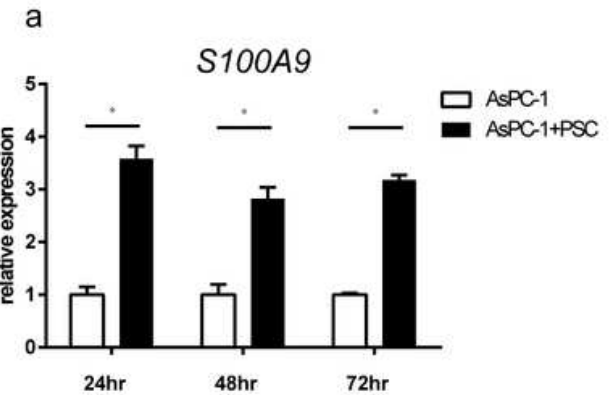

b
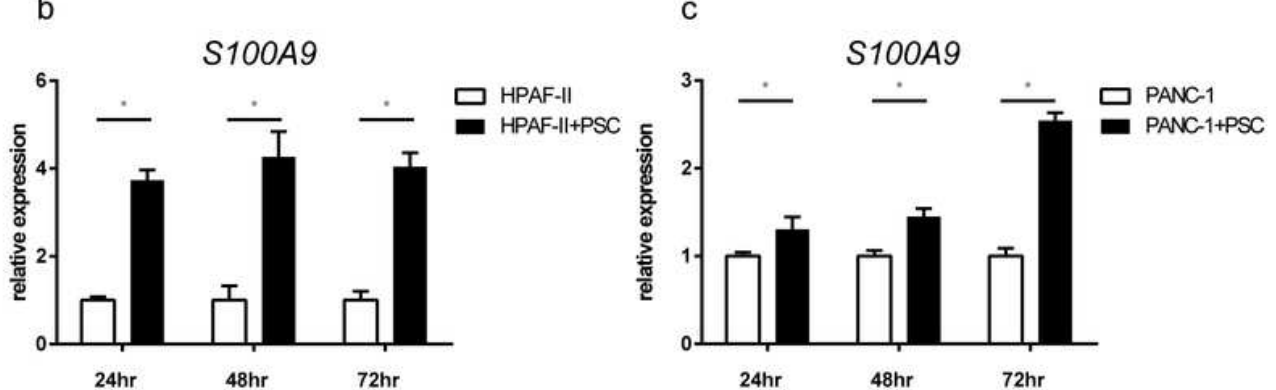

d

e
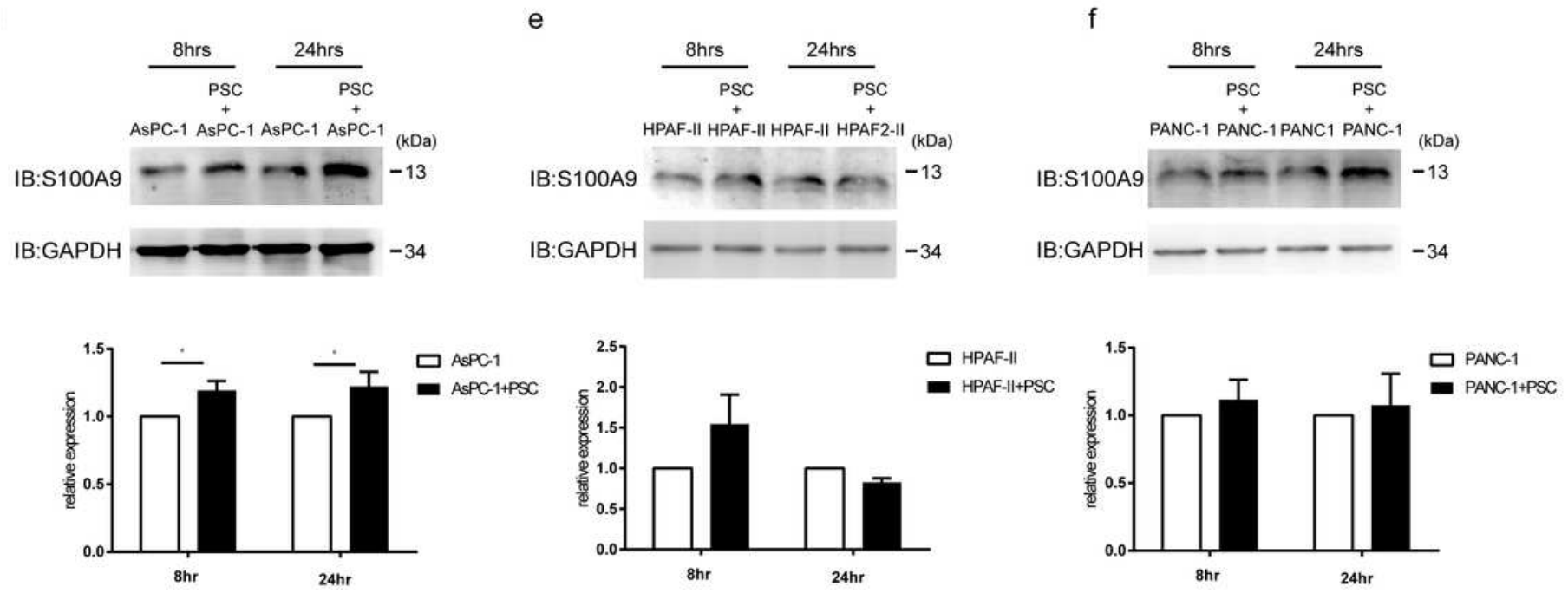

Figure 1

Expression of S100A9 in PDAC cells was enhanced when they are cocultured with PSCs. The protein and gene expression of S100A9 was upregulated when PSCs were cocultured with PDAC cell lines, including AsPC-1 cells ( $a$ and d), HPAF-II cells (b and e) and PANC- 1 cells ( $c$ and $f$ ). In the coculture system, PDAC cells were cultured in a 6-well plate with or without PSCs in Millicell ${ }^{\circledR} 0.4 \mu \mathrm{m}$-pore hanging inserts (Millipore) for the indicated time points. All experiments were performed in triplicate. 

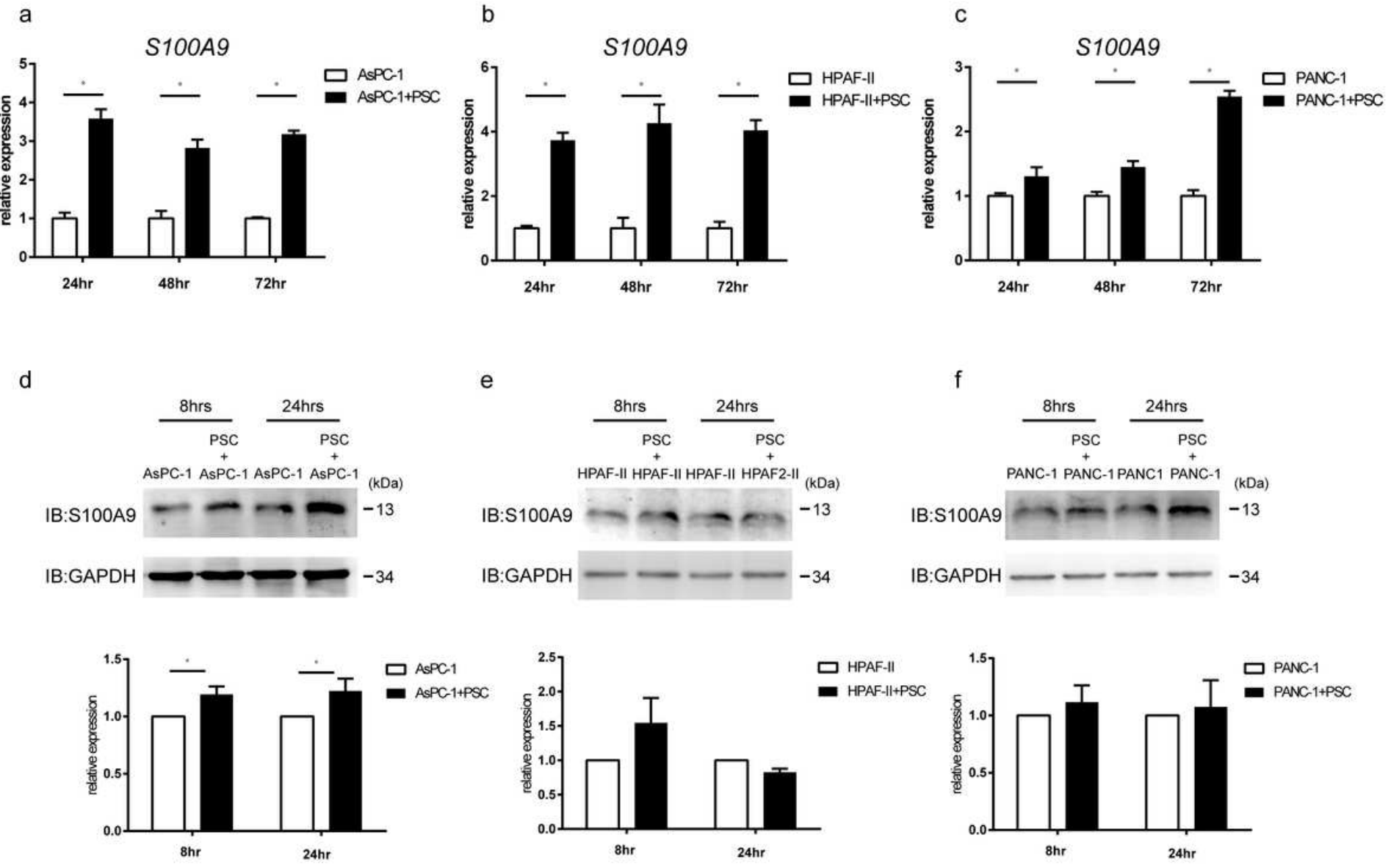

Figure 1

Expression of S100A9 in PDAC cells was enhanced when they are cocultured with PSCs. The protein and gene expression of S100A9 was upregulated when PSCs were cocultured with PDAC cell lines, including AsPC- 1 cells ( $a$ and d), HPAF-II cells ( $b$ and e) and PANC- 1 cells ( $c$ and $f$ ). In the coculture system, PDAC cells were cultured in a 6-well plate with or without PSCs in Millicell ${ }^{\circledR} 0.4 \mu \mathrm{m}$-pore hanging inserts (Millipore) for the indicated time points. All experiments were performed in triplicate. 


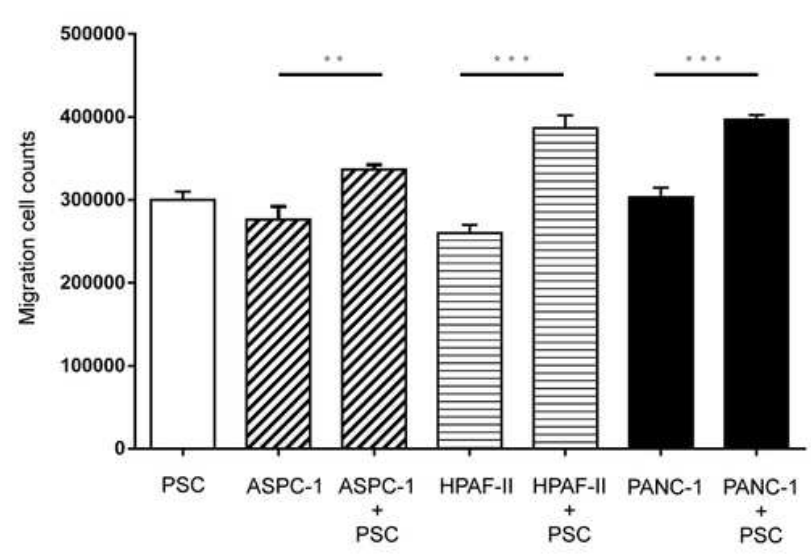

C

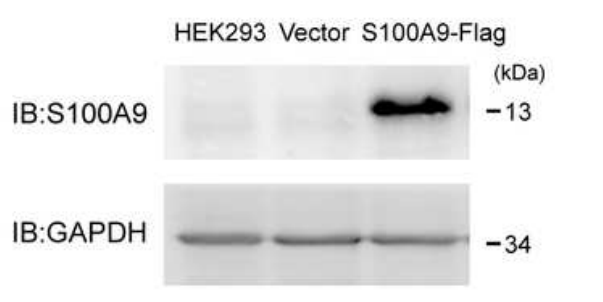

f

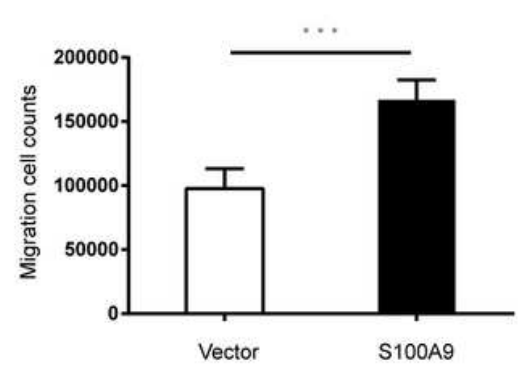

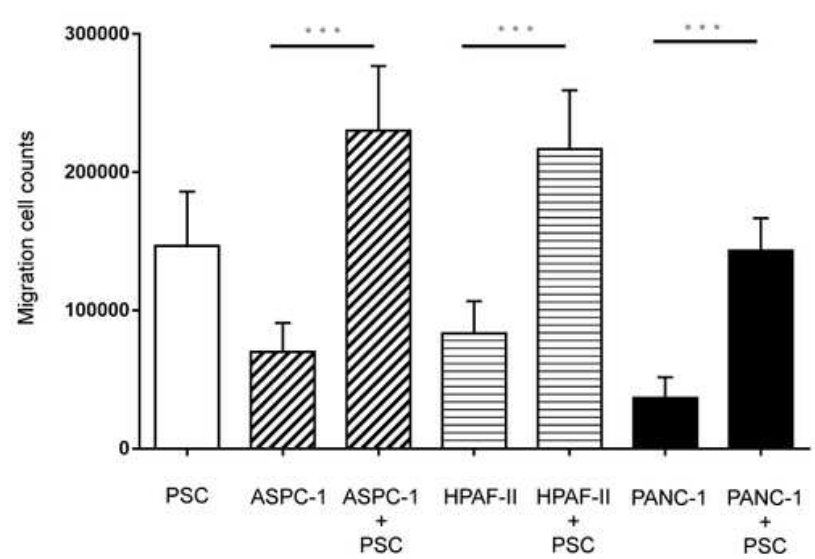

e
HEK293 Vector S100A9-Flag

IB:Flag (kDa)

$-13$

IB:Flag g

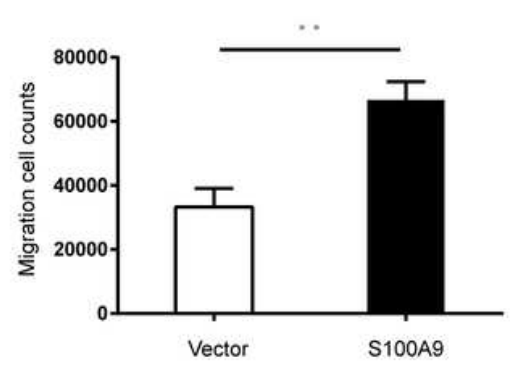

Figure 2

S100A9 in conditioned media from PDAC cells cocultured with PSCs enhanced the migration of monocytes. In transwell migration assays, THP-1 (a) or U937 (b) cells were cultured inside hanging inserts (8.0 $\mu \mathrm{m}$, Millipore) for 24 hours in conditioned media from AsPC-1, HPAF-II and PANC-1 cells cocultured with or without PSCs. The migrated cells were counted in four fields for each sample, and the experiments were performed in triplicate. The migration of THP-1 (a) or U937 (b) cells was enhanced in the conditioned media from pancreatic cancer cell lines cocultured with PSCs for 24 hours. We constructed a S100A9 plasmid with a Flag tag at the $C$ terminus in the pcDNA3.0 vector and transfected the S100A9-Flag vector into HEK293 cells. The expression of S100A9 in HEK293 cells was verified by immunoblot with an anti-S100A9 antibody (c) and an anti-Flag antibody (d). The empty vector served as a control. Flag-tagged S100A9 protein was detected in the culture medium by immunoblot after precipitation with trichloroacetic acid (e). In the transwell migration assays, we placed conditioned media 
from HEK293 cells transduced with the S100A9 expression vector or control in the culture plates and seeded monocyte cell lines, including THP-1 or U937 (2x105) cells, in the hanging inserts, followed by incubation for 24 hours. We calculated the numbers of migrated THP-1 (f) and U937 (g) cells. We found that conditioned media with S100A9 enhanced the migration of THP-1 and U937 cells. The migrated cells were counted in four different fields, and the experiments were repeated in triplicate. $p$ values were obtained by t-test: ${ }^{* *} p<0.005,{ }^{* *} p<0.001$.

a

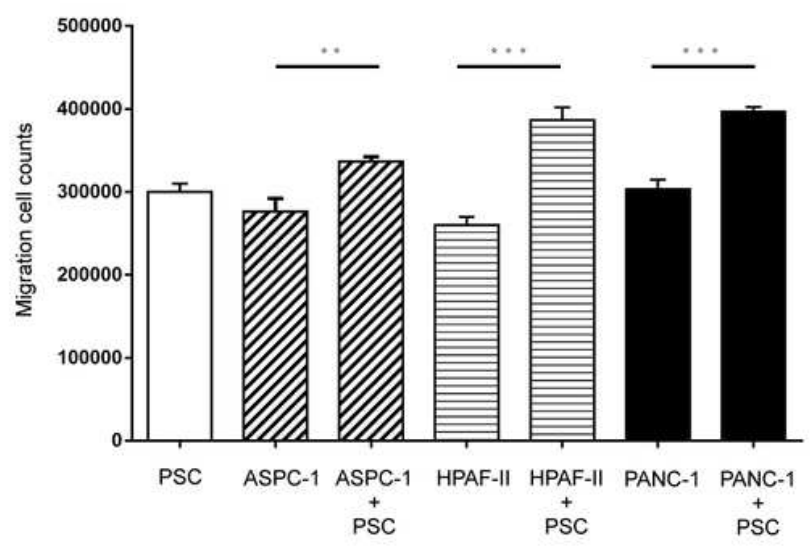

C
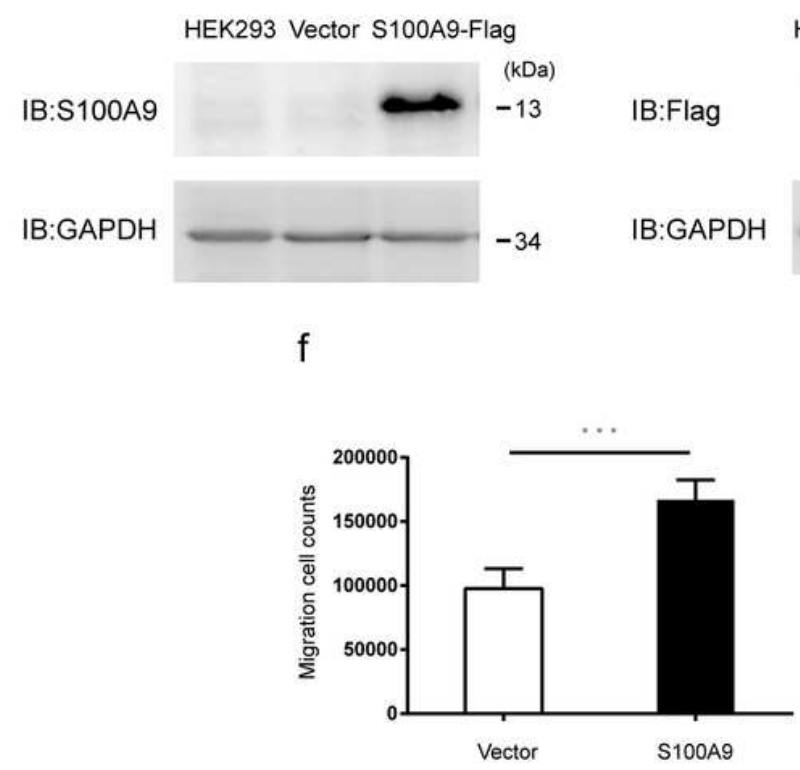

b

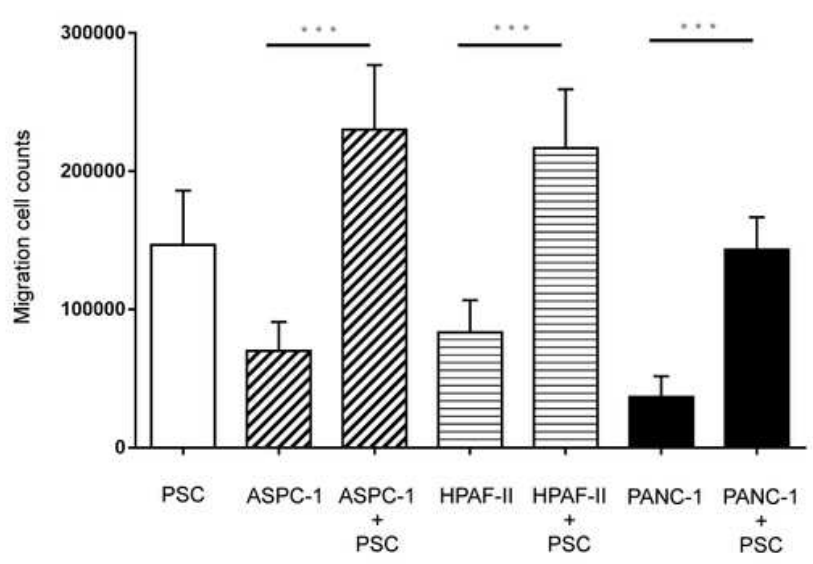

e
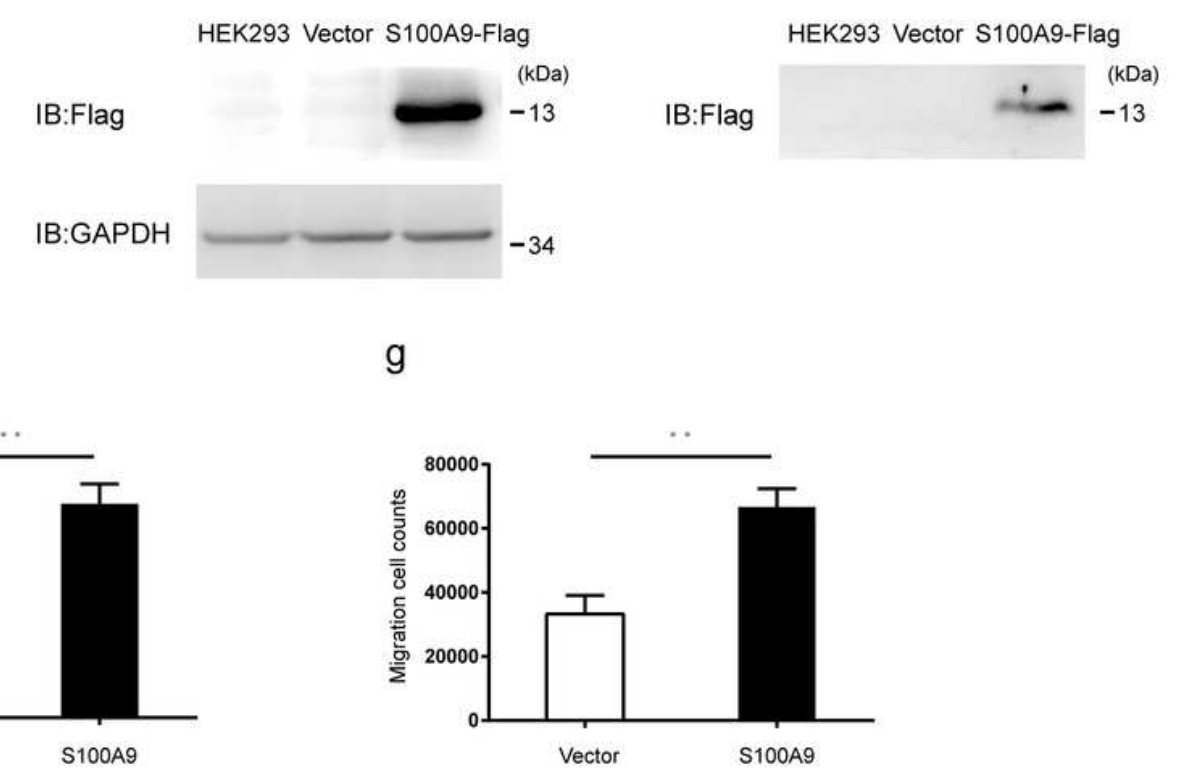

\section{Figure 2}

S100A9 in conditioned media from PDAC cells cocultured with PSCs enhanced the migration of monocytes. In transwell migration assays, THP-1 (a) or U937 (b) cells were cultured inside hanging inserts $(8.0 \mu \mathrm{m}$, Millipore) for 24 hours in conditioned media from AsPC-1, HPAF-II and PANC-1 cells cocultured with or without PSCs. The migrated cells were counted in four fields for each sample, and the experiments were performed in triplicate. The migration of THP-1 (a) or U937 (b) cells was enhanced in 
the conditioned media from pancreatic cancer cell lines cocultured with PSCs for 24 hours. We constructed a S100A9 plasmid with a Flag tag at the $\mathrm{C}$ terminus in the pcDNA3.0 vector and transfected the S100A9-Flag vector into HEK293 cells. The expression of S100A9 in HEK293 cells was verified by immunoblot with an anti-S100A9 antibody (c) and an anti-Flag antibody (d). The empty vector served as a control. Flag-tagged S100A9 protein was detected in the culture medium by immunoblot after precipitation with trichloroacetic acid (e). In the transwell migration assays, we placed conditioned media from HEK293 cells transduced with the S100A9 expression vector or control in the culture plates and seeded monocyte cell lines, including THP-1 or U937 (2x105) cells, in the hanging inserts, followed by incubation for 24 hours. We calculated the numbers of migrated THP-1 (f) and U937 (g) cells. We found that conditioned media with S100A9 enhanced the migration of THP-1 and U937 cells. The migrated cells were counted in four different fields, and the experiments were repeated in triplicate. $p$ values were obtained by t-test: ${ }^{* \star} \mathrm{p}<0.005,{ }^{* * *} \mathrm{p}<0.001$.

a

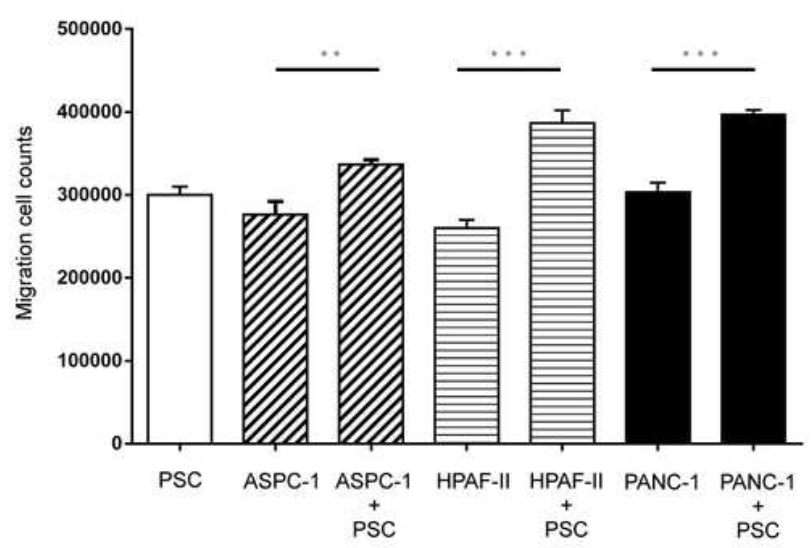

C

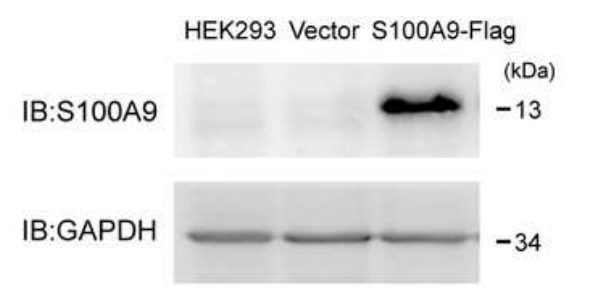

f

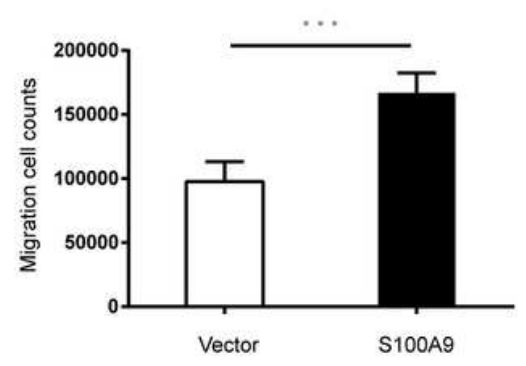

b

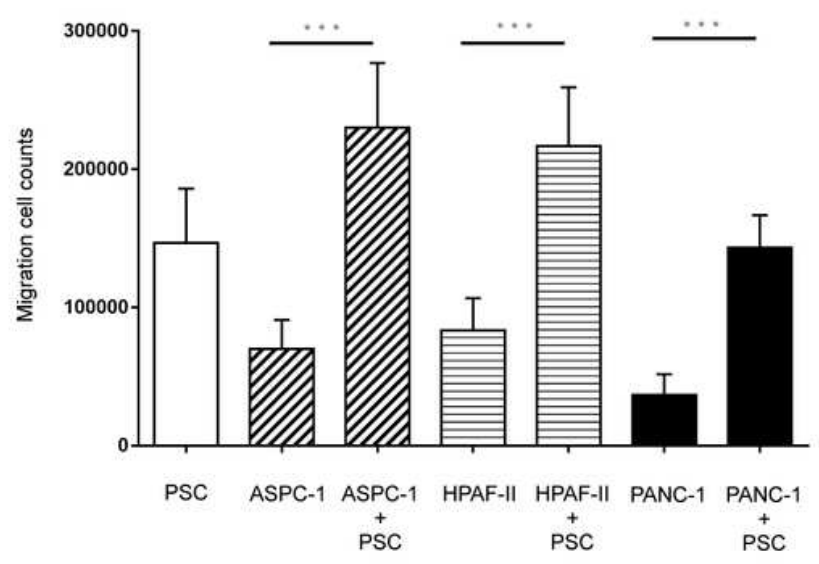

e
HEK293 Vector S100A9-Flag

IB:Flag

IB:GAPDH
HEK293 Vector S100A9-Flag

IB:Flag

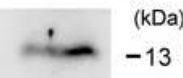


S100A9 in conditioned media from PDAC cells cocultured with PSCs enhanced the migration of monocytes. In transwell migration assays, THP-1 (a) or U937 (b) cells were cultured inside hanging inserts ( $8.0 \mu \mathrm{m}$, Millipore) for 24 hours in conditioned media from AsPC-1, HPAF-II and PANC-1 cells cocultured with or without PSCs. The migrated cells were counted in four fields for each sample, and the experiments were performed in triplicate. The migration of THP-1 (a) or U937 (b) cells was enhanced in the conditioned media from pancreatic cancer cell lines cocultured with PSCs for 24 hours. We constructed a S100A9 plasmid with a Flag tag at the $C$ terminus in the pcDNA3.0 vector and transfected the S100A9-Flag vector into HEK293 cells. The expression of S100A9 in HEK293 cells was verified by immunoblot with an anti-S100A9 antibody (c) and an anti-Flag antibody (d). The empty vector served as a control. Flag-tagged S100A9 protein was detected in the culture medium by immunoblot after precipitation with trichloroacetic acid (e). In the transwell migration assays, we placed conditioned media from HEK293 cells transduced with the S100A9 expression vector or control in the culture plates and seeded monocyte cell lines, including THP-1 or U937 (2x105) cells, in the hanging inserts, followed by incubation for 24 hours. We calculated the numbers of migrated THP-1 ( $\mathrm{f}$ ) and U937 (g) cells. We found that conditioned media with S100A9 enhanced the migration of THP-1 and U937 cells. The migrated cells were counted in four different fields, and the experiments were repeated in triplicate. $p$ values were obtained by t-test: ${ }^{\star \star} p<0.005,{ }^{\star \star *} p<0.001$. 


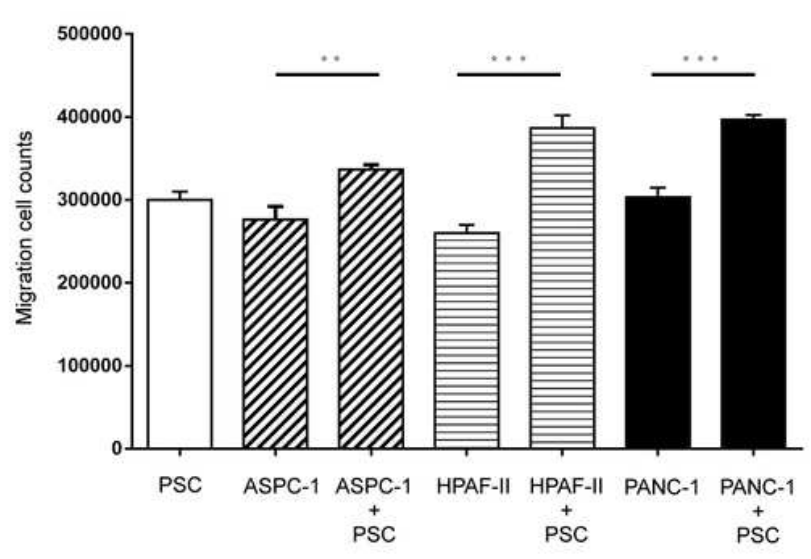

C

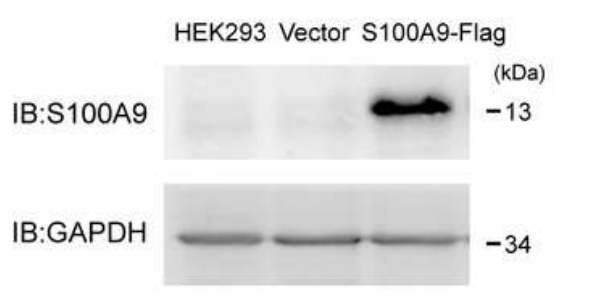

f

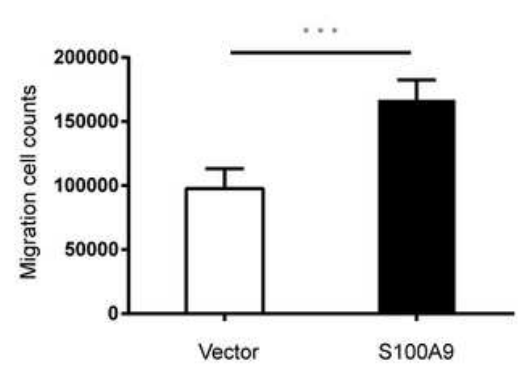

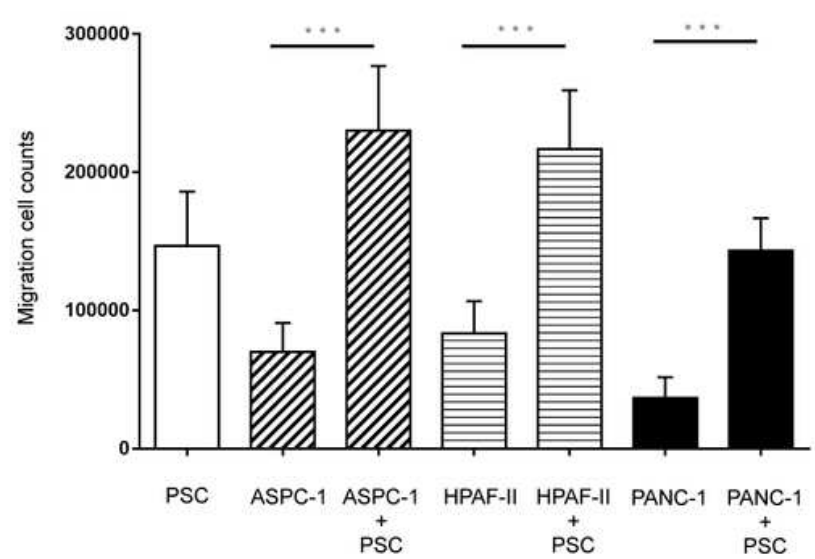

e
HEK293 Vector S100A9-Flag

IB:Flag (kDa)

$-13$

IB:Flag g

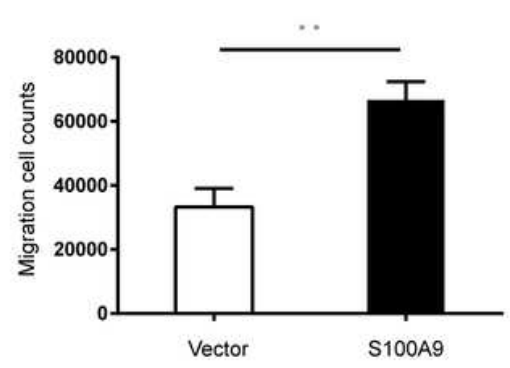

Figure 2

S100A9 in conditioned media from PDAC cells cocultured with PSCs enhanced the migration of monocytes. In transwell migration assays, THP-1 (a) or U937 (b) cells were cultured inside hanging inserts (8.0 $\mu \mathrm{m}$, Millipore) for 24 hours in conditioned media from AsPC-1, HPAF-II and PANC-1 cells cocultured with or without PSCs. The migrated cells were counted in four fields for each sample, and the experiments were performed in triplicate. The migration of THP-1 (a) or U937 (b) cells was enhanced in the conditioned media from pancreatic cancer cell lines cocultured with PSCs for 24 hours. We constructed a S100A9 plasmid with a Flag tag at the $C$ terminus in the pcDNA3.0 vector and transfected the S100A9-Flag vector into HEK293 cells. The expression of S100A9 in HEK293 cells was verified by immunoblot with an anti-S100A9 antibody (c) and an anti-Flag antibody (d). The empty vector served as a control. Flag-tagged S100A9 protein was detected in the culture medium by immunoblot after precipitation with trichloroacetic acid (e). In the transwell migration assays, we placed conditioned media 
from HEK293 cells transduced with the S100A9 expression vector or control in the culture plates and seeded monocyte cell lines, including THP-1 or U937 (2x105) cells, in the hanging inserts, followed by incubation for 24 hours. We calculated the numbers of migrated THP-1 (f) and U937 (g) cells. We found that conditioned media with S100A9 enhanced the migration of THP-1 and U937 cells. The migrated cells were counted in four different fields, and the experiments were repeated in triplicate. $p$ values were obtained by t-test: ${ }^{*} \mathrm{p}<0.005,{ }^{* *} \mathrm{p}<0.001$.

a

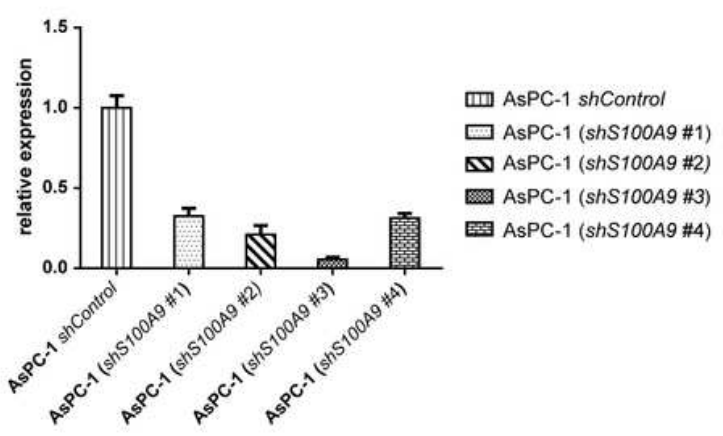

C

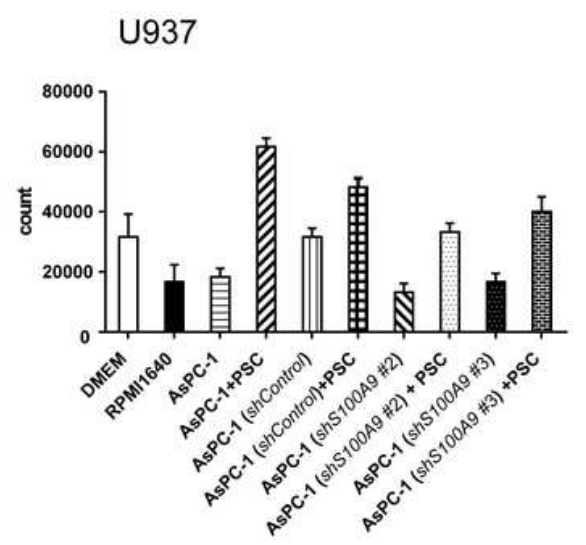

b

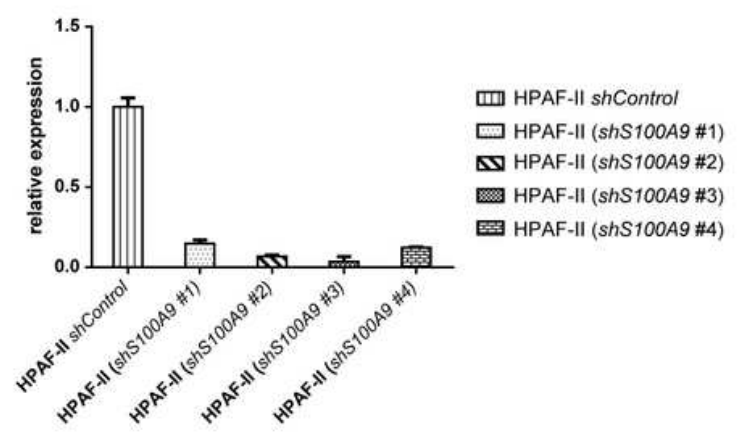

d
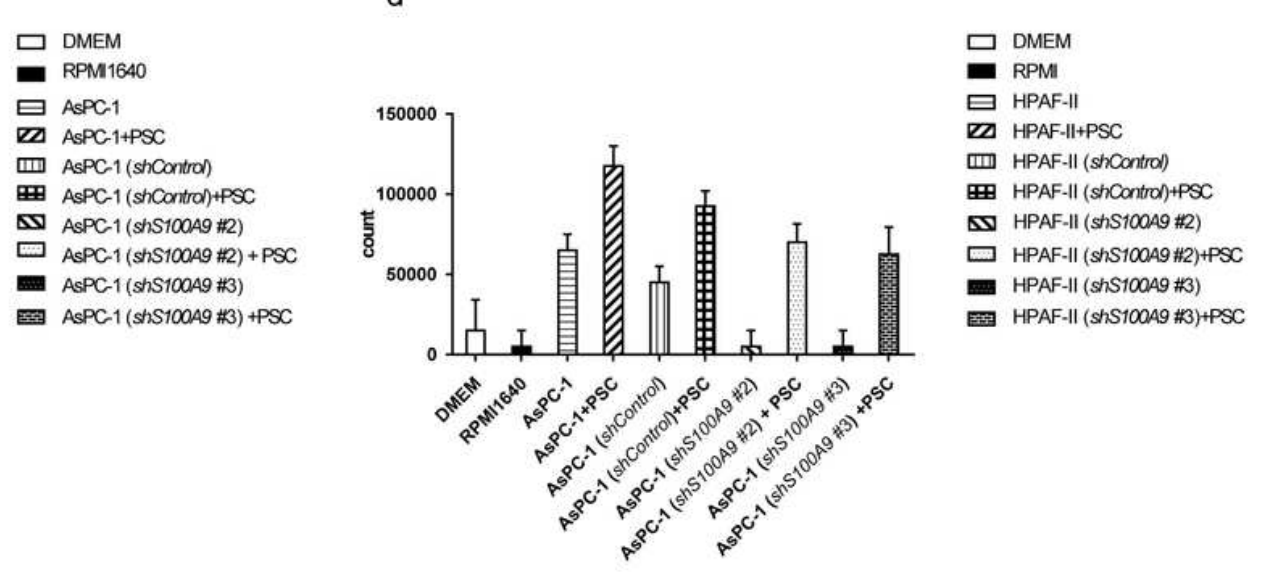

\section{Figure 3}

Knockdown of S100A9 in PDAC cells affected the migration of monocytes in transwell migration assays. The S100A9 mRNA levels in AsPC-1 (a) and HPAF-II (b) cells after knockdown of S100A9 with shRNA are shown. The mRNA level was determined by quantitative real-time PCR. We examined transwell migration of U-937 cells $(1 \times 105)$ cultured in conditioned medium from AsPC-1 (c) or HPAF-II (d) cells with either knocked down or normal S100A9 expression cocultured with or without PSCs. We found that conditioned medium from PDAC cells cocultured with PSCs enhanced the migration of U-937 cells. The conditioned medium from PSCs cocultured with S100A9-knockdown AsPC-1 (c) and HPAF-II (d) cells induced less attraction of U-937 cells than the conditioned medium from PSCs cocultured with control cells. DMEM: Dulbecco's modified Eagle's medium, RPMI 1640: Roswell Park Memorial Institute. 

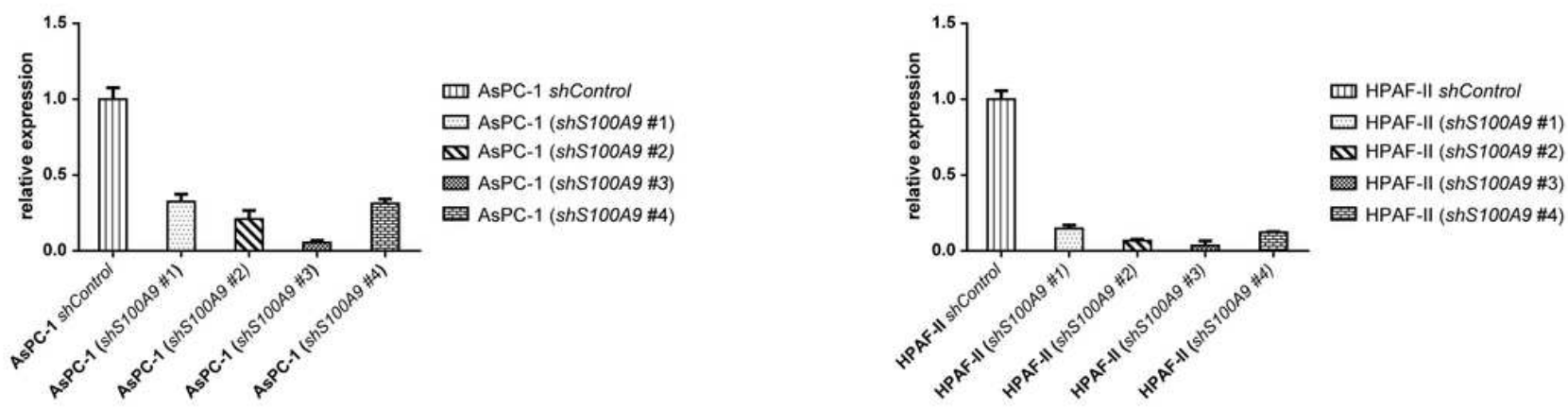

C

d
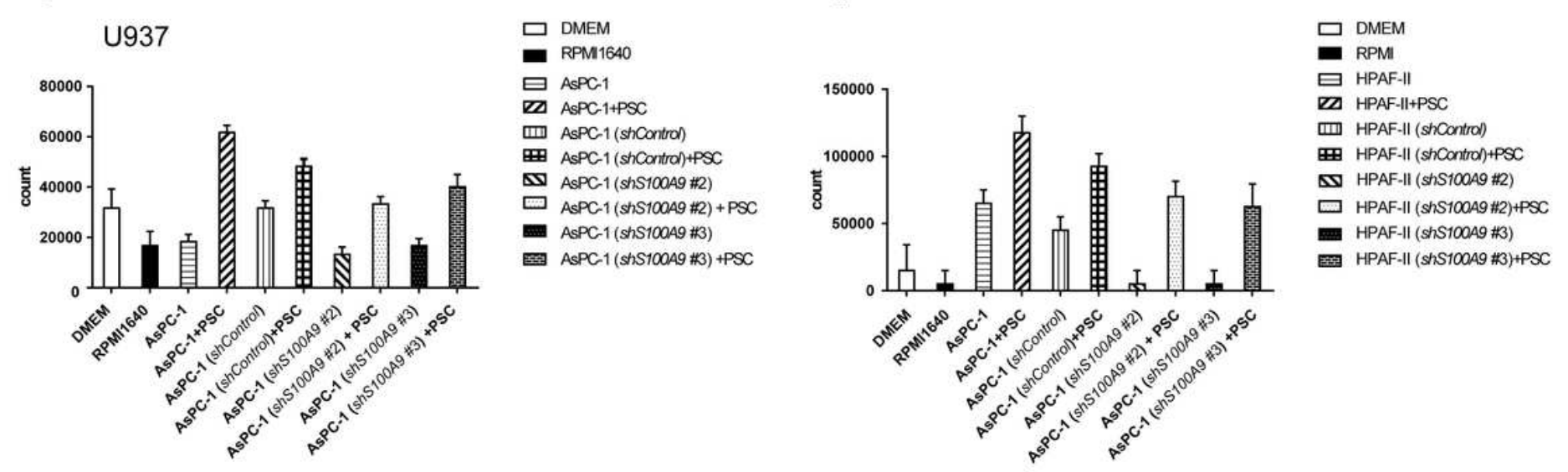

\section{Figure 3}

Knockdown of S100A9 in PDAC cells affected the migration of monocytes in transwell migration assays. The S100A9 mRNA levels in AsPC-1 (a) and HPAF-II (b) cells after knockdown of S100A9 with shRNA are shown. The mRNA level was determined by quantitative real-time PCR. We examined transwell migration of U-937 cells (1x105) cultured in conditioned medium from AsPC-1 (c) or HPAF-II (d) cells with either knocked down or normal S100A9 expression cocultured with or without PSCs. We found that conditioned medium from PDAC cells cocultured with PSCs enhanced the migration of U-937 cells. The conditioned medium from PSCs cocultured with S100A9-knockdown AsPC-1 (c) and HPAF-II (d) cells induced less attraction of U-937 cells than the conditioned medium from PSCs cocultured with control cells. DMEM: Dulbecco's modified Eagle's medium, RPMI 1640: Roswell Park Memorial Institute. 

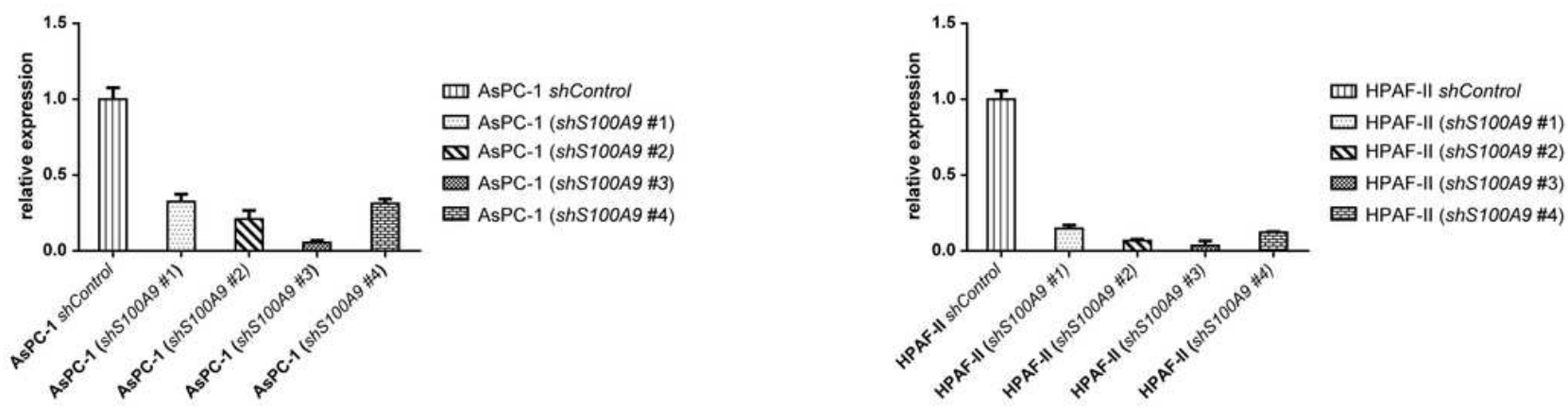

C

d
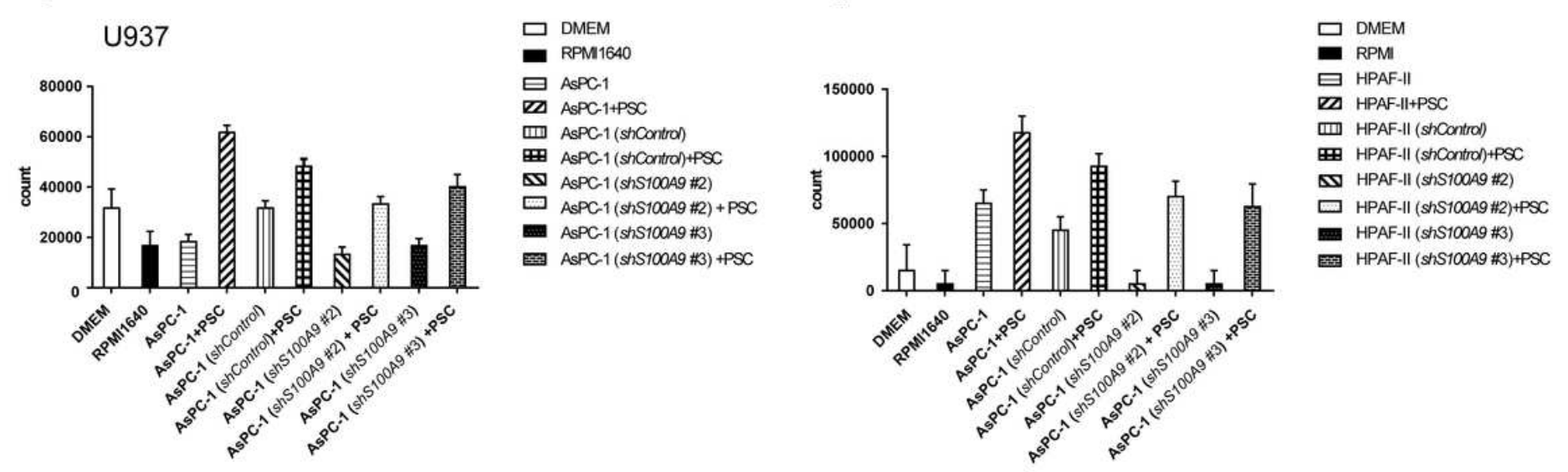

\section{Figure 3}

Knockdown of S100A9 in PDAC cells affected the migration of monocytes in transwell migration assays. The S100A9 mRNA levels in AsPC-1 (a) and HPAF-II (b) cells after knockdown of S100A9 with shRNA are shown. The mRNA level was determined by quantitative real-time PCR. We examined transwell migration of U-937 cells (1x105) cultured in conditioned medium from AsPC-1 (c) or HPAF-II (d) cells with either knocked down or normal S100A9 expression cocultured with or without PSCs. We found that conditioned medium from PDAC cells cocultured with PSCs enhanced the migration of U-937 cells. The conditioned medium from PSCs cocultured with S100A9-knockdown AsPC-1 (c) and HPAF-II (d) cells induced less attraction of U-937 cells than the conditioned medium from PSCs cocultured with control cells. DMEM: Dulbecco's modified Eagle's medium, RPMI 1640: Roswell Park Memorial Institute. 

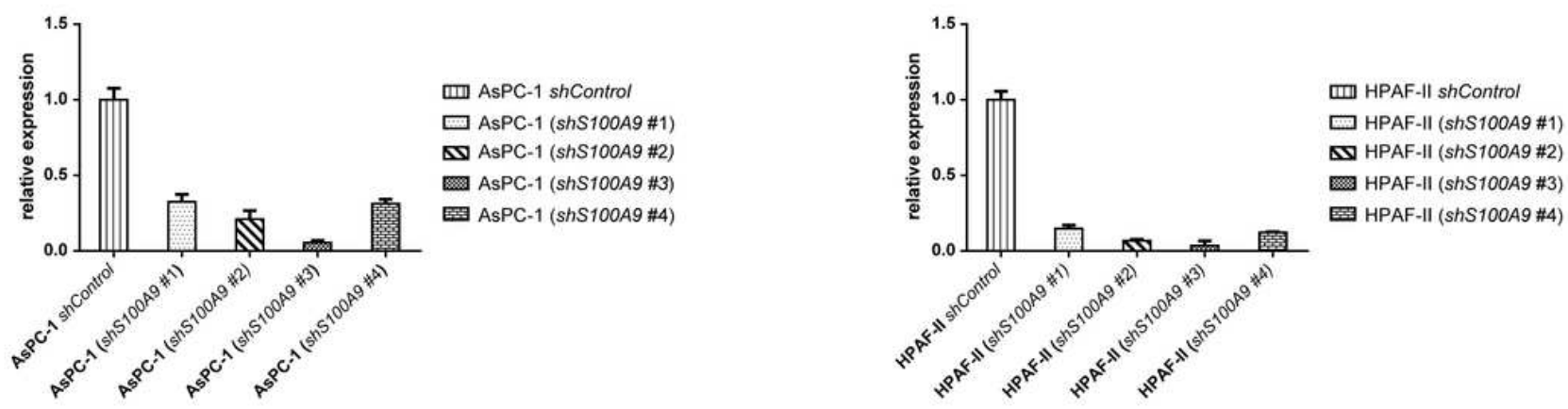

C

d
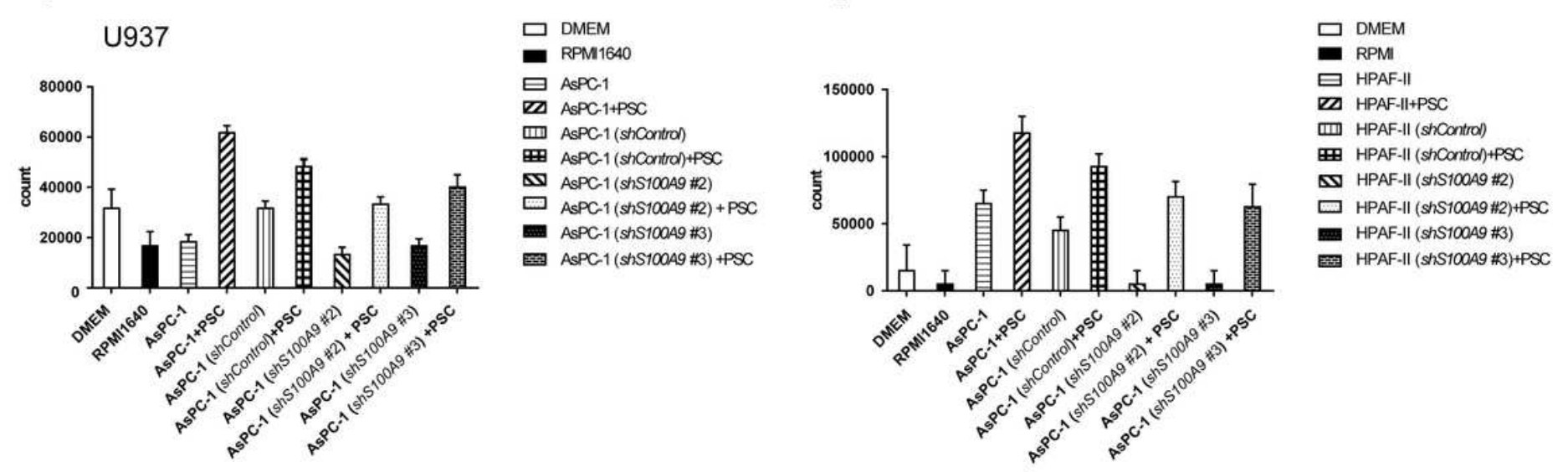

Figure 3

Knockdown of S100A9 in PDAC cells affected the migration of monocytes in transwell migration assays. The S100A9 mRNA levels in AsPC-1 (a) and HPAF-II (b) cells after knockdown of S100A9 with shRNA are shown. The mRNA level was determined by quantitative real-time PCR. We examined transwell migration of U-937 cells (1x105) cultured in conditioned medium from AsPC-1 (c) or HPAF-II (d) cells with either knocked down or normal S100A9 expression cocultured with or without PSCs. We found that conditioned medium from PDAC cells cocultured with PSCs enhanced the migration of U-937 cells. The conditioned medium from PSCs cocultured with S100A9-knockdown AsPC-1 (c) and HPAF-II (d) cells induced less attraction of U-937 cells than the conditioned medium from PSCs cocultured with control cells. DMEM: Dulbecco's modified Eagle's medium, RPMI 1640: Roswell Park Memorial Institute. 
a

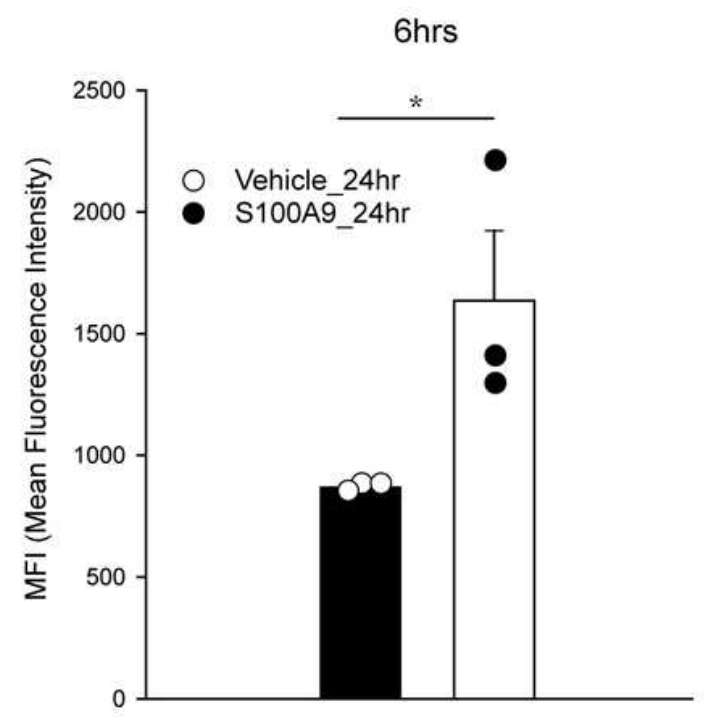

b

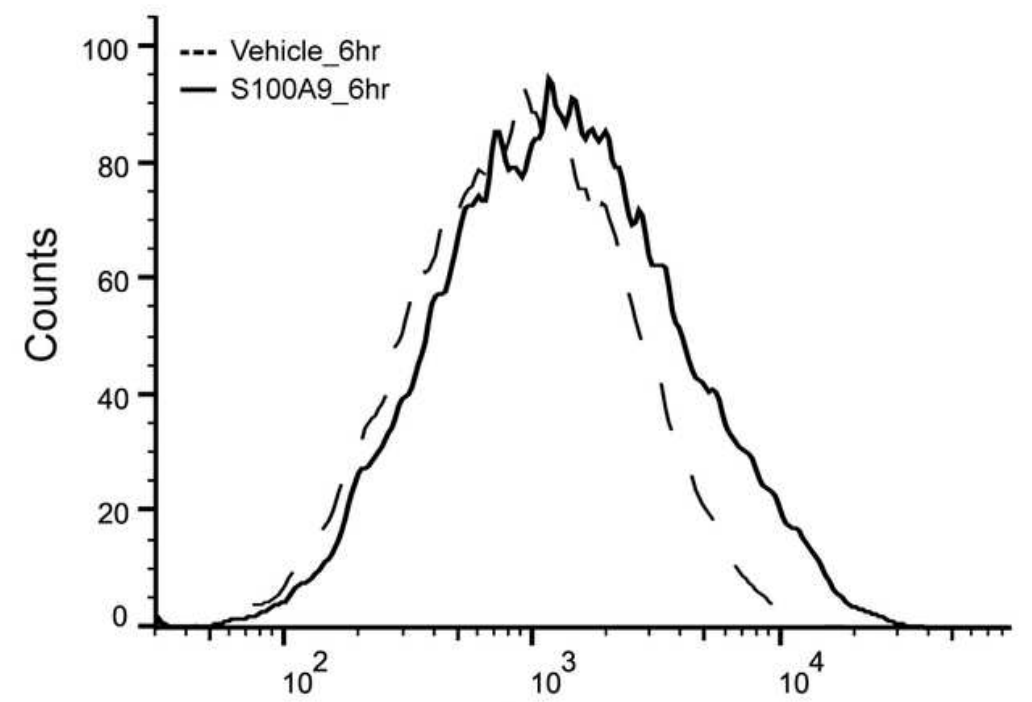

PD-L1
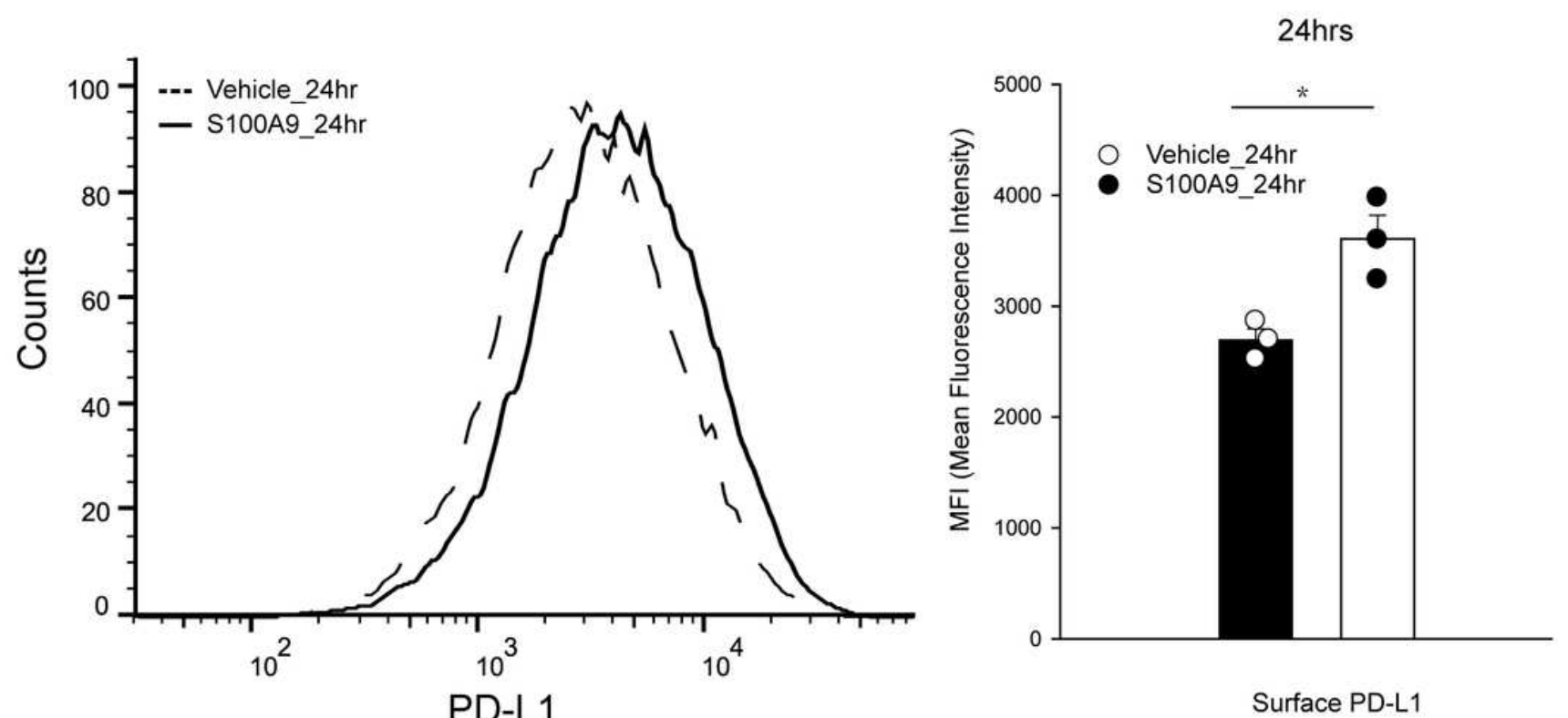

Surface PD-L1

\section{Figure 4}

The surface expression of PD-L1 in monocytes was increased after stimulation with S100A9. We treated U937 cells with IFN-y along with recombinant S100A9 and detected the surface expression of PD-L1 with flow cytometry. We found that treatment of IFN-Y-primed U937 cells with S100A9 protein for 6 (a) and 24 (b) hours enhanced the surface expression of PD-L1. We performed the experiments in triplicate. $p$ values were determined by t-test: ${ }^{*} \mathrm{p}<0.005$. 
a

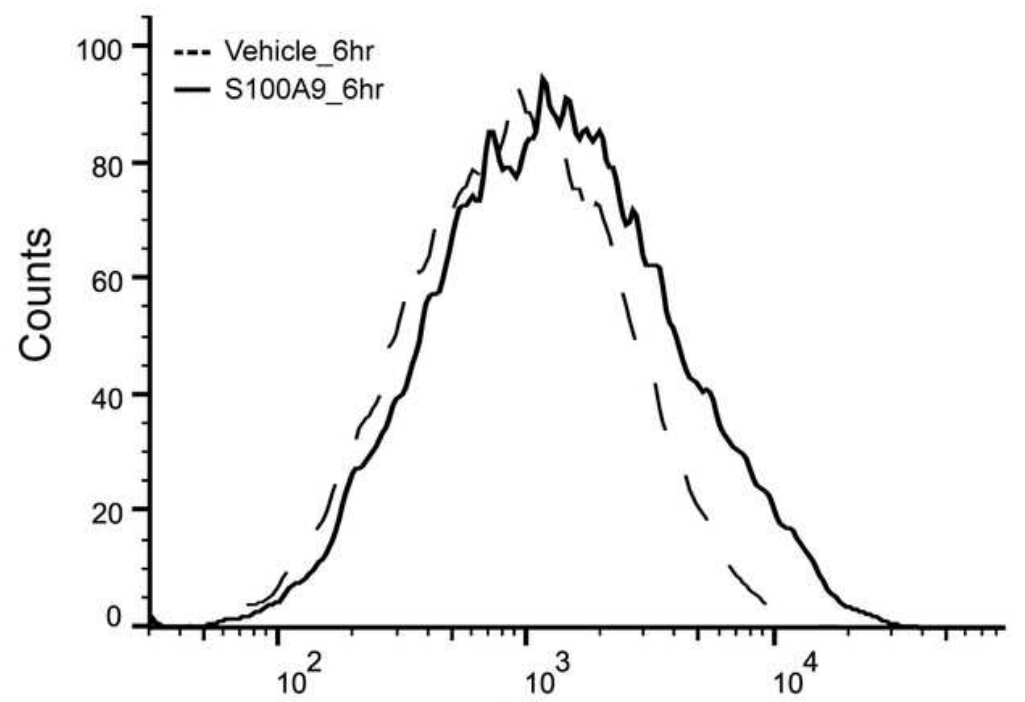

b

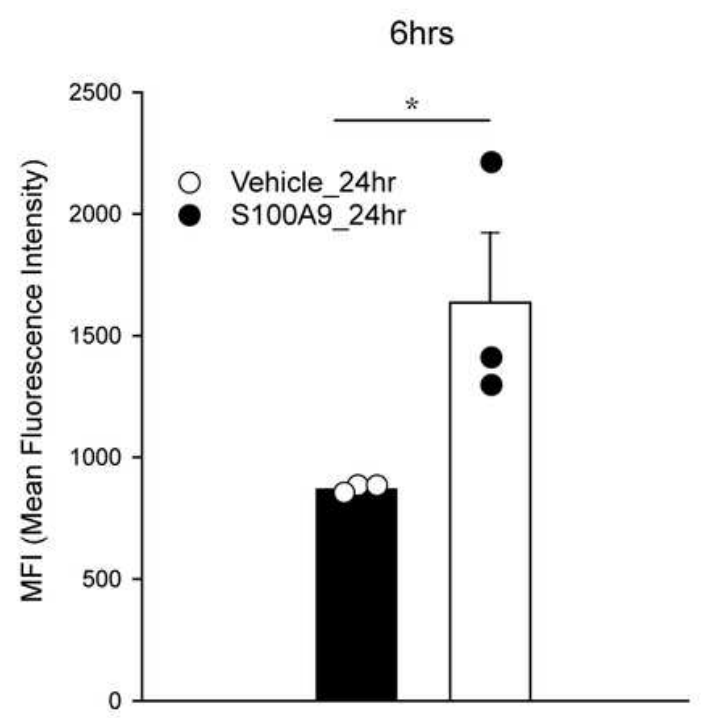

Surface PD-L1

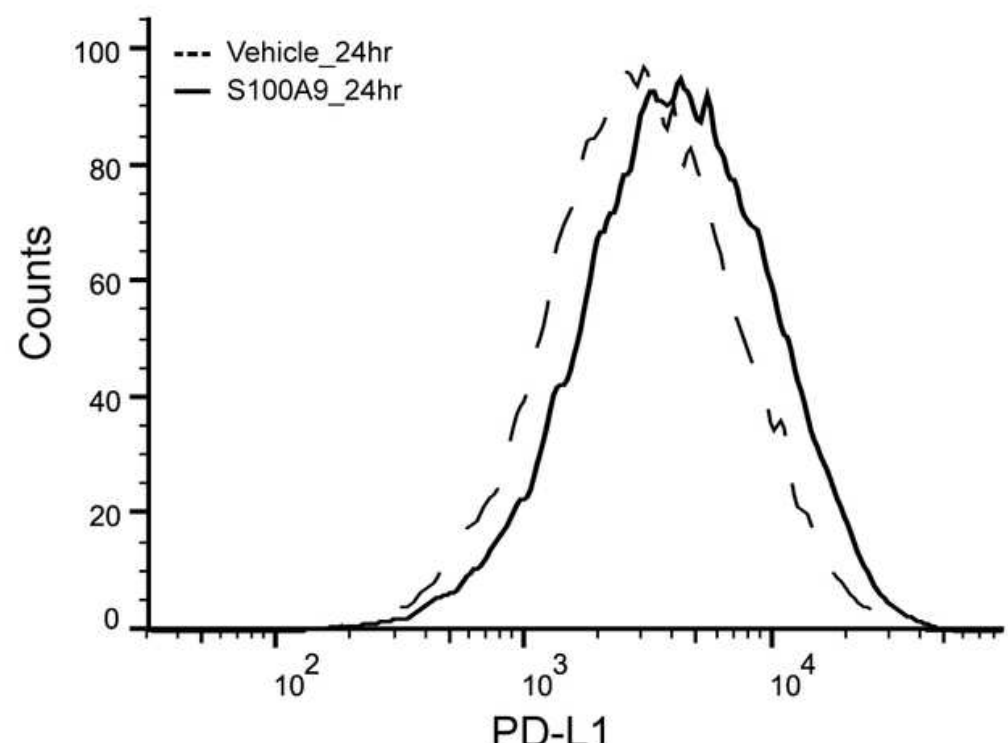

\section{Figure 4}

The surface expression of PD-L1 in monocytes was increased after stimulation with S100A9. We treated U937 cells with IFN-y along with recombinant S100A9 and detected the surface expression of PD-L1 with flow cytometry. We found that treatment of IFN-Y-primed U937 cells with S100A9 protein for 6 (a) and 24 (b) hours enhanced the surface expression of PD-L1. We performed the experiments in triplicate. $p$ values were determined by t-test: ${ }^{*} \mathrm{p}<0.005$. 
a

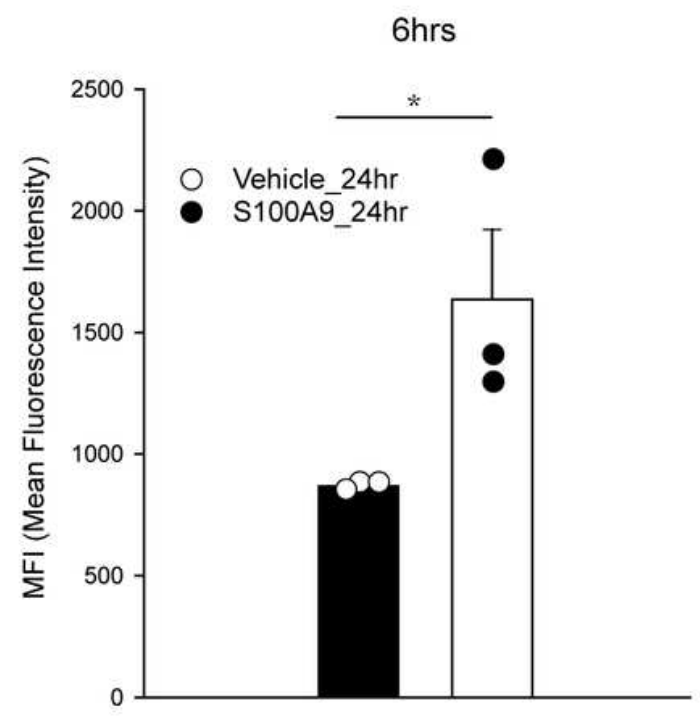

b
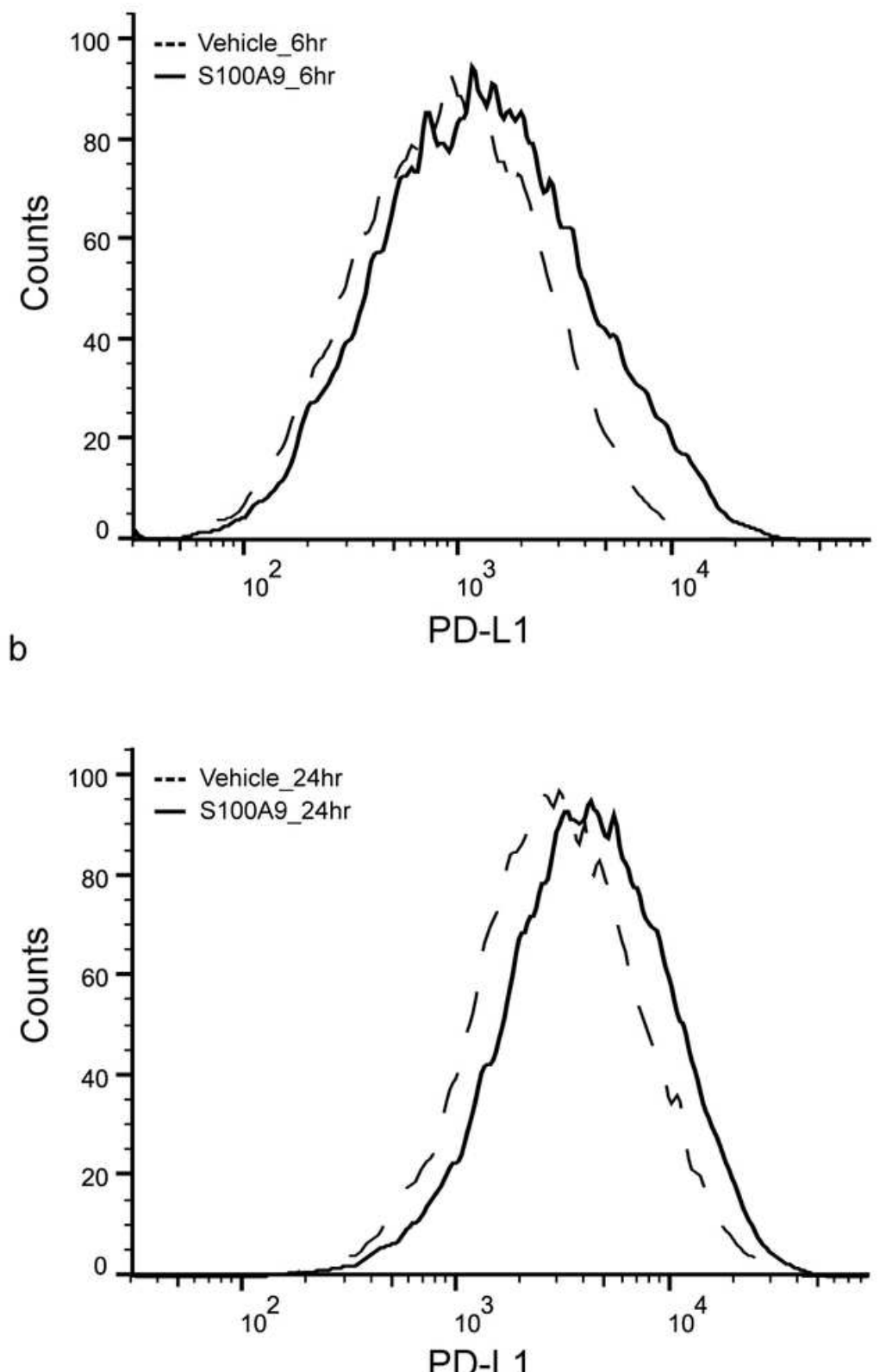

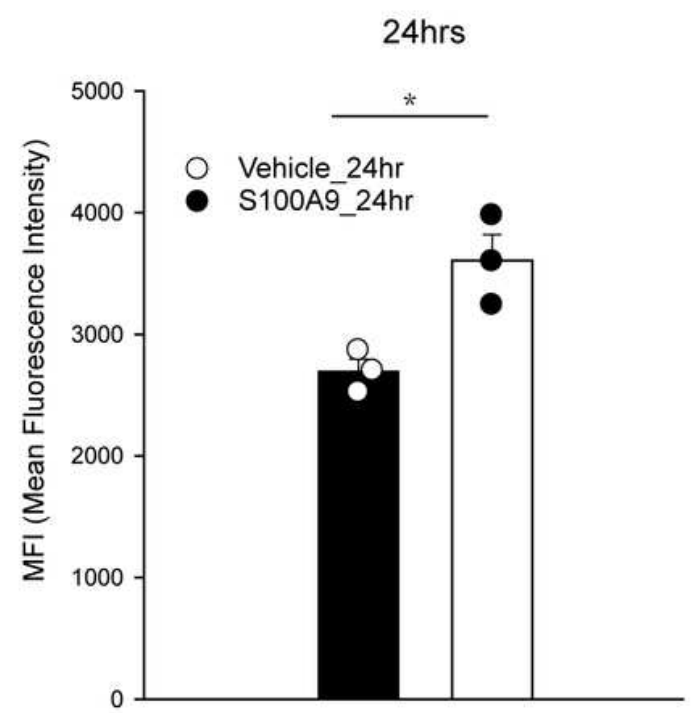

Surface PD-L1

\section{Figure 4}

The surface expression of PD-L1 in monocytes was increased after stimulation with S100A9. We treated U937 cells with IFN-y along with recombinant S100A9 and detected the surface expression of PD-L1 with flow cytometry. We found that treatment of IFN-Y-primed U937 cells with S100A9 protein for 6 (a) and 24 (b) hours enhanced the surface expression of PD-L1. We performed the experiments in triplicate. $p$ values were determined by t-test: ${ }^{*} \mathrm{p}<0.005$. 
a

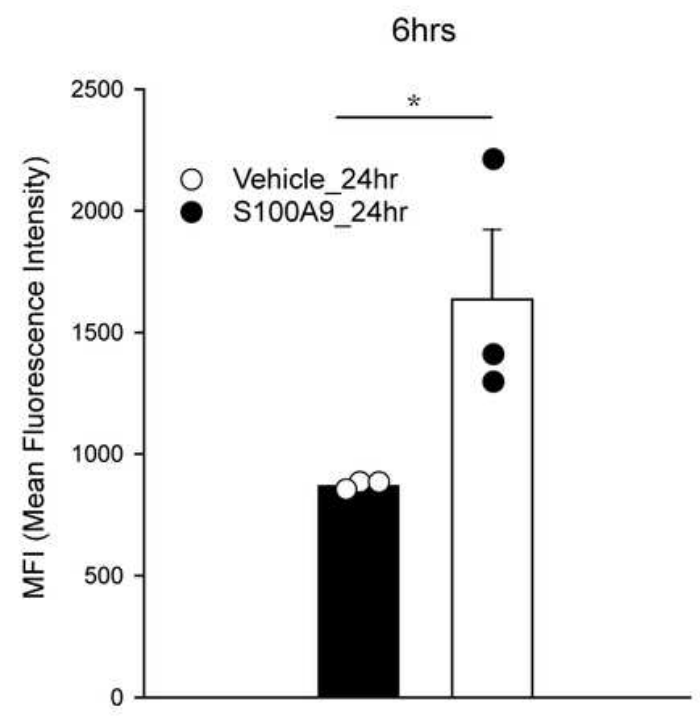

b
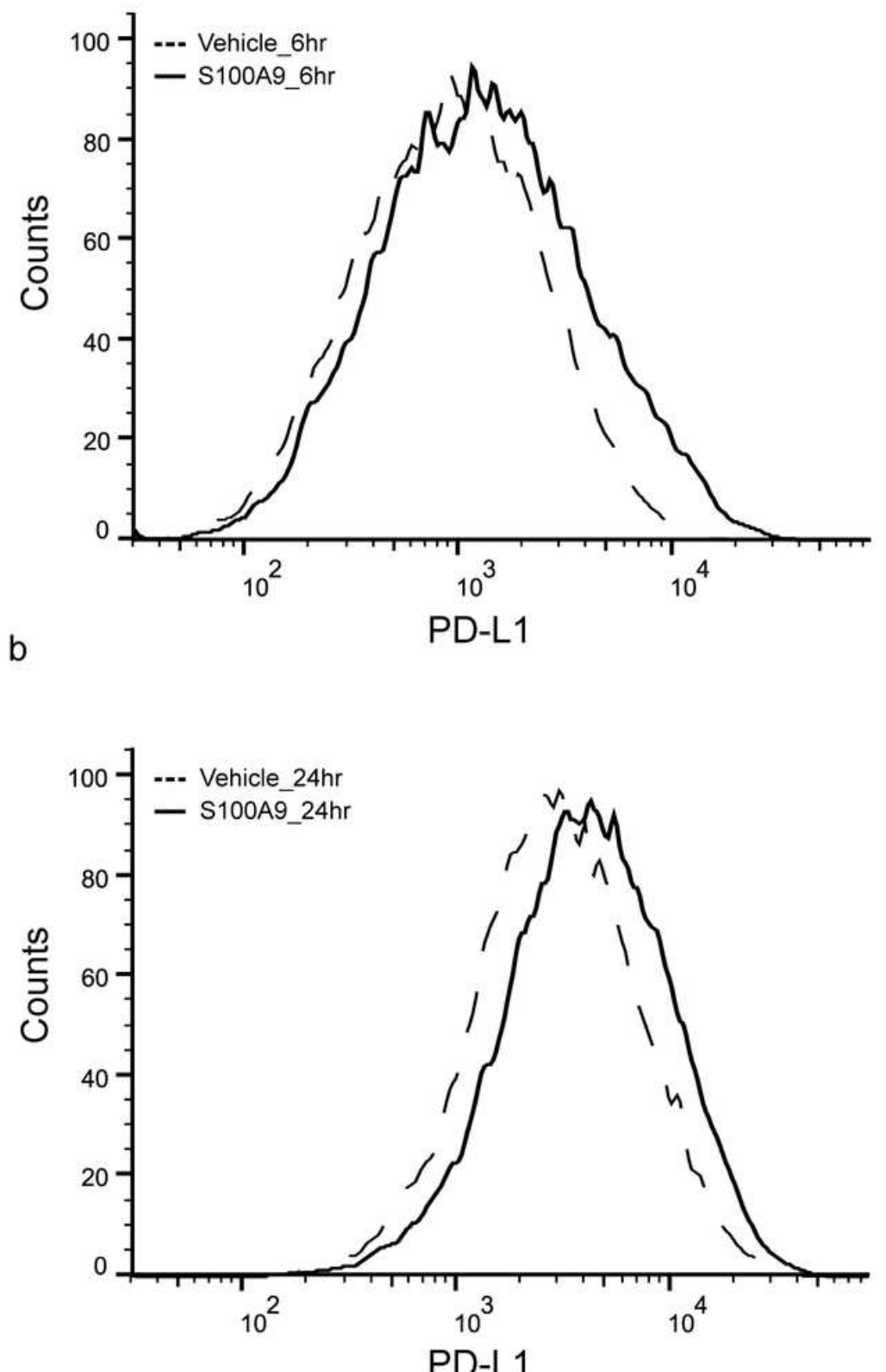

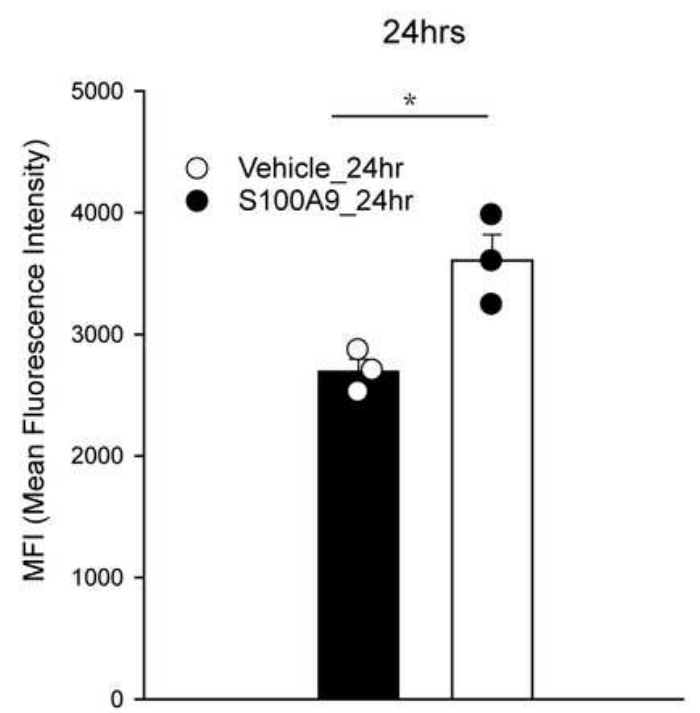

Surface PD-L1

\section{Figure 4}

The surface expression of PD-L1 in monocytes was increased after stimulation with S100A9. We treated U937 cells with IFN-y along with recombinant S100A9 and detected the surface expression of PD-L1 with flow cytometry. We found that treatment of IFN-Y-primed U937 cells with S100A9 protein for 6 (a) and 24 (b) hours enhanced the surface expression of PD-L1. We performed the experiments in triplicate. $p$ values were determined by t-test: ${ }^{*} \mathrm{p}<0.005$. 


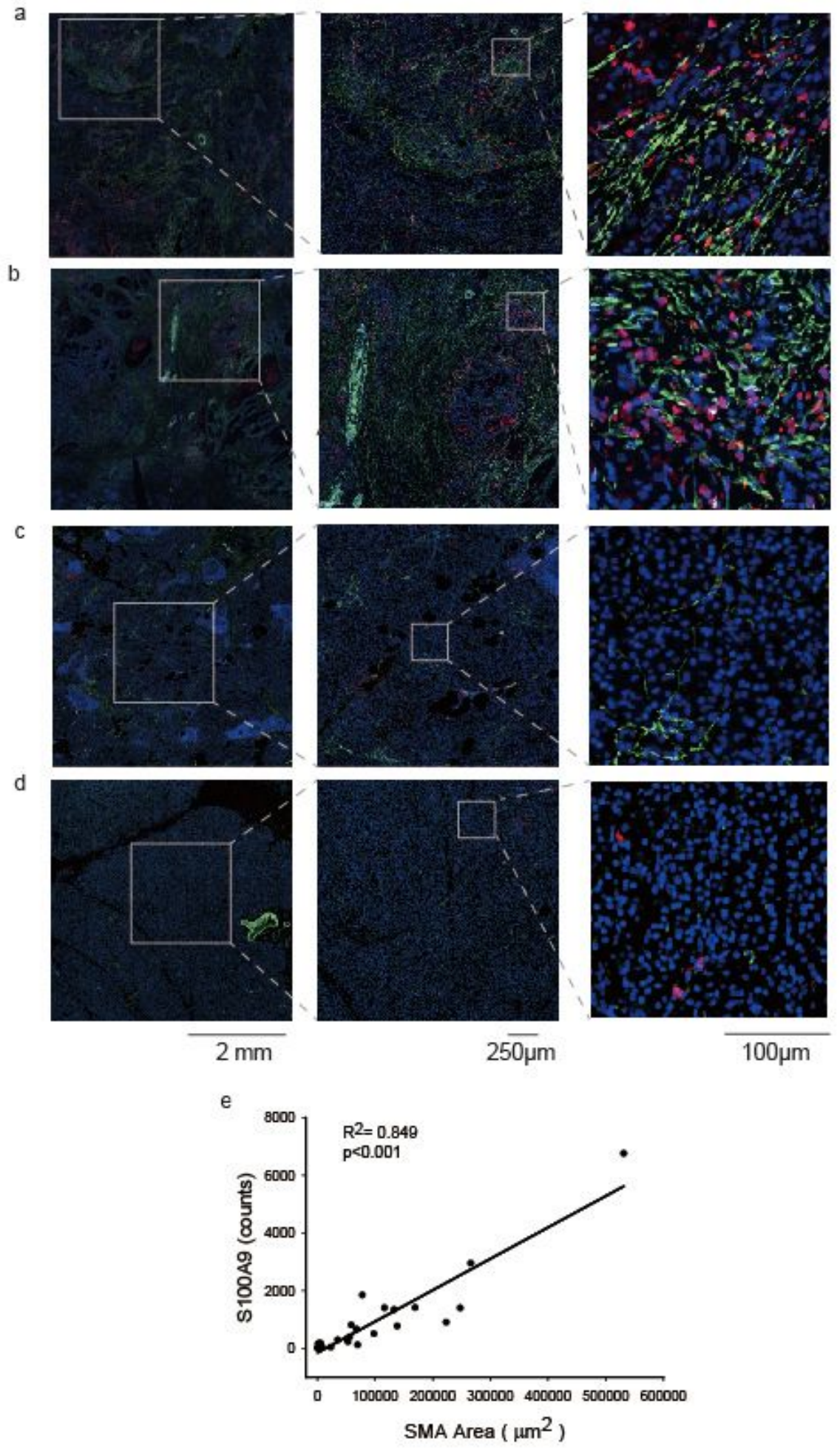

\section{Figure 5}

Immunofluorescence analysis of S100A9 and stellate cells in human PDAC tissue. Using immunofluorescence, S100A9-expressing cells (red) were found to be located near cells expressing aSMA (green), a marker for activated PSCs, in specimens from PDAC patients with metastasis ( $a$ and $b$ ). Less PSC infiltration correlated with fewer S100A9-expressing cells in the specimens from patients with PDAC without metastasis (c and d). We used Hoechst 33342 for nuclear counterstaining (blue). (e) The 
correlation between the number of cells expressing of S100A9 and the number of cells expressing a-SMA in patients with PDAC was significant in the regression model $(R 2=0.849, p<0.001)$. Each spot represents staining of a specimen from one patient $(\mathrm{N}=22)$.

a

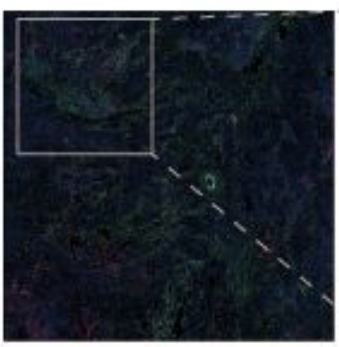

b

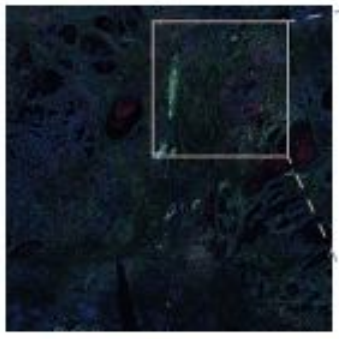

c

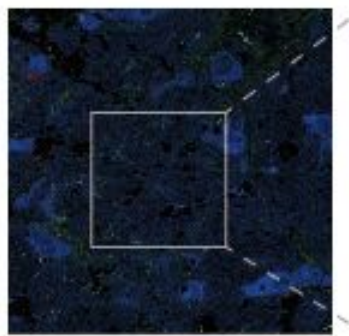

d

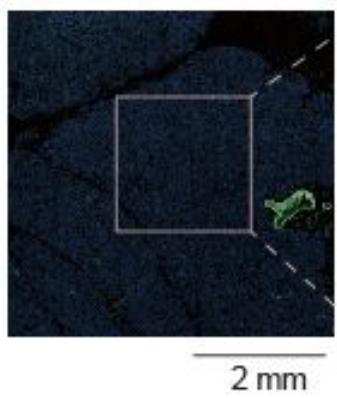

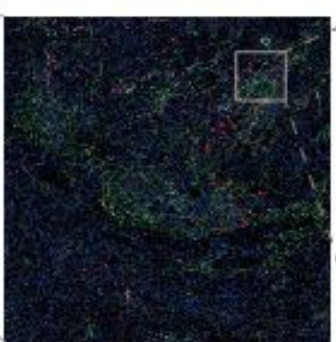
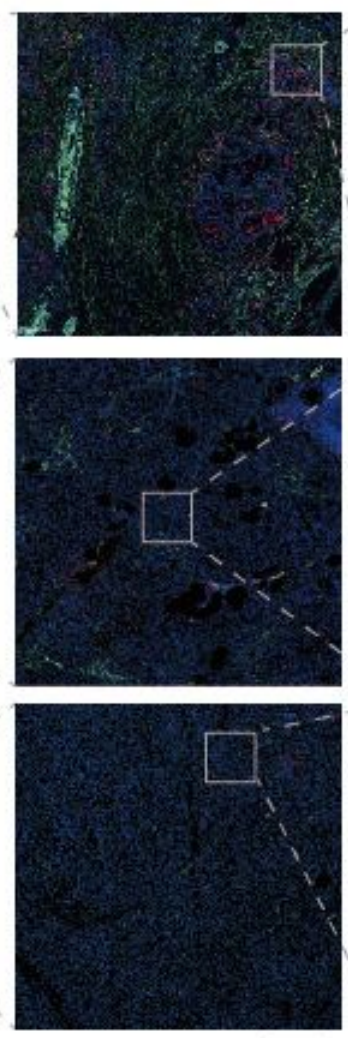

$25 \overline{0 \mu} \mathrm{m}$

e
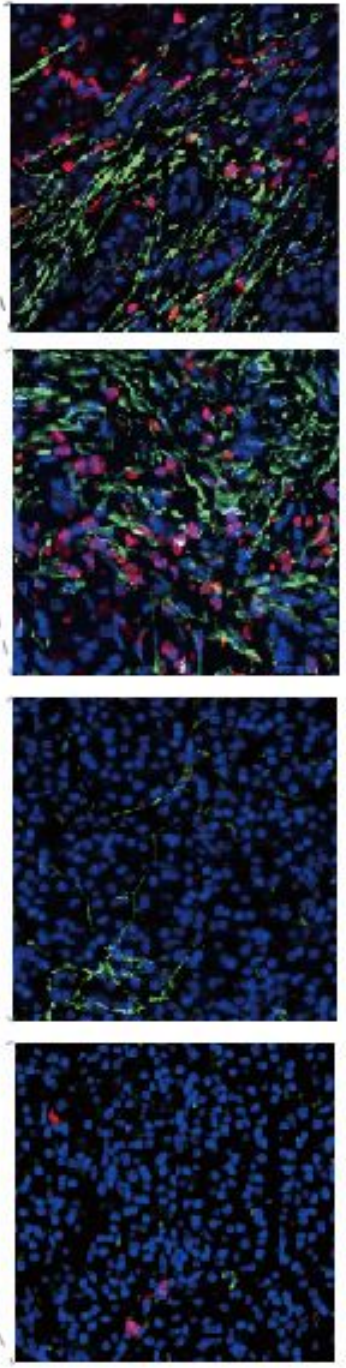

$100 \mu \mathrm{m}$

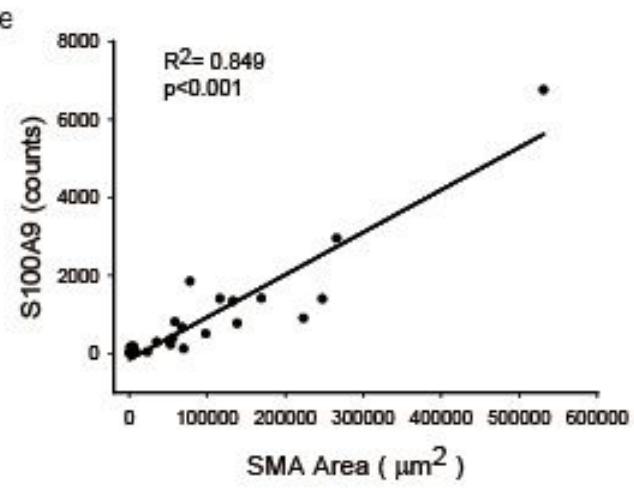

Figure 5

Immunofluorescence analysis of S100A9 and stellate cells in human PDAC tissue. Using immunofluorescence, S100A9-expressing cells (red) were found to be located near cells expressing a- 
SMA (green), a marker for activated PSCs, in specimens from PDAC patients with metastasis ( $a$ and $b$ ). Less PSC infiltration correlated with fewer S100A9-expressing cells in the specimens from patients with PDAC without metastasis (c and d). We used Hoechst 33342 for nuclear counterstaining (blue). (e) The correlation between the number of cells expressing of S100A9 and the number of cells expressing a-SMA in patients with PDAC was significant in the regression model $(R 2=0.849, p<0.001)$. Each spot represents staining of a specimen from one patient $(\mathrm{N}=22)$.

a

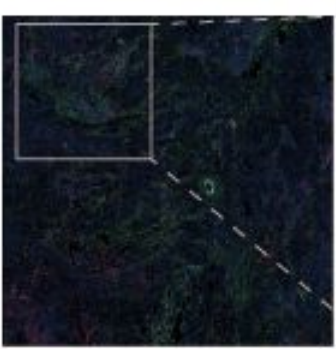

b

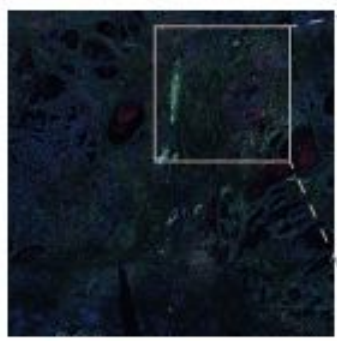

c

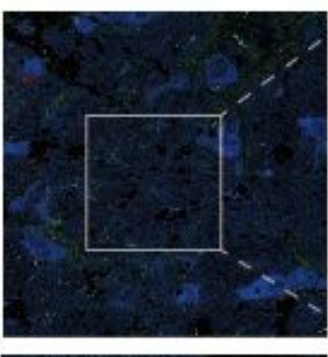

d

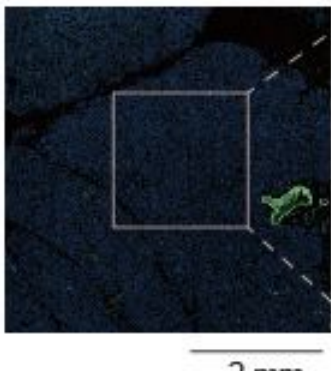

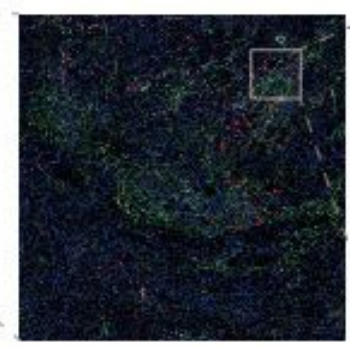
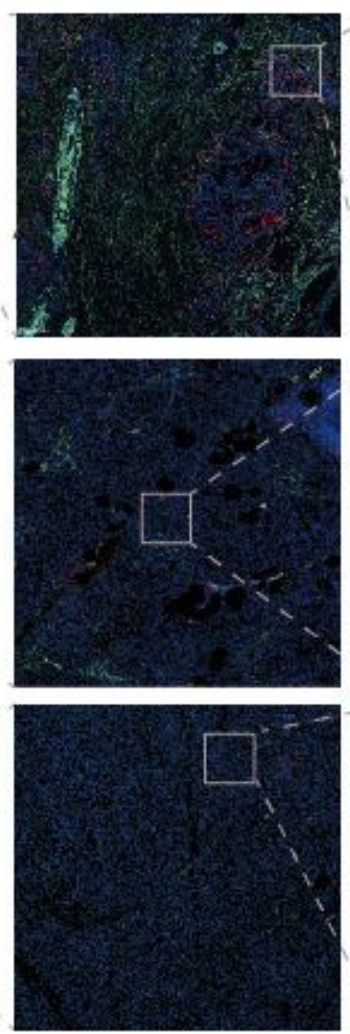

$25 \overline{0 \mu} \mathrm{m}$

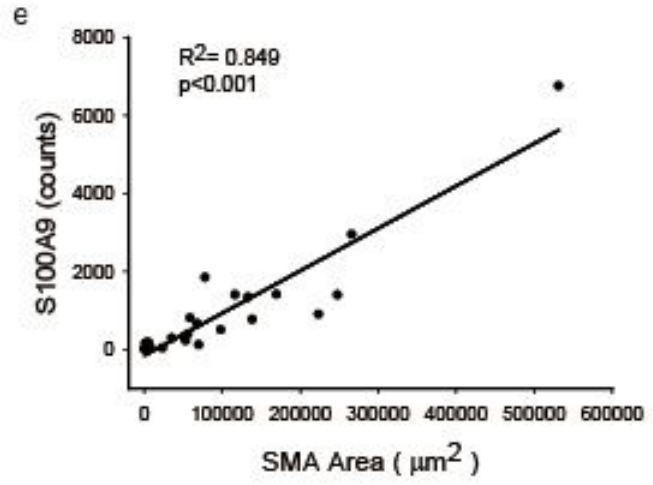

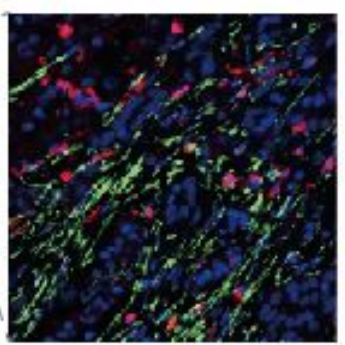
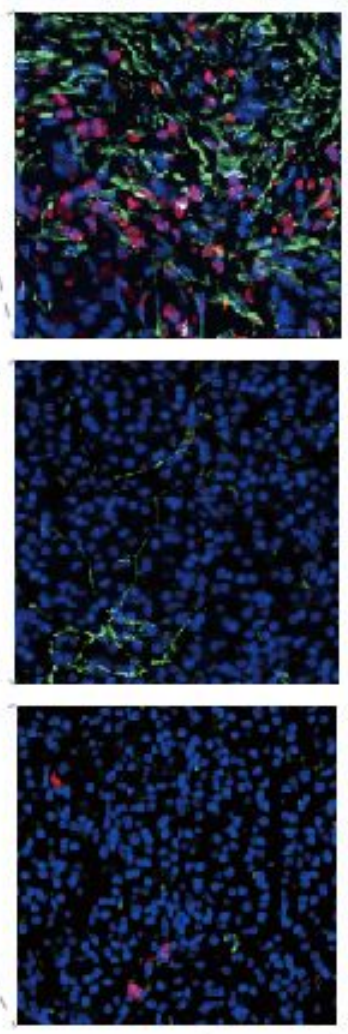

$100 \mu \mathrm{m}$

Figure 5 
Immunofluorescence analysis of S100A9 and stellate cells in human PDAC tissue. Using immunofluorescence, S100A9-expressing cells (red) were found to be located near cells expressing aSMA (green), a marker for activated PSCs, in specimens from PDAC patients with metastasis (a and $b$ ). Less PSC infiltration correlated with fewer S100A9-expressing cells in the specimens from patients with PDAC without metastasis (c and d). We used Hoechst 33342 for nuclear counterstaining (blue). (e) The correlation between the number of cells expressing of S100A9 and the number of cells expressing a-SMA in patients with PDAC was significant in the regression model $(R 2=0.849, p<0.001)$. Each spot represents staining of a specimen from one patient $(\mathrm{N}=22)$. 


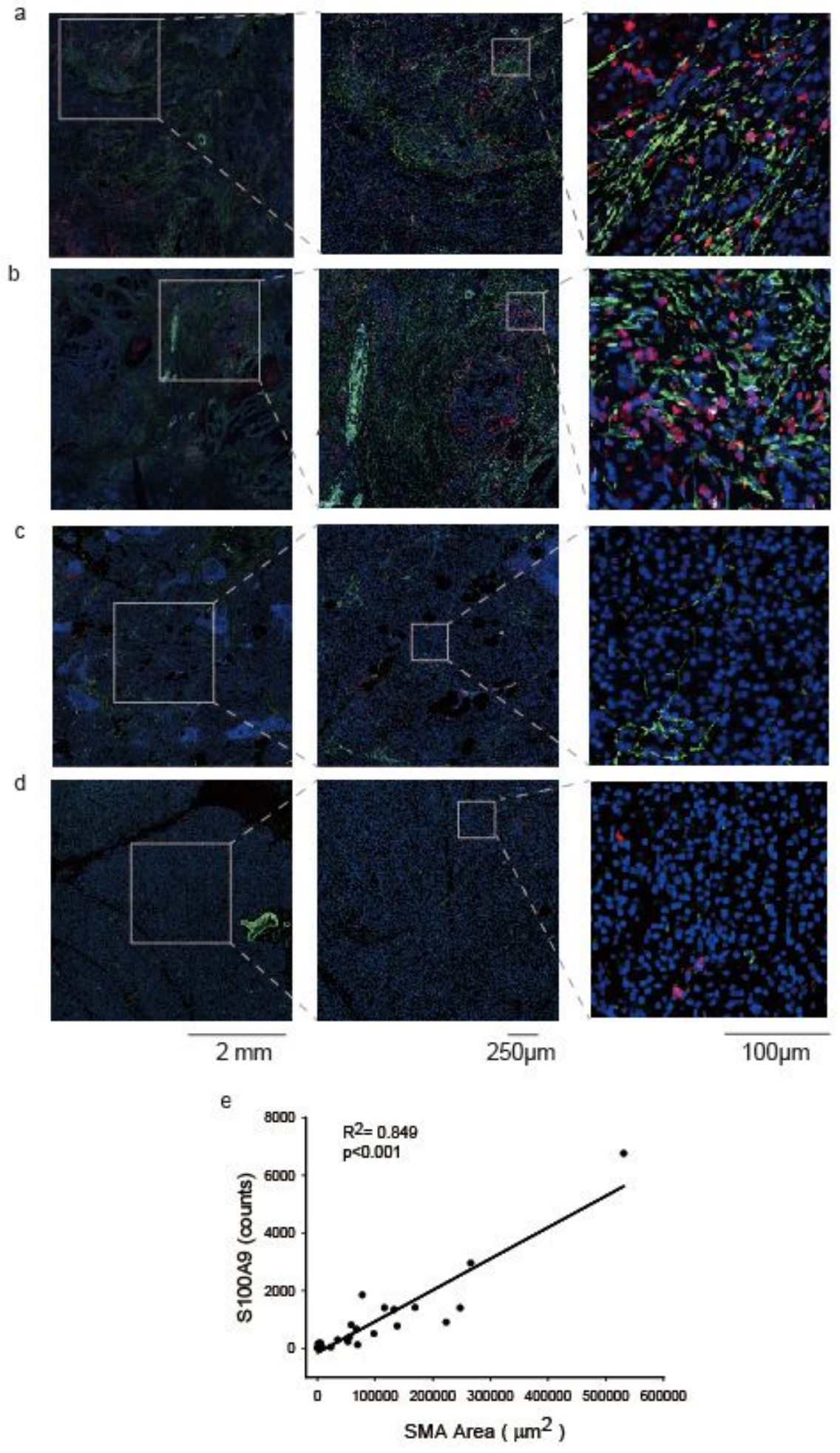

\section{Figure 5}

Immunofluorescence analysis of S100A9 and stellate cells in human PDAC tissue. Using immunofluorescence, S100A9-expressing cells (red) were found to be located near cells expressing aSMA (green), a marker for activated PSCs, in specimens from PDAC patients with metastasis ( $a$ and $b$ ). Less PSC infiltration correlated with fewer S100A9-expressing cells in the specimens from patients with PDAC without metastasis (c and d). We used Hoechst 33342 for nuclear counterstaining (blue). (e) The 
correlation between the number of cells expressing of S100A9 and the number of cells expressing a-SMA in patients with PDAC was significant in the regression model $(R 2=0.849, p<0.001)$. Each spot represents staining of a specimen from one patient $(\mathrm{N}=22)$.

a

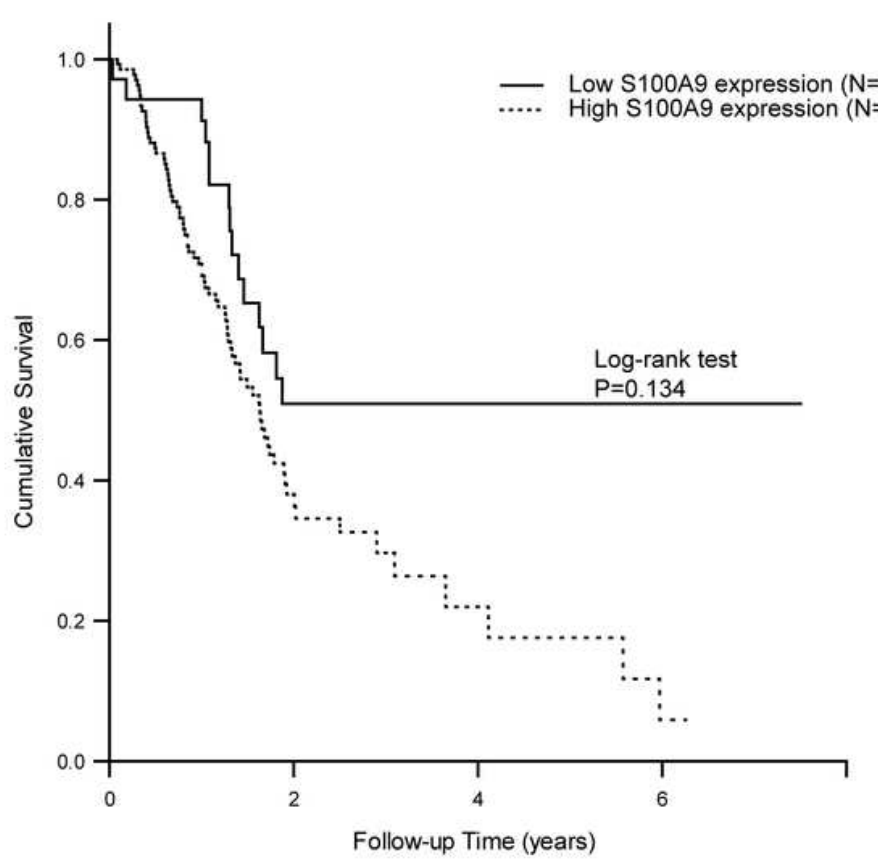

b

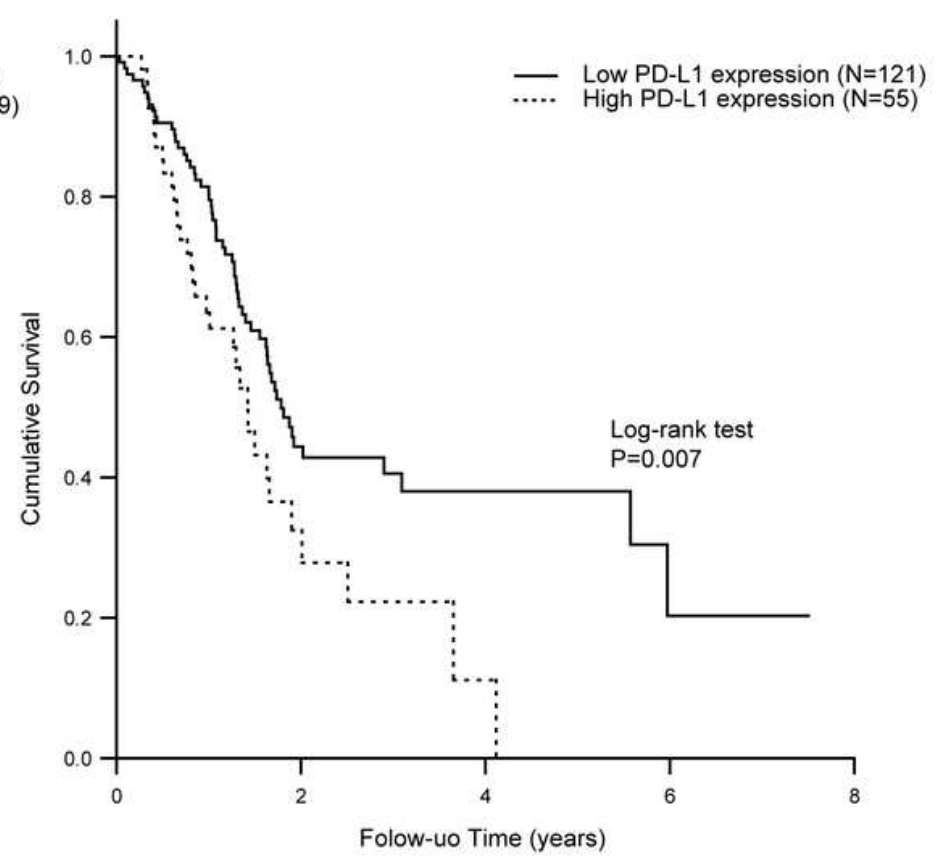

\section{Figure 6}

Kaplan-Meier survival curves generated based on S100A9 (a) and PD-L1 (b) expression. We obtained survival and immunohistochemistry staining data from 176 patients with PDAC from The Human Protein Atlas (https://www.proteinatlas.org/). Patients were divided into high and low expression groups based on the default setting on the website. The survival of each group was examined by Kaplan-Meier survival estimators, and the survival outcomes of the two groups were compared by log-rank tests. The patients with lower expression of S100A9 (a, p=0.013, log-rank test) and PD-L1 (b, $p=0.007$, log-rank test) in their PDAC samples had better survival than those with high expression. 

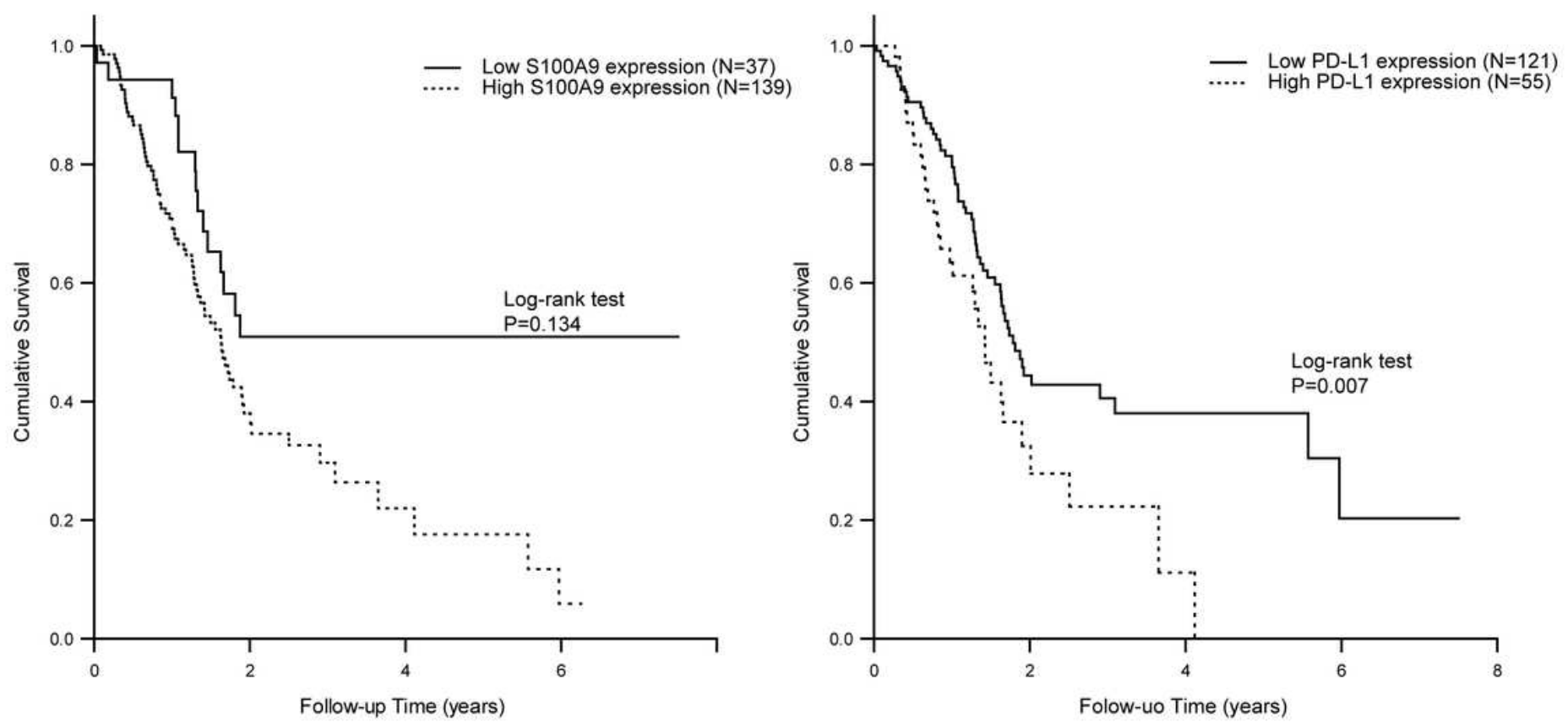

\section{Figure 6}

Kaplan-Meier survival curves generated based on S100A9 (a) and PD-L1 (b) expression. We obtained survival and immunohistochemistry staining data from 176 patients with PDAC from The Human Protein Atlas (https://www.proteinatlas.org/). Patients were divided into high and low expression groups based on the default setting on the website. The survival of each group was examined by Kaplan-Meier survival estimators, and the survival outcomes of the two groups were compared by log-rank tests. The patients with lower expression of S100A9 ( $a, p=0.013$, log-rank test) and PD-L1 (b, $p=0.007$, log-rank test) in their PDAC samples had better survival than those with high expression. 
a

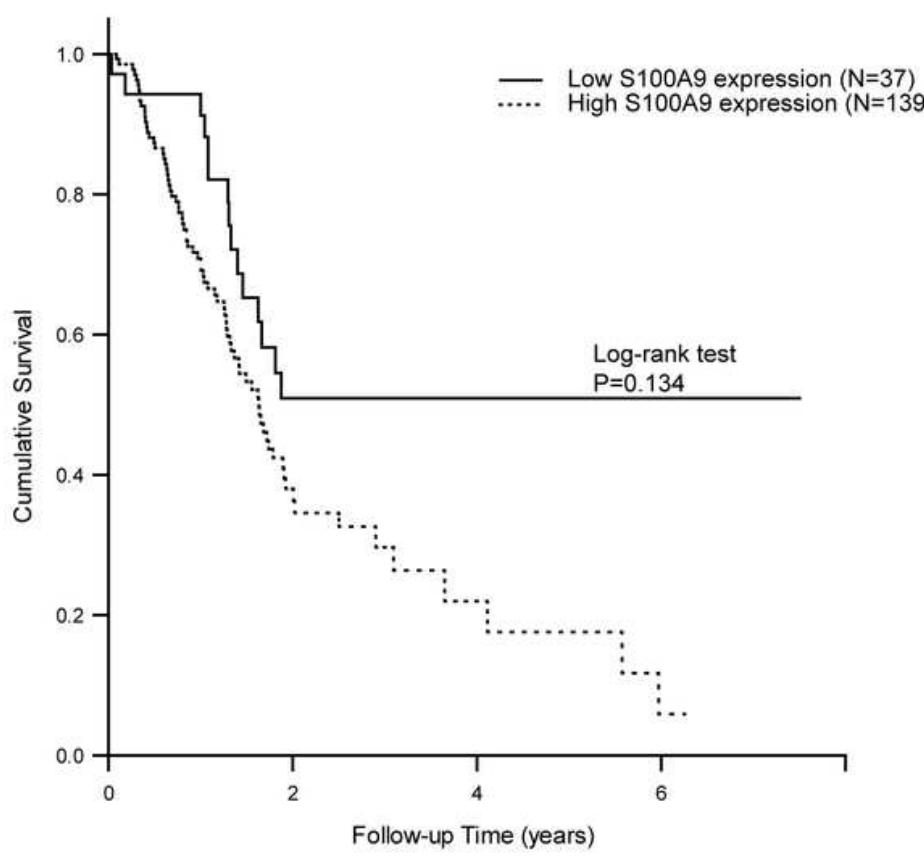

b

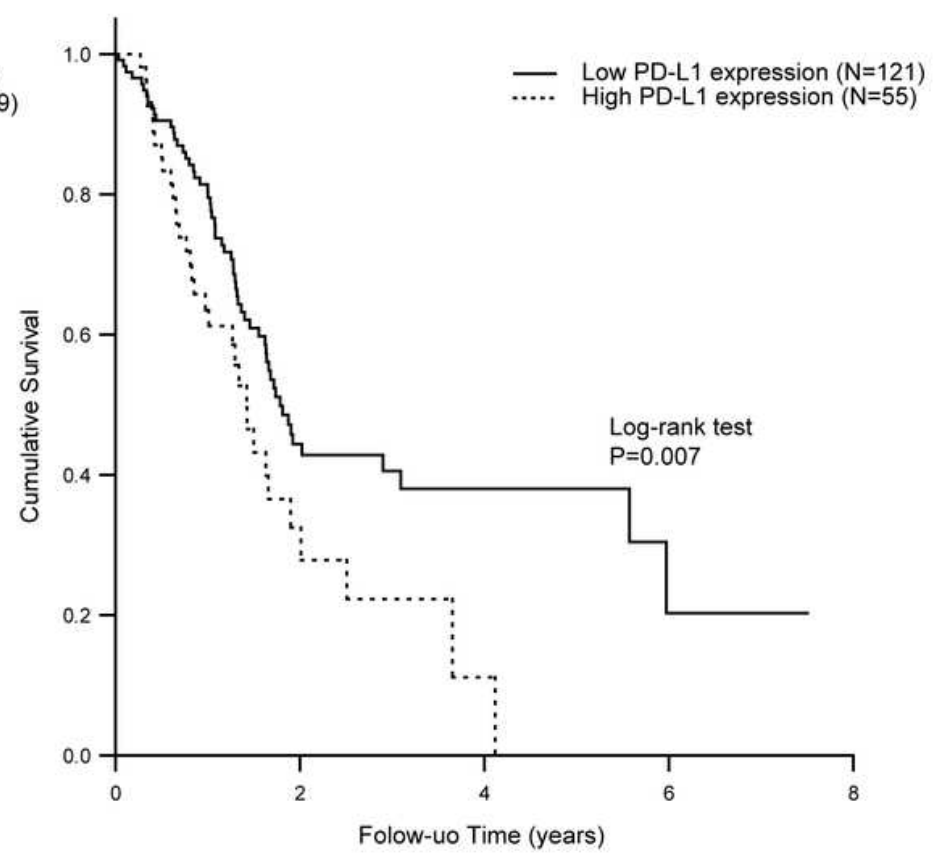

\section{Figure 6}

Kaplan-Meier survival curves generated based on S100A9 (a) and PD-L1 (b) expression. We obtained survival and immunohistochemistry staining data from 176 patients with PDAC from The Human Protein Atlas (https://www.proteinatlas.org/). Patients were divided into high and low expression groups based on the default setting on the website. The survival of each group was examined by Kaplan-Meier survival estimators, and the survival outcomes of the two groups were compared by log-rank tests. The patients with lower expression of S100A9 (a, p=0.013, log-rank test) and PD-L1 (b, $p=0.007$, log-rank test) in their PDAC samples had better survival than those with high expression. 

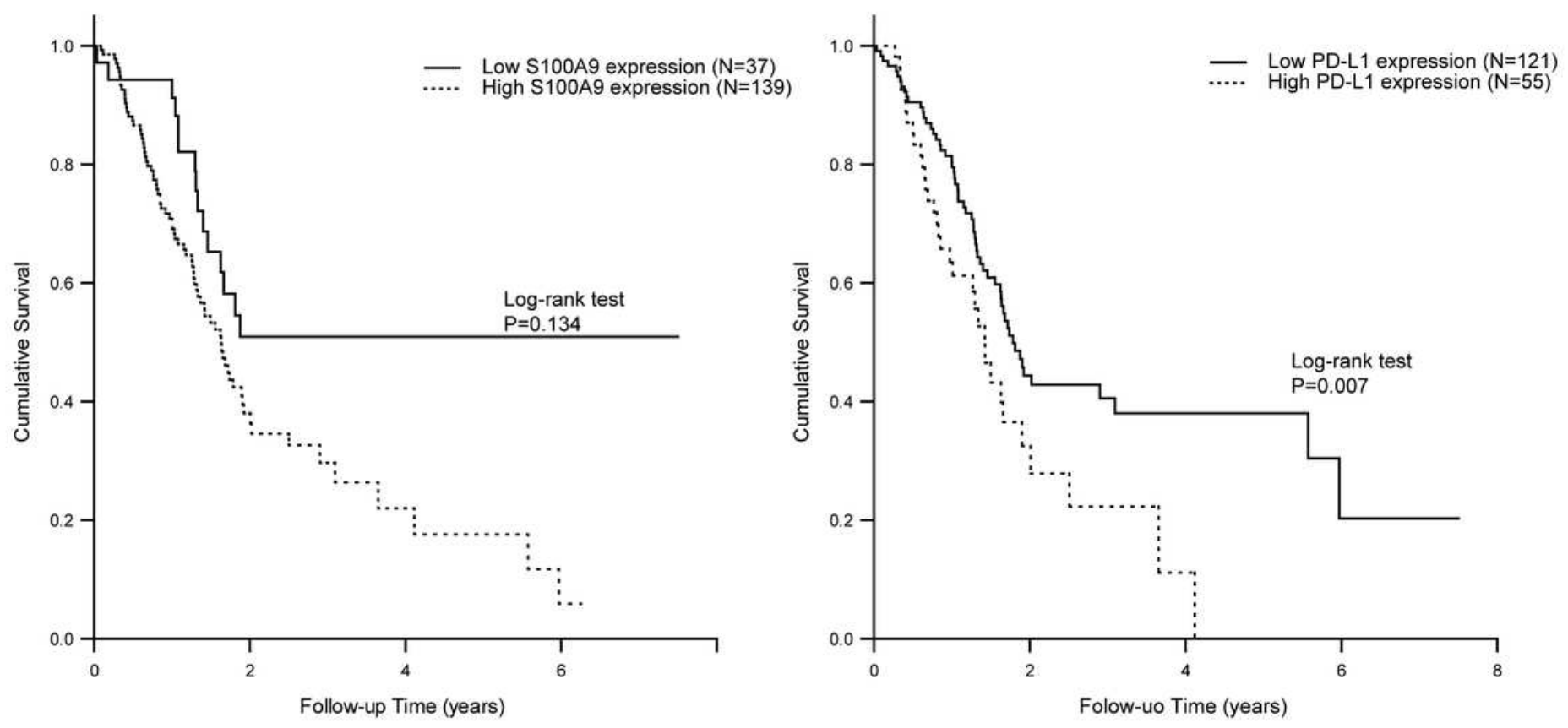

\section{Figure 6}

Kaplan-Meier survival curves generated based on S100A9 (a) and PD-L1 (b) expression. We obtained survival and immunohistochemistry staining data from 176 patients with PDAC from The Human Protein Atlas (https://www.proteinatlas.org/). Patients were divided into high and low expression groups based on the default setting on the website. The survival of each group was examined by Kaplan-Meier survival estimators, and the survival outcomes of the two groups were compared by log-rank tests. The patients with lower expression of S100A9 ( $a, p=0.013$, log-rank test) and PD-L1 (b, $p=0.007$, log-rank test) in their PDAC samples had better survival than those with high expression. 


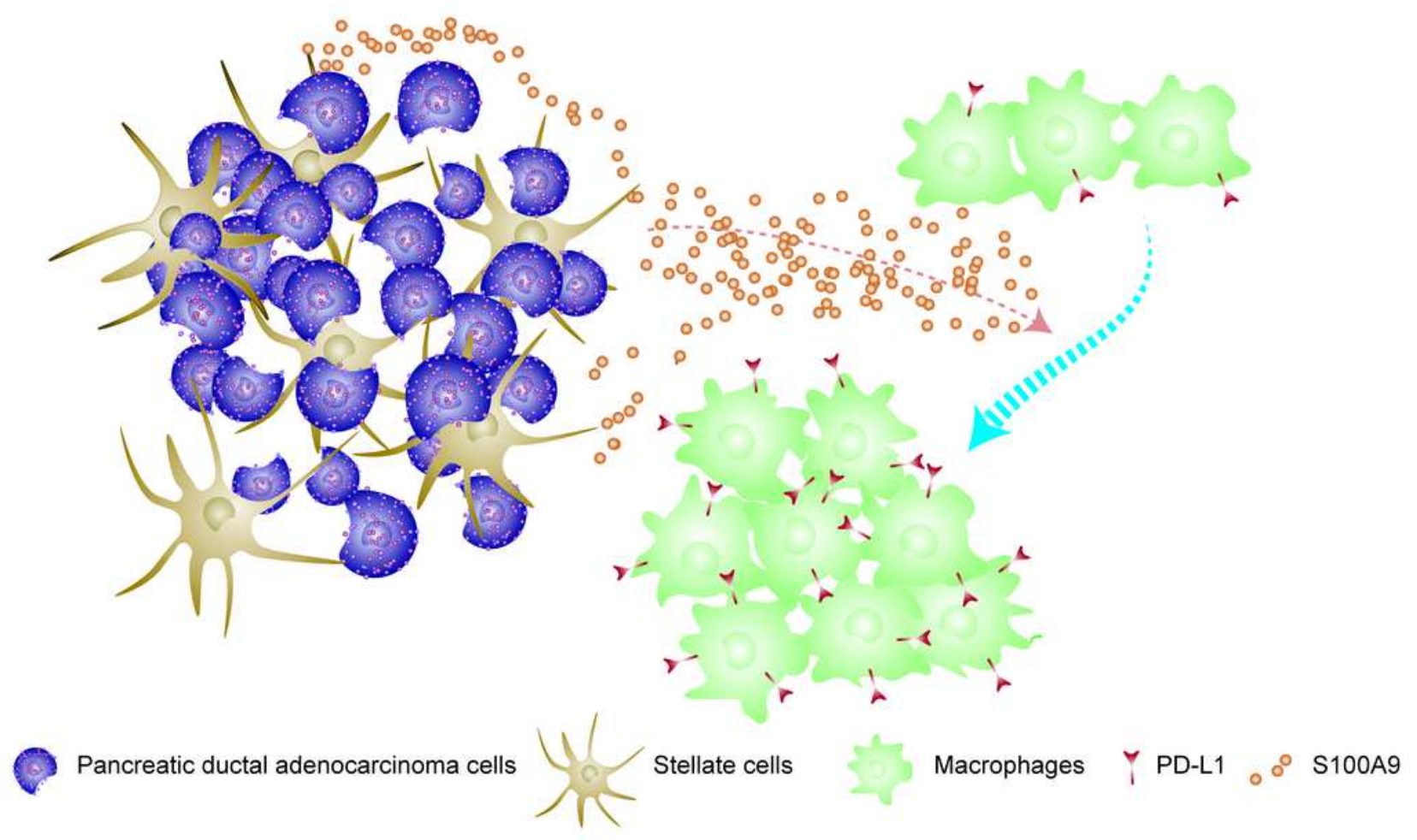

\section{Figure 7}

A proposed model summarizing the interaction between PDAC cells and their surrounding microenvironment. S100A9 expression can be induced in PDAC cells incubated with PSCs and acts as a chemoattractant for monocytes. S100A9 can also induce surface expression of PD-L1 on macrophages.

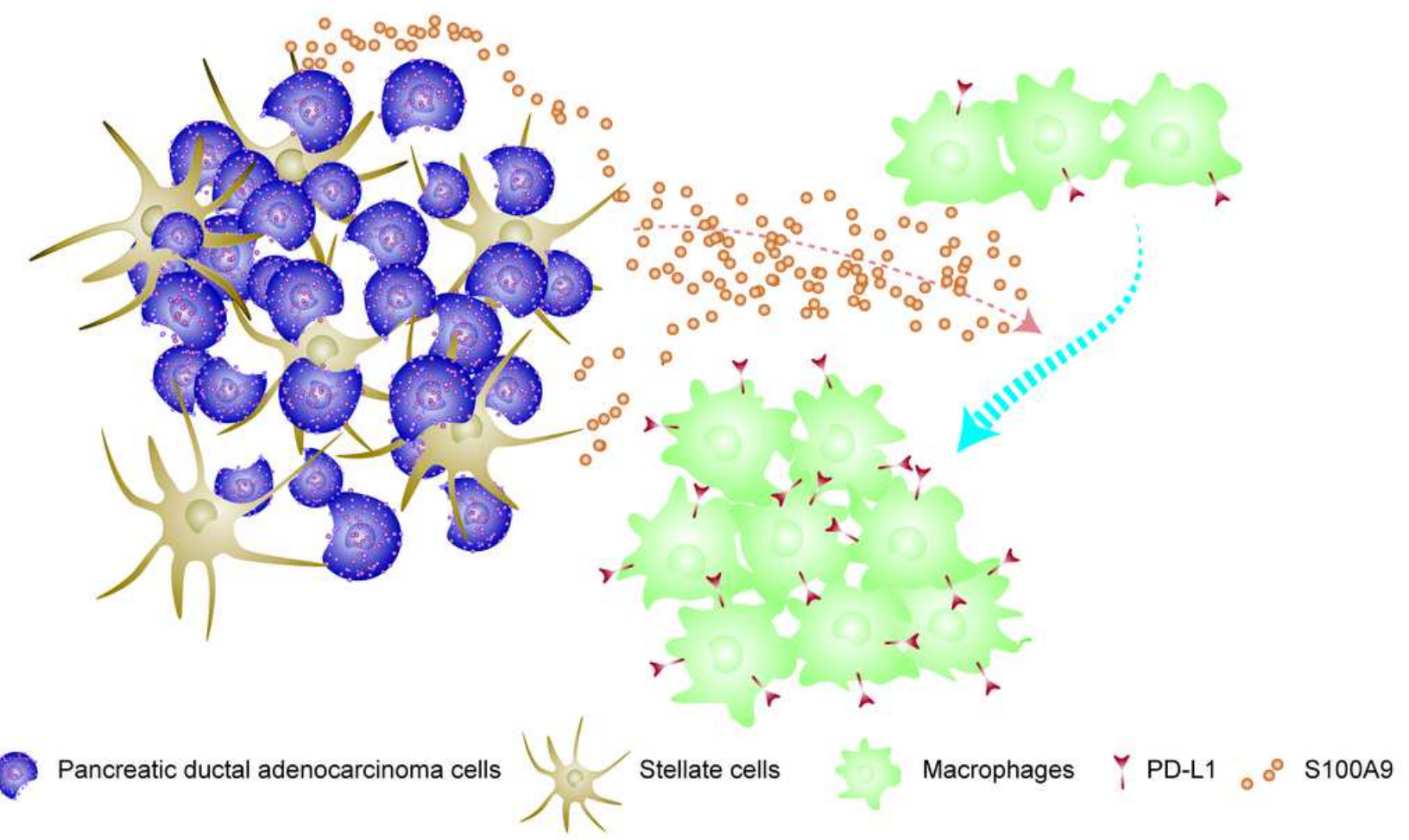




\section{Figure 7}

A proposed model summarizing the interaction between PDAC cells and their surrounding microenvironment. S100A9 expression can be induced in PDAC cells incubated with PSCs and acts as a chemoattractant for monocytes. S100A9 can also induce surface expression of PD-L1 on macrophages.

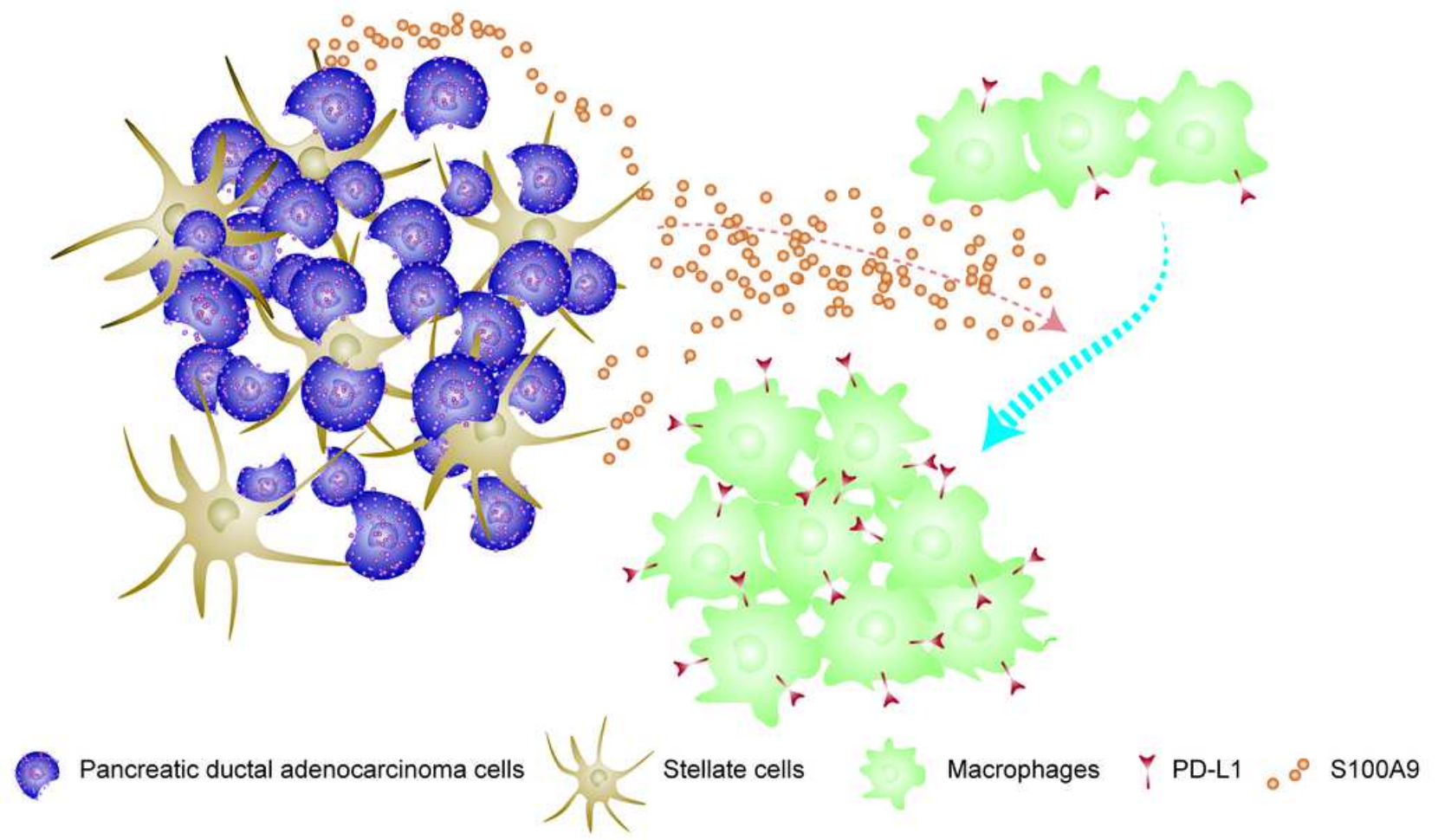

\section{Figure 7}

A proposed model summarizing the interaction between PDAC cells and their surrounding microenvironment. S100A9 expression can be induced in PDAC cells incubated with PSCs and acts as a chemoattractant for monocytes. S100A9 can also induce surface expression of PD-L1 on macrophages. 


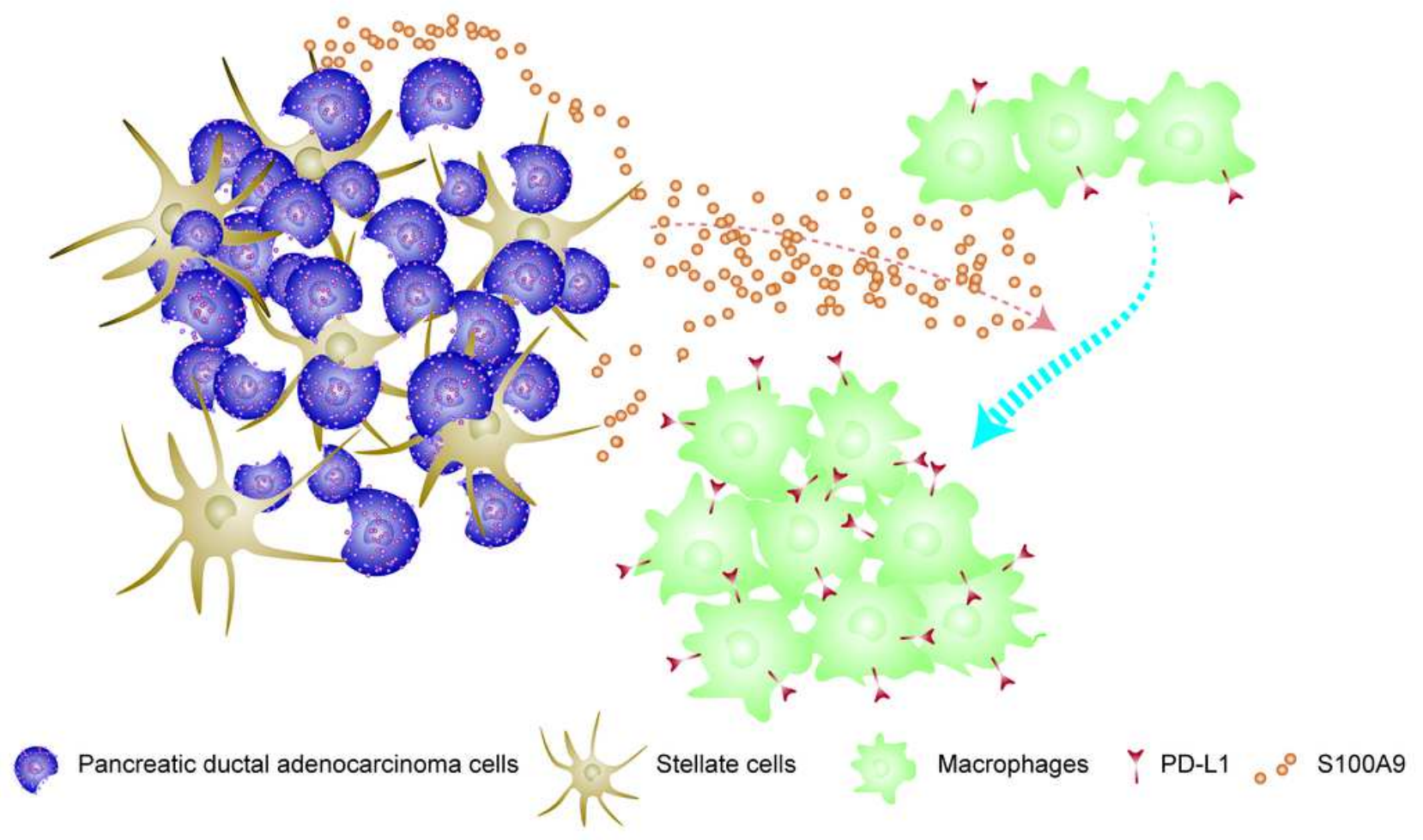

\section{Figure 7}

A proposed model summarizing the interaction between PDAC cells and their surrounding microenvironment. S100A9 expression can be induced in PDAC cells incubated with PSCs and acts as a chemoattractant for monocytes. S100A9 can also induce surface expression of PD-L1 on macrophages.

\section{Supplementary Files}

This is a list of supplementary files associated with this preprint. Click to download.

- SupplementaryfigureS1.jpg

- Supplementaryfigures1.jpg

- SupplementaryfigureS1.jpg

- SupplementaryfigureS1.jpg 